\title{
Miscellaneous standard methods for Apis mellifera research
}

Human, Hannelie; Brodschneider, Robert; Dietemann, Vincent; Dively, Galen; Ellis, James D.; Forsgren, Eva; Fries, Ingemar; Hatjina, Fani; Hu, Fu-Liang; Jaffe, Rodolfo; Jensen, Annette Bruun; Koehler, Angela; Magyar, Josef P.; Ozkyrym, Asli; Pirk, Christian W. W.; Rose, Robyn; Strauss, Ursula; Tanner, Gina; Tarpy, David R.; van der Steen, Jozef J. M.; Vaudo, Anthony; Vejsnaes, Fleming; Wilde, Jerzy; Williams, Geoffrey R.; Zheng, Huo-Qing Published in:

Journal of Apicultural Research \& Bee World

DOI:

10.3896/IBRA.1.52.4.10

Publication date:

2013

Document version

Publisher's PDF, also known as Version of record

Citation for published version (APA):

Human, H., Brodschneider, R., Dietemann, V., Dively, G., Ellis, J. D., Forsgren, E., Fries, I., Hatjina, F., Hu, F-L., Jaffe, R., Jensen, A. B., Koehler, A., Magyar, J. P., Ozkyrym, A., Pirk, C. W. W., Rose, R., Strauss, U., Tanner, G., Tarpy, D. R., ... Zheng, H-Q. (2013). Miscellaneous standard methods for Apis mellifera research. Journal of Apicultural Research \& Bee World, 52(4). https://doi.org/10.3896/IBRA.1.52.4.10 


\section{Miscellaneous standard methods for Apis mellifera}

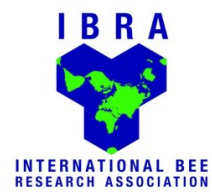

\section{research}

\section{Hannelie Human ${ }^{1} *$, Robert Brodschneider ${ }^{2}$, Vincent Dietemann ${ }^{1,3}$, Galen Dively ${ }^{4}$, James D Ellis ${ }^{5}$, Eva Forsgren ${ }^{6}$, Ingemar Fries ${ }^{6}$, Fani Hatjina ${ }^{7}$, Fu-Liang Hu${ }^{8}$, Rodolfo Jaffé9 , Annette Bruun Jensen ${ }^{10}$, Angela Köhler ${ }^{1}$, Josef P Magyar ${ }^{11}$, Asli Özkýrým ${ }^{12}$, Christian W W Pirk', Robyn Rose ${ }^{13 \dagger}$, Ursula Strauss ${ }^{1}$, Gina Tanner, ${ }^{3,14}$, David R Tarpy ${ }^{16}$, Jozef J M van der Steen ${ }^{15}$, Anthony Vaudo ${ }^{16}$, Fleming Vejsnæs ${ }^{17}$, Jerzy Wilde ${ }^{18}$, Geoffrey R Williams ${ }^{3,14}$ and Huo-Qing Zheng ${ }^{8}$}

${ }^{1}$ Department of Zoology \& Entomology, University of Pretoria, Pretoria, 0002, South Africa.

${ }^{2}$ Department of Zoology, Karl-Franzens-University, Graz, Austria.

${ }^{3}$ Swiss Bee Research Centre, Agroscope Liebefeld-Posieux Research Station ALP-Haras, Bern, Switzerland.

${ }^{4}$ University of Maryland, College Park, MD 20742-4454, USA.

${ }^{5}$ Honey bee Research and Extension Laboratory, Department of Entomology and Nematology, University of Florida, Gainesville, Florida, USA.

${ }^{6}$ Department of Ecology, Swedish University of Agricultural Sciences, Uppsala, Sweden.

${ }^{7}$ Hellenic Institute of Apiculture (N.AG.RE.F.), N. Moudania, Greece.

${ }^{8}$ College of Animal Sciences, Zhejiang University, Hangzhou 310058, China.

${ }^{9}$ Laboratório de Abelhas, Depto. de Ecologia, Instituto de Biociências, Universidade de São Paulo (USP), Rua do Matão 321, 05508-090 São Paulo-SP, Brazil.

${ }^{10}$ Department of Agriculture and Ecology, University of Copenhagen, Thorvaldsensve, 40, 1817 Frederiksberg C, Denmark.

${ }^{11}$ NEXTREAT, Weltistrasse 11, 5000 Aarau, Switzerland.

${ }^{12}$ Bee Health Laboratory, Department of Biology, Hacettepe University, Beytepe, Ankara, Turkey.

${ }^{13}$ United States Department of Agriculture, Animal and Plant Health Inspection Service, USA.

${ }^{14}$ Institute of Bee Health, Vetsuisse Faculty, University of Bern, Bern, Switzerland.

${ }^{15}$ Plant Research International, Wageningen University and Research Centre, Business Unit Plant Research International, Wageningen, Netherlands.

${ }^{16}$ Department of Entomology, The Pennsylvania State University, University Park, PA, USA.

${ }^{17}$ Konsulent Danmarks Biavlerforening, Fulbyvej 15, DK-4180 Sorø, Denmark.

${ }^{18}$ Apiculture Division, Faculty of Animal Bioengineering, Warmia and Mazury University, Sloneczna 48, 10-710 Olsztyn, Poland.

${ }^{\dagger}$ The views expressed in section 4.7 are those of the author and do not reflect the views of the United States Department of Agriculture, Animal and Plant Health Inspection Service (USDA APHIS).

Received 22 May 2012, accepted subject to revision 11 July 2012, accepted for publication 9 May 2013.

*Corresponding author: Email: hhuman@zoology.up.ac.za

\section{Summary}

A variety of methods are used in honey bee research and differ depending on the level at which the research is conducted. On an individual level, the handling of individual honey bees, including the queen, larvae and pupae are required. There are different methods for the immobilising, killing and storing as well as determining individual weight of bees. The precise timing of developmental stages is also an important aspect of sampling individuals for experiments. In order to investigate and manipulate functional processes in honey bees, e.g. memory formation and retrieval and gene expression, microinjection is often used. A method that is used by both researchers and beekeepers is the marking of queens that serves not only to help to locate her during her life, but also enables the dating of queens. Creating multiple queen colonies allows the beekeeper to maintain spare queens, increase brood production or ask questions related to reproduction. On colony level, very useful techniques are the measurement of intra hive mortality using dead bee traps, weighing of full hives, collecting pollen and nectar, and digital monitoring of brood development via location recognition. At the population level, estimation of population density is essential to evaluate the health status and using beelines help to locate wild colonies. These methods, described in this paper, are especially valuable when investigating the effects of pesticide applications, environmental pollution and diseases on colony survival.

Footnote: Please cite this paper as: HUMAN, H; BRODSCHNEIDER, R; DIETEMANN, V; DIVELY, G; ELLIS, J; FORSGREN, E; FRIES, I; HATJINA, F; HU, F-L; JAFFÉ, R; JENSEN, A B; KÖHLER, A; MAGYAR, J; ÖZKÝRÝM, A; PIRK, C W W; ROSE, R; STRAUSS, U; TANNER, G; TARPY, D R; VAN DER STEEN, J J M; VAUDO, A; 


\section{Métodos estándar diversos para la investigación en Apis mellifera}

\section{Resumen}

En la investigación de la abeja de la miel, se han usado una variedad de métodos que se diferencian en función del nivel en el que se realiza la investigación. Al nivel individual, el manejo de las abejas individuales es necesario, incluyendo a la reina, las larvas y las pupas. Existen diferentes métodos para la inmovilización, mortandad y almacenamiento, así como para la determinación del peso individual de las abejas. La precisión en la sincronización de las etapas de desarrollo es también un aspecto importante de los experimentos con muestreos individuales. La microinyección se utiliza a menudo con el fin de investigar y manipular los procesos funcionales de las abejas melíferas, como por ejemplo, la formación y recuperación de la memoria y la expresión génica. Un método utilizado tanto por investigadores como apicultores es el marcado de las reinas, que sirve no sólo para ayudar a localizarlas durante su vida, sino que también permite su datación. La creación de varias colmenas a partir de reinas permite al apicultor mantener reinas de repuesto, aumentar la producción de cría o hacer preguntas relacionadas con la reproducción. Al nivel de colmena, la medición de la mortalidad intra colmena utilizando trampas de abejas muertas, el pesaje de las colmenas completas, la recolección de polen y néctar, y el seguimiento digital del desarrollo de la cría a través del reconocimiento de su ubicación, son algunas de las técnicas más útiles. Al nivel poblacional, la estimación de la densidad de población es fundamental para evaluar el estado de salud y el uso de líneas rectas para ayudar a localizar colmenas silvestres. Los métodos descritos en este artículo, son especialmente valiosos en la investigación de los efectos de la aplicación de pesticidas, la contaminación ambiental y las enfermedades sobre la supervivencia de la colmena.

\section{MANDARIN SUMMARY}

\section{TO FOLLOW}

A variety of methods are used in honey bee research and differ depending on the level at which the research is conducted. On an individual level, the handling of individual honey bees, including the queen, larvae and pupae are required. There are different methods for the immobilising, killing and storing as well as determining individual weight of bees. The precise timing of developmental stages is also an important aspect of sampling individuals for experiments. In order to investigate and manipulate functional processes in honey bees, e.g. memory formation and retrieval and gene expression, microinjection is often used. A method that is used by both researchers and beekeepers is the marking of queens that serves not only to help to locate her during her life, but also enables the dating of queens. Creating multiple queen colonies allows the beekeeper to maintain spare queens, increase brood production or ask questions related to reproduction. On colony level, very useful techniques are the measurement of intra hive mortality using dead bee traps, weighing of full hives, collecting pollen and nectar, and digital monitoring of brood development via location recognition. At the population level, estimation of population density is essential to evaluate the health status and using beelines help to locate wild colonies. These methods, described in this paper, are especially valuable when investigating the effects of pesticide applications, environmental pollution and diseases on colony survival.

Keywords: COLOSS BEEBOOK, immobilising bees, killing bees, storing bees, bee weight, microinjection, marking and clipping queens, haemocytometer, colony density, hive weight, dead bee traps, collecting pollen and nectar, digital recognition 
Table of Contents

\begin{tabular}{|l|l|l|}
\hline $\mathbf{1 .}$ & Introduction & \\
\hline $\mathbf{2 .}$ & Research methods at the individual level & \\
\hline 2.1. & $\begin{array}{l}\text { Standard methods for immobilising, killing and storing } \\
\text { adult Apis mellifera in the laboratory }\end{array}$ & \\
\hline 2.1 .1$. & Introduction & \\
\hline
\end{tabular}

\begin{tabular}{|l|l|l|}
\hline 2.1 .1$. & Introduction & \\
\hline 2.1.2. & Immobilising adults & \\
\hline
\end{tabular}

2.1.2.1

\begin{tabular}{l|l}
\hline 2.1.2.2. & Chemical and physical immobilisation
\end{tabular}

\begin{tabular}{|l|l|r|}
\hline 2.1 .2 .2 .1$. & Carbon dioxide & \\
\hline 2.1 .2 .2 .2$. & Chilling & \\
\hline
\end{tabular}

\begin{tabular}{|l|l|l|}
\hline 2.1 .2 .2 .3$. & Anaesthesia considerations & 6 \\
\hline 2.1 .3 .2 .2 .2$. & 6 \\
\hline
\end{tabular}

\begin{tabular}{|l|l|l|}
\hline 2.1 .3$. & Killing adults & \\
\hline 2.1.3.1. & Thermal killing & \\
\hline
\end{tabular}

\begin{tabular}{|l|l|l|}
\hline 2.1 .3 .1 .1$. & Cold & \\
\hline 2.1 .3 .1 .2$. & Heat & \\
\hline
\end{tabular}

\begin{tabular}{|l|l|l|}
\hline 2.2. & Determination of individual bee weight & \\
\hline 2.2.1. & $\begin{array}{l}\text { Balance required for weighing individual bees or larvae } \\
\text { or body parts }\end{array}$ & \\
\hline 2.2.2. & Weighing of larvae & \\
\hline
\end{tabular}

\begin{tabular}{|l|l|l|}
\hline 2.2.3. & Weighing of adult honey bees & \\
\hline 2.2 .4$. & Weighing body parts & \\
\hline 2.2.5. & Determining dry weight & \\
\hline
\end{tabular}

\begin{tabular}{|l|l|l|}
\hline 2.2.5. & Determining dry weight & \\
\hline 2.3. & Microinjection & \\
\hline 2.3.1. & Introduction & \\
\hline 2.3.2. & Microinjection using a Hamilton syringe & \\
\hline 2.3.3. & $\begin{array}{l}\text { Microinjection of small volumes using the Nanoject } \\
\text { device and other micro injectors }\end{array}$ & \\
\hline 2.3.4. & Perspectives & 1 \\
\hline
\end{tabular}

\begin{tabular}{|l|r|r|}
\hline 2.3 .4$. & Perspectives & 10 \\
\hline 2.4. & Marking honey bee queens & 10 \\
\hline 2.4 .1$. & Colour-marking queens & 10 \\
\hline
\end{tabular}

\begin{tabular}{|l|l|r|}
\hline 2.4.1.1. & Marking type & 10 \\
\hline 2.4.1.2. & Procedure for paint marking & 11 \\
\hline 2.4 .1 .3 & Procedure for marking with Opalith discs & 11 \\
\hline
\end{tabular}

\begin{tabular}{|l|l|r|}
\hline 2.4.1.3. & Procedure for marking with Opalith discs & 11 \\
\hline 2.4.1.4. & Colour marking code & 11 \\
\hline 2.4.2. & Clipping queens' wings & 12 \\
\hline
\end{tabular}

\begin{tabular}{|l|l|l|l|l|}
\hline 2.4.2. & Clipping queens' wings & 12 & 4.3 .3 .2$. & Worker sampling \\
\hline 2.5. & Obtaining brood and adults of known age & 12 & 4.3 .3 .3$. & Genotyping \\
\hline 2.5.1. & Obtaining brood of known age & 13 & 4.3 .3 .4$. & $\begin{array}{l}\text { Genetic diversity measures and reconstruction of queen } \\
\text { genotypes }\end{array}$ \\
\hline 2.5.1.1. & Procedure to obtain worker or drone brood of known age & 13 & 4.3 .3 .5$. & Non-detection and non-sampling errors \\
\hline 2.5.1.2. & Procedure to obtain queen brood of known age & 14 & 4.3 .3 .6$. & Density estimation \\
\hline 2.5.2. & Obtaining pupae of known age & 14 & 4.3 .4$. & Future research needs and perspectives \\
\hline 2.5.3. & Recognising the instar of larvae & 16 & 4.4. & $\begin{array}{l}\text { Estimating the number of dead honey bees expelled } \\
\text { from a honey bee colony with a trap }\end{array}$ \\
\hline 2.5.4. & Recognising the age of larvae 34 & 35 \\
\hline 2.5.5. & Recognising the age of pupae & 16 & 4.4 .1$. & Aim of using dead bee traps \\
\hline 2.5.6. & Obtaining workers of known age & 17 & 4.4 .2$. & Limitations of using dead bee traps \\
\hline \multicolumn{2}{|c|}{35} \\
\hline
\end{tabular}

\begin{tabular}{|l|l|l|l|l|}
\hline 2.5. & Obtaining brood and adults of known age & 12 & 4.3 .3 .3$. & Genotyping \\
\hline 2.5.1. & Obtaining brood of known age & 13 & 4.3 .3 .4$. & $\begin{array}{l}\text { Genetic diversity measures and reconstruction of queen } \\
\text { genotypes }\end{array}$ \\
\hline 2.5.1.1. & Procedure to obtain worker or drone brood of known age & 13 & 4.3 .3 .5$. & Non-detection and non-sampling errors \\
\hline 2.5.1.2. & Procedure to obtain queen brood of known age & 14 & 4.3 .3 .6$. & Density estimation \\
\hline 2.5.2. & Obtaining pupae of known age & 14 & 4.3 .4$. & Future research needs and perspectives \\
\hline 2.5.3. & Recognising the instar of larvae & 16 & 4.4. & $\begin{array}{l}\text { Estimating the number of dead honey bees expelled } \\
\text { from a honey bee colony with a trap }\end{array}$ \\
\hline 2.5.4. & Recognising the age of larvae & 16 & 4.4 .1$. & Aim of using dead bee traps \\
\hline 2.5.5. & Recognising the age of pupae & 17 & 4.4 .2$. & Limitations of using dead bee traps \\
\hline 2.5.6. & Obtaining workers of known age & 17 & 4.4 .3$. & Types of dead bee traps \\
\hline
\end{tabular}




\begin{tabular}{|c|c|c|c|c|c|}
\hline Tab & $t^{\prime} d$ & $\begin{array}{l}\text { Page } \\
\text { No. }\end{array}$ & & & $\begin{array}{l}\text { Page } \\
\text { No. }\end{array}$ \\
\hline 4.4.4. & $\begin{array}{l}\text { Dead bee traps requirements as gathered from the } \\
\text { literature }\end{array}$ & 35 & 4.6.4. & Finalisation of the analysis & 42 \\
\hline 4.4.5. & Recommended dead bee traps to use & 36 & 4.6.5. & Conclusion & 43 \\
\hline 4.4.6. & Building a dead bee trap & 36 & 4.7. & Collecting pollen and nectar from bees and flowers & 43 \\
\hline 4.4.7. & Protocol for calibrating dead bees in traps & 36 & 4.7.1. & Introduction & 43 \\
\hline 4.4.8. & Protocol for using a dead bee trap & 36 & 4.7 .2$. & Methods for pollen collection & 43 \\
\hline 4.4.9. & Dead bee trap trade-offs & 36 & 4.7.3. & Nectar collection & 44 \\
\hline 4.5. & Creating multiple queen colonies & 36 & 4.7.3.1. & Collecting nectar from honey bees & 45 \\
\hline 4.5 .1 & Mandible clipping procedure & 38 & 4.7.3.2. & Nectar collection from flowers & 45 \\
\hline 4.5.2. & $\begin{array}{l}\text { Preparation of colonies destined to host the multiple } \\
\text { queens }\end{array}$ & 38 & 4.7.4. & $\begin{array}{l}\text { Precautions when sampling pollen and nectar for residue } \\
\text { analyses }\end{array}$ & 45 \\
\hline 4.6. & $\begin{array}{l}\text { Digital monitoring of brood development via location } \\
\text { recognition }\end{array}$ & 40 & 4.7.4.1.1. & Using paper bags to collect fresh pollen & 46 \\
\hline 4.6.1. & Introduction & 40 & 4.7.4.1.2. & Manual collection of fresh pollen & 46 \\
\hline 4.6.2. & Procedure for data acquisition & 40 & 4.7.4.1.3. & Using a paint brush for collection of fresh pollen & 47 \\
\hline 4.6.2.1. & Software requirements & 40 & 4.7.4.1.4. & $\begin{array}{l}\text { Collection of fresh pollen from smaller flowers such as } \\
\text { canola }\end{array}$ & 47 \\
\hline 4.6.2.2. & Before starting the project & 41 & 4.7.4.2. & Collection of bee collected pollen using pollen traps & 47 \\
\hline 4.6.2.3. & Image acquisition & 41 & 4.7.4.3. & Ensuring quality of bee collected pollen & 48 \\
\hline 4.6.3. & Image analysis & 41 & 5. & Acknowledgements & 48 \\
\hline 4.6.3.1. & Analysis of the first image (BFD 00) & 41 & 6. & References & 48 \\
\hline 4.6.3.2. & For all consecutive images (BFD $+05,10,16,22)$ & 41 & & & \\
\hline
\end{tabular}

\section{Introduction}

Honey bees are one of the most studied insects, primarily due to their crucial role in agriculture and the ecosystem and their high economic value. In light of the concern over global honey bee decline experienced in many regions of the world, and with their economic importance in mind, funding has been readily available for research. The honey bee is a fascinating research model, its positive perception in general and its eusociality and importance for the food security and eco-system services makes it a model organism of choice. Therefore it is not surprising that a huge variety of research methods have been employed, evaluating and investigating different aspects of this organism, e.g. their interactions with parasites and pests (Volume 2 of the $B E E B O O K$ ), the behavioural and chemical ecology of this superorganism as well as aspects of breeding and population dynamics (Volume 1 of the BEEBOOK), to name a few. Since the interest in honey bees reaches from applied to fundamental research, numerous basic techniques are used across all disciplines. In this chapter, we will present various methods on recording basic demographic parameters like estimating number of dead bees, the weighing of a colony or of an individual, using a haemocytometer as well as pollen trapping. In addition, we describe ways of marking queens, how to inject, immobilise, kill and store honey bees, and how to obtain brood and adults of known age. Finally we discuss how to locate wild honey bee colonies, estimate honey bee colony density, create multiple queen colonies, and digitally monitor brood development via location recognition.

\section{Research methods at the}

\section{individual level}

\subsection{Standard methods for immobilising, killing and storing adult Apis mellifera in the laboratory}

\subsubsection{Introduction}

Laboratory studies with honey bees usually involve a certain amount of handling of the experimental bees and often the termination and subsequent storage of the bee samples. There are a wide range of potential methods to immobilise, kill and store bees. Standardised methods for these experimental steps enable the comparison within the same trial and between different studies. The following section displays available methods, advantages and disadvantages of the different approaches and recommendations in terms of application.

\subsubsection{Immobilising adults}

Researchers are often required to immobilise adult honey bees, for example, when inoculating individuals with parasites during 
experiments (see section 1.3 on microinjection) or when removing live honey bees from hoarding cages or colonies to study intra-host parasite development. It is essential that sensitive body parts of the honey bee, such as the abdomen, antennae, eyes, and mouthparts, are not disturbed or damaged during immobilisation.

\subsubsection{Physical immobilisation}

Fine tip forceps can be used to gently grasp wings and legs; however, butterfly or featherweight forceps are more forgiving and can be used to grasp the thorax, in addition to appendages. The most effective, and sensitive, method for immobilising honey bees is to pinch the wings together gently above their base to ensure that the individual is securely held and cannot sting (Fig. 1).

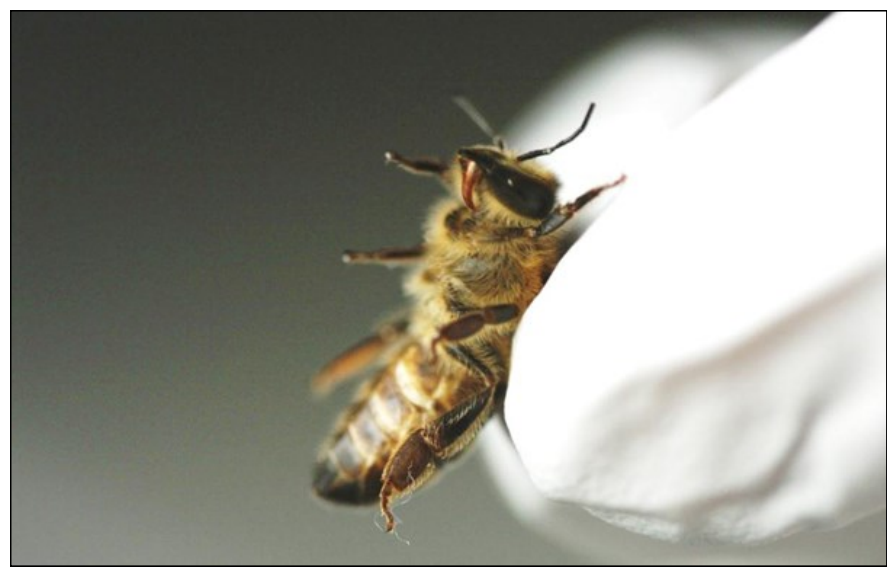

Fig. 1. A worker honey bee held by gently squeezing its wings between the index finger and thumb. Note that the distal part of the abdomen is pointed in such a way that the honey bee cannot sting the handler. Photo: G R Williams.

\subsubsection{Chemical and physical immobilisation}

In some cases a general anaesthetic is needed to facilitate the handling or immobilisation of very young or mature adult honey bees because of insufficient exoskeletal development or high activity, respectively. Both chemical (e.g., carbon dioxide, diethyl ether, nitrogen, ethyl acetate) and physical (e.g. chilling, freezing) anaesthetics are available. Below we discuss only the two most commonly used methods employed by researchers to immobilise adult honey bees.

\subsection{Carbon dioxide}

Exposure to carbon dioxide deprives individuals of oxygen, and depending on dose, can lead to anoxia or asphyxiation in various tissues, as well as the accumulation of acid metabolites that can impair physiological processes, especially in the nervous system (Nicolas and Sillans, 1989). Exposure to carbon dioxide can result in premature aging and reduced lifespan of worker honey bees (e.g., Mackensen, 1947; Austin, 1955; Woyciechowski and Moron, 2009), as well as affect behaviour and memory (Erber, 1975; Nicolas and Sillans,
1989). Although, exposure to carbon dioxide can influence intra-host parasite development (Czekońska, 2007), it is uncertain if honey bees exposed to the gas are subsequently more susceptible to parasitic diseases.

Phenotypic response to carbon dioxide is dose-dependent. Whereas large dosages and long exposure of carbon dioxide (i.e., > $95 \%$ for $105 \mathrm{~min}$ ) result in significant mortality and behavioural changes (Rueppel et al., 2010), much shorter exposure duration can still affect workers. For example, pure carbon dioxide treatments greater than 15 seconds influenced sucrose response, foraging behaviour, and survival, although, in some cases certain symptoms may abate over time (Ebadi et al., 1980; Pankiw and Page, 2003). Similar to workers, queens receiving a carbon dioxide anaesthetic can also exhibit symptoms; for example, higher carbon dioxide: nitrogen ratios resulted in significantly earlier oviposition events (ChudaMickiewicz et al., 2012). More details on anaesthetising queens can be found in the BEEBOOK paper on instrumental insemination (Cobey et al., 2013). To immobilise worker honey bees using carbon dioxide, researchers should provide individuals to pure gas for 10-15 seconds (Ebadi et al., 1980); this should render individuals unconscious for approximately $15-30$ seconds.

Protocol to immobilise bees with carbon dioxide:

1. Place honey bees in a well-ventilated cage.

2. Transfer the cage to a sealable plastic container with a small opening in the lid. Place the caged honey bees at the bottom of the sealed container as an added precaution to ensure full carbon dioxide exposure (Ebadi et al., 1980), since carbon dioxide is heavier than air.

3. Connect a tube to the gas source (carbon dioxide bottle).

4. Insert the other end of the tube into the opening of the plastic container lid.

5. Provide constant supply of carbon dioxide (e.g., $100 \mathrm{ml}$ per minute) for $10-15$ seconds.

\subsection{Chilling}

Cold temperatures can temporarily immobilise adult honey bees by reducing the amplitude of neuron action potentials (Wieser, 1973). Similar to carbon dioxide, length of exposure and dose, as well as recovery time (Frost et al., 2011), can greatly influence phenotypic response to chilling exposure. For example, chilling for $3 \mathrm{~min}$ at $-20^{\circ} \mathrm{C}$ did not affect worker longevity, orientation, or foraging behaviour (Ebadi et al., 1980); whereas, ice-chilling at $0^{\circ} \mathrm{C}$ for the minimum amount of time needed to immobilise individuals significantly impaired learning, but not sugar responsiveness, compared to refrigeration at $4-5^{\circ} \mathrm{C}$ or freezing at $-18^{\circ} \mathrm{C}$ (Frost et al., 2011). Additionally, honey bee age can influence response to chilling, as newly emerged individuals less than $18 \mathrm{~h}$ old normally move at $22^{\circ} \mathrm{C}$ compared to $17^{\circ} \mathrm{C}$ for older foragers (Allen, 1959), and $85 \%$ of one 
Table 1. Examples of methods used to kill honey bees depending on purpose of the study.

\begin{tabular}{|c|c|c|c|}
\hline Method of termination & Termination description & Body part examined and purpose & Reference \\
\hline \multirow[t]{3}{*}{ Thermal } & Exposed to $-20^{\circ} \mathrm{C}$ in freezer & $\begin{array}{l}\text { Worker ovarian development and midgut and rectum } \\
\text { protein content }\end{array}$ & Human et al. (2007) \\
\hline & Exposed to $-80^{\circ} \mathrm{C}$ in freezer & $\begin{array}{l}\text { Worker abdomen for molecular analyses of Nosema } \\
\text { infection }\end{array}$ & Williams et al. (in prep.) \\
\hline & Exposed to $-20^{\circ} \mathrm{C}$ in a freezer & Worker body viral analyses & Yañez et al. (2012) \\
\hline \multirow[t]{5}{*}{ Mechanical } & $\begin{array}{l}\text { Removed internal organs and } \\
\text { decapitated }\end{array}$ & $\begin{array}{l}\text { Queen spermatheca, gut, ovaries, haemolymph, head, } \\
\text { eviscerated body virus levels }\end{array}$ & Chen et al. (2006) \\
\hline & Decapitated & $\begin{array}{l}\text { Drone photoreceptor and glial cell intracellular potassium } \\
\text { movement }\end{array}$ & $\begin{array}{l}\text { Coles and Orkhand } \\
(1983)\end{array}$ \\
\hline & Crushed head and thorax & $\begin{array}{l}\text { Queen spermatheca removal for gamete- backcross } \\
\text { mating }\end{array}$ & Gladstone et al. (1964) \\
\hline & Crushed thorax & Worker thorax mass & Heinrich (1979) \\
\hline & Crushed thorax & Worker hypopharyngeal gland and ovarian development & Pernal and Currie (2000) \\
\hline Mechanical and chemical & $\begin{array}{l}\text { Crushed body and immersion in } \\
\text { RNALater } \AA\end{array}$ & Worker body virus analyses & Williams et al. (in prep.) \\
\hline \multirow[t]{3}{*}{ Chemical and thermal } & Exposed to dry ice in a container & Worker body chemical residue analyses & Mullin et al. (2010) \\
\hline & Exposed to dry ice in a box & Worker gut polystyrene microparticle quantity & Naug and Gibbs (2009) \\
\hline & $\begin{array}{l}\text { Immersed in liquid nitrogen in a } \\
\text { container }\end{array}$ & Adult bee genetic analyses & Zayed et al. (2005) \\
\hline \multirow[t]{2}{*}{ Chemical } & Immersed in $95 \%$ ethanol & Drone genetic analyses & Jaffé et al. (2009b) \\
\hline & $\begin{array}{l}\text { Exposed to potassium cyanide } \\
\text { in killing jar }\end{array}$ & Worker crop load & Visscher et al. (1996) \\
\hline
\end{tabular}

day old workers died when exposed for $3 \mathrm{~min}$ to $-20^{\circ} \mathrm{C}$ (Robinson and 2.1.3. Killing adults

Visscher, 1984) when no death in older workers receiving the same dose was observed (Ebadi et al., 1980).

An exposure of the bee to $-20^{\circ} \mathrm{C}$ for $3 \mathrm{~min}$ is recommended to immobilise mature individuals greater than 1 day old using chilling. At this time no recommendation can be made for chilling time of individuals younger than this due to seemingly adverse effects.

Protocol to immobilise honey bees with chilling:

1. Place required number of honey bees in a cage.

2. Transfer the cage into a freezer $\left(-20^{\circ} \mathrm{C}\right)$.

3. Remove the cage with the immobilised bees from the freezer after $3 \mathrm{~min}$.

\subsubsection{2,3. Anaesthesia considerations}

Anaesthetics should be easy to apply, repeatable, cheap, nonhazardous to humans, and have no or limited long-term effects on honey bees. Regardless of method chosen, and because of dosedependence, all experimental individuals should receive the same dose, exposure length, and frequency of exposure, and methods should be described in full detail. Additionally, recordings of observations, such as honey bee mortality or responsiveness to sucrose, for example, should be delayed at least $1 \mathrm{~h}$ to provide anaesthetised honey bees with a recovery period (Pankiw and Page, 2003). Because honey bee anaesthetising provides a relatively poorly understood sublethal dose of a potentially lethal agent, the benefits of its use for an experiment should be clear. Conflicting data in the scientific literature suggest that carbon dioxide may be a more ideal anaesthetic than chilling, at least until specific methods can be developed for particular experiments that may use differently aged honey bees or need individuals to be sedated for varying lengths of time.
Adult honey bees used for research are often killed during or after experiments to allow for further examination, such as to take measurements of internal organs, to quantify parasite intensity or gene expression (e.g. Pernal and Currie, 2000; Maistrello et al., 2008; Antúnez et al., 2009), or simply to dispose of them safely. Generally, termination methods can be categorised as thermal, mechanical, or chemical; the method chosen will largely depend on the purpose for termination (Table 1).

\subsubsection{Thermal killing}

\subsection{Cold}

Freezing is a common method for killing adult honey bees because it can be easily and effectively applied, and will preserve genetic material. Freezing can, however, result in damage to cell structures, and therefore it is not recommended for studies that require internal tissues to remain intact, such as for quantifying hypopharyngeal development or midgut parasitism by Nosema spp. Exposing individuals to temperatures below $-20^{\circ} \mathrm{C}$ will result in quick death; however, time required will vary depending on temperature and the number of individuals being collectively frozen (i.e. a higher number of honey bees collectively together will take longer to kill because of clustering behaviour). Placing individuals in a $-20^{\circ} \mathrm{C}$ freezer for $2 \mathrm{~h}$ usually sufficient. Conversely, honey bees can be placed in a box of dry ice (e.g. Naug and Gibbs, 2009) or immersed in liquid nitrogen (e.g. Zayed et al., 2005) for near instant termination.

\subsubsection{2, Heat}

Heat can also be used to kill honey bees, although its use is much less common than freezing, likely because it results in the denaturation of macromolecules such as nucleic acids (e.g. DNA and RNA) and proteins 
that in many cases may be studied post-mortem. Honey bees will typically die within one hour of exposure to $46^{\circ} \mathrm{C}$ (Allen, 1959), but this will depend on crop content and relative humidity.

\subsubsection{Mechanical killing}

Numerous studies kill adult honey bees by physically damaging or removing an essential body section (e.g. head, thorax, or abdomen) using forceps, one's index finger and thumb, or a scalpel. This method is relatively easy to perform, depending upon activity level and quantity of honey bees, and avoids the use of chemicals or other equipment that perhaps are not easily accessible. If there are many bees to kill, this can be a tedious method. Mechanical termination usually leaves the unaffected body part(s) intact; however, it may potentially promote parasite transmission when the exoskeleton is ruptured. The precise method of mechanical termination chosen will largely depend on the purpose of the study, but it can be monotonous (Table 1).

\subsubsection{Chemical killing}

The use of chemicals, including water, to kill honey bees commonly occurred in the $20^{\text {th }}$ century; in recent years fewer studies use this technique. Because of the dangers of cyanide, and the numerous adequate alternatives, the use of this substance is not recommended. Care should be taken when using any chemical in the laboratory or field.

Asphyxiates such as carbon dioxide or ethyl acetate can also effectively kill honey bees, provided the appropriate dose is applied. For ethyl acetate, or alternatively nail polish remover, a sealable glass killing jar $<500 \mathrm{ml}$ in volume and lined at the bottom with $1-2 \mathrm{~cm}$ of plaster of Paris can be created or purchased from a entomological supply store. Ethyl acetate should be pipetted onto the plaster until satiation, and excess liquid removed, before insects destined to be killed are introduced (Steyskal, 1986). Five minutes within the sealed container should be sufficient to kill honey bees, although this may depend on the volume of the jar, the number of individuals being killed, and the quantity of ethyl acetate provided. Care must be taken to ensure that exposed honey bees are killed, rather than anaesthetised. When maintained in the killing jar for a number of hours, or even days, individuals can still be easily manipulated because of the ability of ethyl acetates to hold moisture, although decomposition may set in. Additionally, asphyxiation by drowning can be performed using pure water, soapy water, or ethanol. The latter, when $95 \%$ pure, will also, to some extent, preserve honey bees, as well as organisms and chemical residues present within them; water will promote decomposition. As mentioned earlier (see section 1.3.1.1.), honey bees can also be exposed to dry ice (Naug and Gibbs, 2009) or liquid nitrogen (Zayed et al., 2005) for quick termination.

\subsubsection{Storing dead adults}

When post-mortem examinations, or necropsies, are to be performed for a particular study it is imperative that honey bees to be examined are maintained under appropriate conditions to ensure degradation does not occur. Ideally, samples should be placed under optimal preservation conditions as soon as possible after death if analyses or examination does not occur immediately. Storage conditions, as well as the materials to be preserved, will largely depend upon the question being asked.

Generally, freezing is the best and most commonly used strategy for maintaining well preserved samples; however, when this is not available certain chemical stabilisers (e.g. RNALater ${ }^{\circledR}$ (Qiagen, Hilden, Germany), and TN, Kiev and TRIS-NaCL buffers) may provide alternative options, at least in the short term (Table 2). Careful attention must be paid during examination of easily degradable material, such as DNA and in particular RNA because of its single stranded architecture and because of endogenous RNases that occur ubiquitous in organisms and the environment (Chen et al., 2007; Winnebeck et al., 2010; Dainat et al., 2011). Additionally, pheromone, pesticide residue, and whole tissue examination also require appropriate preservation (Table 2).

Ideally, samples should be preserved at $-80^{\circ} \mathrm{C}$; however, freezing at $-20^{\circ} \mathrm{C}$ or less should be sufficient for relatively short-term storage. More in depth discussions on sample preservation can be found in respective papers of the $B E E B O O K$, such as de Miranda et al. (2013) for viruses, Fries et al., (2013) for Nosema, and Medrzycki et al. (2013) for toxicology.

\subsection{Determination of individual bee weight}

The fresh weight of an Apis mellifera worker drastically increases during its 21 days of development from an egg weighing about 0.03-0.1 $\mathrm{mg}$ to about $120 \mathrm{mg}$ at adult emergence. In contrast, drones reach 277-290 mg after emergence (Hrassnigg and Crailsheim, 2005). Hence, the weight of larvae is, among others factors, important in determining their age (see section 2.5 Obtaining adult and brood of known age; Wang, 1965). Determining the weight of individual honey bees can also be important when assessing the effect of pathogens, parasites or toxins on their development and health or when assessing their nutritional intake. In this section, we describe procedures to obtain fresh weight of immatures (see section 2.2.2.), adult honey bees (2.2.3.) or their parts (2.2.4.) as well as dry weight of adults (2.2.5). Larvae or adults collected for later analysis are best stored frozen to prevent desiccation.

\subsubsection{Balance required for weighing individual bees or larvae or body parts}

A well calibrated and sufficiently sensitive analytical balance should be 
Table 2. Examples of methods used to store honey bees and selected bee products depending on purpose of the study.

\begin{tabular}{|c|c|c|c|}
\hline Method of storage & Storage description & Body part stored and purpose & Reference \\
\hline \multirow[t]{10}{*}{ Cold } & $-20^{\circ} \mathrm{C}$ & $\begin{array}{l}\text { Adult worker ventriculi for Nosema qPCR } \\
\text { quantification }\end{array}$ & Forsgren and Fries (2010) \\
\hline & $-20^{\circ} \mathrm{C}$ & $\begin{array}{l}\text { Whole adult workers for Nosema species } \\
\text { identification }\end{array}$ & Williams et al. (2008; 2011) \\
\hline & $-20^{\circ} \mathrm{C}$ & $\begin{array}{l}\text { Adult workers, honey \& beeswax for gas } \\
\text { chromatography (GC)-tandem mass spectrometry } \\
\text { (MS/MS) \& liquid chromatography (LC-MS/MS) } \\
\text { chemical residue analyses }\end{array}$ & Nguyen et al. (2009) \\
\hline & $-20^{\circ} \mathrm{C}$ & $\begin{array}{l}\text { Beebread, brood, adult workers for LC/MS-MS } \\
\text { and GC/MS pesticides residue analyses }\end{array}$ & Mullin et al. (2010) \\
\hline & $-80^{\circ} \mathrm{C}$ & $\begin{array}{l}\text { Mature queen spermathecal fluid protein } \\
\text { profiling using gel electrophoresis }\end{array}$ & Baer et al. (2009) \\
\hline & $-80^{\circ} \mathrm{C}$ & $\begin{array}{l}\text { Mature queen ovaries \& eviscerated abdomens } \\
\text { (cuticle with attached fat bodies) for quantitative } \\
\text { real-time PCR of Vitellogenin gene expression }\end{array}$ & Kocher et al. (2008) \\
\hline & $-80^{\circ} \mathrm{C}$ & $\begin{array}{l}\text { Adult drone antennae for microarray and qPCR } \\
\text { sex pheromone gene expression quantification }\end{array}$ & Wanner et al. (2007) \\
\hline & $-80^{\circ} \mathrm{C}$ & $\begin{array}{l}\text { Whole adult workers for quantitative real-time } \\
\text { PCR of immune gene expression }\end{array}$ & Antúnez et al. (2009) \\
\hline & $-80^{\circ} \mathrm{C}$ & $\begin{array}{l}\text { Extracted RNA from adult workers, eggs, queen } \\
\text { faeces \& queen tissues for RT-PCR analyses of } \\
\text { viruses }\end{array}$ & Chen et al. (2006) \\
\hline & $-80^{\circ} \mathrm{C}$ & $\begin{array}{l}\text { Brood comb (beeswax, beebread and brood) } \\
\text { and adult workers for LC/MS-MS and GC/MS } \\
\text { pesticides residue analyses }\end{array}$ & Mullin et al. (2010) \\
\hline \multirow[t]{2}{*}{ Cold \& chemical } & $-20^{\circ} \mathrm{C} \&$ Kiev buffer & Queen spermathecae for sperm counting & Kocher et al. (2008) \\
\hline & $-80^{\circ} \mathrm{C} \&$ RNALater $\AA$ & Worker honey bee RT-PCR virus analyses & Williams et al. (2009) \\
\hline
\end{tabular}

used, automated data transfer to computer, a standard feature, facilitate higher sampling rates. Remember, most analytical balances have a precision or readability of $0.1 \mathrm{mg}$ which is sufficient for larvae and adults, but near the weight of an egg. To precisely determine the latter, we recommend measuring egg length following Henderson (1992) or use a high precision micro balance.

\subsubsection{Weighing of larvae}

1. Carefully take the larva out of its cell.

Injuries of larval surfaces result in the loss of haemolymph and injured larvae must be discarded.

If the larvae are to be weighed when stored frozen, they have to be brought to room temperature to prevent convection during weighing and then weighed quickly before desiccation.

2. Wash larvae with either saline, alcohol or distilled water to remove remainders of the larval food.

3. Quickly dry them on filter paper.

Due to the low weight and quick drying up of young larvae, time between sampling and weighing should be minimised.

4. Tare the balance with container.

5. Place larvae in container.

6. Weigh larvae.

7. Record weight.

\subsubsection{Weighing of adult honey bees}

The fresh weight of adult bees is a measure for nutritional and health state and can be measured from live (see section 2.1. on immobilising honey bees) or dead honey bees.
1. Tare the balance with container.

2. Place honey bee in container.

3. Weigh honey bee.

Note that the weight of newly emerged bees is influenced by the meconium (faeces that is expelled in purging flights after emergence, Jackson and Hart, 2009). Adult weight is also influenced by the consumption of food, and standardised starvation of bees in an incubator corrects for this increase (see the $B E E B O O K$ paper on maintaining adults in vitro in the laboratory, Williams et al., 2013).

4. Record weight.

\subsubsection{Weighing body parts}

Before establishing the weight of dead honey bees (see section 2.2.3) we suggest separating the body with small scissors into head, thorax (including legs and wings) and abdomen. This allows to roughly ascribe weight deficiencies to one of these body parts. Total dry weight is the sum of all body parts. For example, the fresh weight of the head correlates with the acini-size of hypopharyngeal glands (Hrassnigg and Crailsheim, 1998) and the fresh and dry weight of the thorax is a measure for the development of flight musculature (Brodschneider et al., 2009). Note that the weight of the abdomen is often determined without the gastrointestinal tract, because of the pollen or meconium in it (Hrassnigg and Crailsheim, 2005; Jackson and Hart, 2009).

\subsubsection{Determining dry weight}

The dry weight of adult bees is determined by putting whole bees or 
their body parts (see section 2.2.4.) in individually labelled and preweighed Eppendorf tubes in an incubator at $55-70^{\circ} \mathrm{C} ; 60^{\circ} \mathrm{C}$ can be recommended (Henderson, 1992). The tubes remain open during incubation. Dry weight is reached when the sample show constant weight in successive measures, which usually occurs within 7 days in honey bees, depending on incubation temperature. Samples can also be transferred to weighing dishes, but care must be taken not to lose extremities. Refer to the procedure described in section 2.2.3 to weigh the dried samples. The dry weight of newly emerged bees indicates the nutritional investment in larvae, which may result in different emerging weights during season. In adult bees, dry weight changes depending on nutrition and age, reaching a maximum after five days, and decreases again towards the foraging age (Hrassnigg and Crailsheim, 2005). Finally, parasites like the varroa mite can exert weight differences of more than $10 \%$ in emerging honey bee drones (Duay et al., 2003).

\subsection{Microinjection}

\subsubsection{Introduction}

Injection is a technique widely employed to manipulate functional processes in honey bees. Injections have been performed at different stages of the honey bee life cycle, from early embryos to adults (Lozano et al., 2001; Aase et al., 2005; Kucharski et al., 2008). In adult honey bees, the injection of receptor antagonists into the brain or antennal lobes provided insights into pathways involved in memory formation and retrieval (Lozano et al., 2001; Farooqui et al., 2003; Wright et al., 2010). Gene expression can be manipulated by injecting double stranded RNA (Schlüns and Crozier, 2007; see also Section VI - RNA interference). Injections of pathogens (Wilson and Rothenbuhler, 1968) and insecticides (Bendahou et al., 1999), as well as injection of labelled markers to trace substance distributions (Crailsheim, 1992) are further applications.

Irrespective of the substance being injected, rupturing the cuticle with the needle is invasive and causes an immune response in honey bees, including increased expression of the immune response gene Defensin2 and antimicrobial peptide production (Richard et al., 2008; Laughton et al., 2011). In addition, researchers should be aware that handling during injection induces a stress response and the tissue damage further poses a risk of secondary infection (Kucharski and Maleszka, 2003). The stress and immune response may even result in death of injected individuals. In adult $A$. mellifera, a $20 \%$ mortality rate was observed within $48 \mathrm{~h}$ of injection with control buffers (Picard -Nizou et al., 1997). Most studies do not report survival rates following injection, but immune responses and mortality risks should be considered when choosing to inject substances.

\subsubsection{Microinjection using a Hamilton syringe}

In multiple studies, honey bees have been injected using a Hamilton syringe (Kucharski and Maleszka, 2003; Barron et al., 2007; Schlüns and Crozier, 2007; Wright et al., 2010; Köhler et al., 2012). The following method is suggested:

1. Select workers to be injected.

When using newly emerged workers, no anaesthesia is required as they do not sting or fly. Older workers need to be anaesthetised (see section 2.1 standard methods for immobilising, killing and storing adult Apis mellifera in the laboratory).

2. Hold the honey bee gently on the side of the thorax between thumb and index finger of one hand.

3. Inject bee with the other hand.

The most common place of injection is between tergites (the needle can easily be inserted specifically between the $3^{\text {rd }}$ and $4^{\text {th }}$ tergite) at the side of the abdomen. The needle should be inserted parallel to the tergite to avoid puncturing of the gut. Handling time must be kept to a minimum (few seconds per bee) to prevent unnecessary stress. Saline or insect ringer are typically injected as carrier and control (Lozano et al., 2001; Barron et al., 2007; Schlüns and Crozier, 2007; Wright et al., 2010).

\subsubsection{Microinjection of small volumes using the Nanoject device and other micro injectors}

For very small injection volumes $(<1 \mu \mathrm{l})$, the Nanoject injector (Drummond) can be used. It consists of a microinjection pipette with an automated microprocessor that can precisely inject a set volume. The injection tips are made from glass capillaries. This automated injection method eliminates vibration and thus minimises tissue injury It may therefore reduce deleterious effects on honey bees, compared to manual injections. The second advantage over manual injections is the high precision of the injector that will eliminate variations in injection volumes. The Nanoject injector has been successfully used on insects (e.g. Teixeira et al., 2008; Yamane and Miyatake, 2010). Furthermore, embryonic injections have been performed using a microscope with a micromanipulator and a microinjector (Narishige) with glass capillary (Sasaki and Ishikawa, 2000). Beye et al. (2002) injected honey bee eggs under a microscope using an Oxford micromanipulator (Singer) and a microinjector with borosilicate capillaries. Lozano et al. (2001) injected adult honey bee workers using a custom-made microinjection system consisting of a glass micropipette mounted on a microelectrode puller (Campden Instruments).

1. Prior to injection, adult individuals should be anaesthetised (see section 2.1).

Anaesthesia with $\mathrm{CO}_{2}$ is not recommended, given known $\mathrm{CO}_{2}$ driven physiological and behavioural modifications in honey bees (Ebadi et al., 1980; Koywiwattrakul et al., 2005).

2. Immobilise the individual to be injected. This can be done by physical means (see section 2.2.1.) or by 
chilling them (section 2.2.2). Anaesthesia with $\mathrm{CO}_{2}$ is not recommended, given known $\mathrm{CO}_{2}$ driven physiological and behavioural modifications in honey bees (Ebadi et al., 1980; Koywiwattrakul et al., 2005).

3. Inject the individual. The method of injection will depend on the device used (for methods see references in the introduction of this section).

\subsubsection{Perspectives}

Future studies should compare survival rates following manual and automated injection at different parts of the body, e.g. injection into the thorax vs. the abdomen. The abdomen has been chosen as the injection site in different studies (e.g. Amdam et al., 2006; Schlüns and Crozier, 2007; Richard et al., 2008). The intersegmental membrane is soft between the tergites and can be easily punctured by the needle. Drugs are directly administered into the haemolymph and spread throughout the body with haemolymph circulation. However, if the worker has ingested a large meal prior to injection, one may puncture the full stomach with the needle. This may be avoided by injecting individuals immediately following emergence prior to the first ingestion of honey from the comb.

Survival rates may also differ between honey bees injected with or without anaesthesia. Workers handled without anaesthesia showed lower sucrose responsiveness $30 \mathrm{~min}$ after handling than immobilised individuals (Pankiw and Page, 2003), and a delayed onset of feeding may increase mortality. Control individuals should be subjected to the same handling times to control for stress effects.

Lastly, nutritional composition of the diet may also affect survival. Worker survival on sucrose-only solutions was drastically reduced following injection (Köhler et al., 2012), but adding protein to the diet may increase the production of immune system components (e.g. antibacterial peptides), which may help in fighting infections and improve survival (Alaux et al., 2010; DeGrandi-Hoffman et al., 2010); see also the $B E E B O O K$ paper on 'maintaining adult honey bees in vitro under laboratory conditions' by Williams et al. (2013). Mortality rate following injection may depend on multiple factors, including injection technique, types and amounts of injected substances, type of needle, needle thickness and sharpness, age of the honey bees, handling stress, and type of anaesthesia (if any). It may prove valuable to assess the mortality following injection in a particular experimental setup to be able to adjust the sample size for the study (see the BEEBOOK paper on statistics (Pirk et al., 2013). The effects of injections should be considered when deciding on a technique for substance application and all parameters or injection methods should be described in detail.

Checklist for injections:

1. Decide on the injection method (Hamilton syringe, Nanoject device, etc.).
2. Decide on a suitable injection site (e.g. abdomen of adults, between tergites).

3. Decide whether anaesthesia is required. Young workers do not sting or fly, older workers may need to be immobilised by cooling prior to injection.

4. Make sure to have defined age-cohorts.

5. Determine the dose and injection volume (ideally $<5 \mu$ for adult workers).

6. Decide on a suitable buffer (saline, insect ringer).

7. Reduce possibilities of unintended secondary infections: use new glass capillaries; disinfect the Hamilton syringe (e.g. ethanol, acetone) before and after use; the needle can be sterilised in a flame to avoid contamination between individuals.

8. Take initial high mortality into account.

9. A test run to practise the injection technique is recommended. This way survival rate following injection can also be determined.

\subsection{Marking honey bee queens}

\subsubsection{Colour-marking queens}

Not only does marking the queen helps in finding her in the hive, but a queen which has been marked and recorded can be 'dated' by reference to the hive card or record book. It also makes it possible to ascertain if and when she has been superseded, or if she has attempted to leave with a swarm, in which case she is usually lost. Generally, queens are marked before being introduced, but they can be marked at any time.

A wide variety of markers have been used to assess insect population dynamics, dispersal, trophic-level interactions, and other ecological interactions. The ideal marker should persist without inhibiting the insect's 'normal' biology. Furthermore, the marker should be environmentally safe, cost-effective, and easy to use (Hagler and Jackson, 2001).

\subsubsection{Marking type}

Queens can be marked with a variety of paints or equipped with numbered and coloured Opalith discs on top of the thorax (Fig. 2).

- Queen marking pens are handy and make queen marking easier (no risk of spilling the bottle with paint or glue), but usually wear off very quickly.

- Fast drying nail varnishes are also good markers.

- Model car paint can be used.

- The longest lasting queen marker is made by mixing a pigment with shellac.

- Opalith discs (Fig. 2) are commercially available in a variety of colours. 


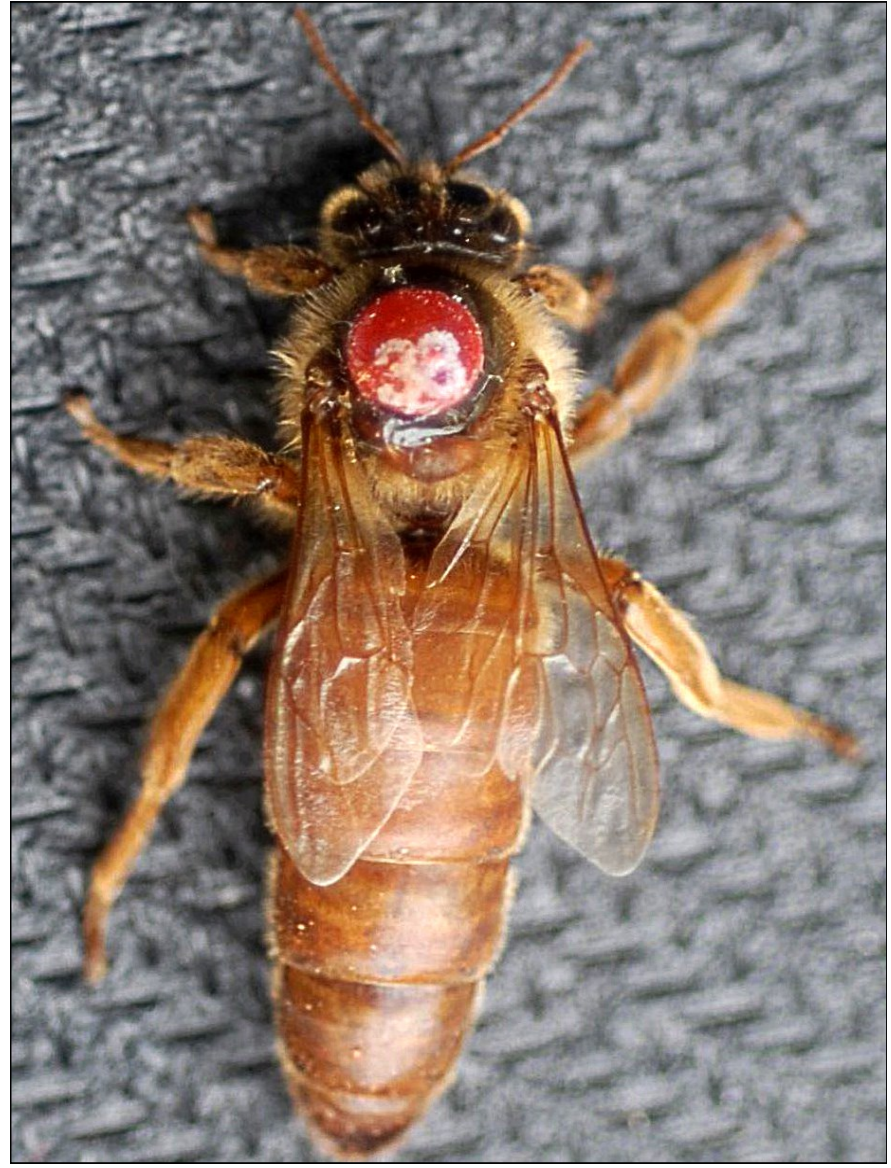

Fig. 2. A queen marked with Opalithplättchen.

Photo: W Wei.

- A special glue is provided with the discs but partially dried shellac or cyanoacrylate ester glues (e.g. Super Glue ${ }^{\circledR}$ ) will serve the same purpose.

\subsubsection{Procedure for paint marking}

1.a. Hold onto the legs or thorax of the queen with one hand (Fig. 3 bottom)

1.b. Alternatively, introduce the queen in a special 'marking tube'. The queen is inserted through the open end of a glass tube and carefully pressed upward with a soft plunger against a net on top of tube. This holds the queen stable during the marking process, thus facilitating it.

2. Dab the marking stick in the paint.

Only the minimum necessary amount of paint should be transferred onto the stick in order not to smear too much material on the queen's thorax and other appendages.

3. Mark the queen by quickly dabbing the paint on the dorsal side of her thorax.

The mark should be small, so that it does not cover any other part of the queen and impair her behaviour.

4. Give paint ample time to dry before the queen is released into the colony.

\subsubsection{Procedure for marking with Opalith discs}

1.a. Hold onto the legs or thorax of the queen with one hand.

1.b. Alternatively, introduce the queen in a marking tube (Section 2.4.1.2.).

2. Dab the marking stick in the glue.

Only the minimum necessary amount of glue or paint should be transferred onto the stick in order not to smear too much material on the queen's thorax and other appendages.

3. Place the glue on the dorsal side of the queen's thorax applying the glue on an area the size of the disc.

4. Moisten the opposite end of the marking stick (where there is no glue).

5. Touch the numbered side of an Opalith disk with this wet end. This allows the disc being picked up.

6. Apply the disc with a slight pressure on the glue.

7. Give glue ample time to dry before the queen is released into the colony.

\subsubsection{Colour-marking code}

An International Colour Code system exists within the beekeeping industry to indicate the year the queen was introduced and facilitates recognition of queen age (Table 3). Since queens do not live more than 5 years, the colour coding starts over in the sixth year (Table 3).

Marking queens with a dot of paint is cost-effective and easy to use and thus practical in beekeeping. While Opalith disks, enabling individual identification of bees (Figs. 2 and 3), have been widely used in research and breeding where it is essential to know the pedigree / history of the queens and colonies.

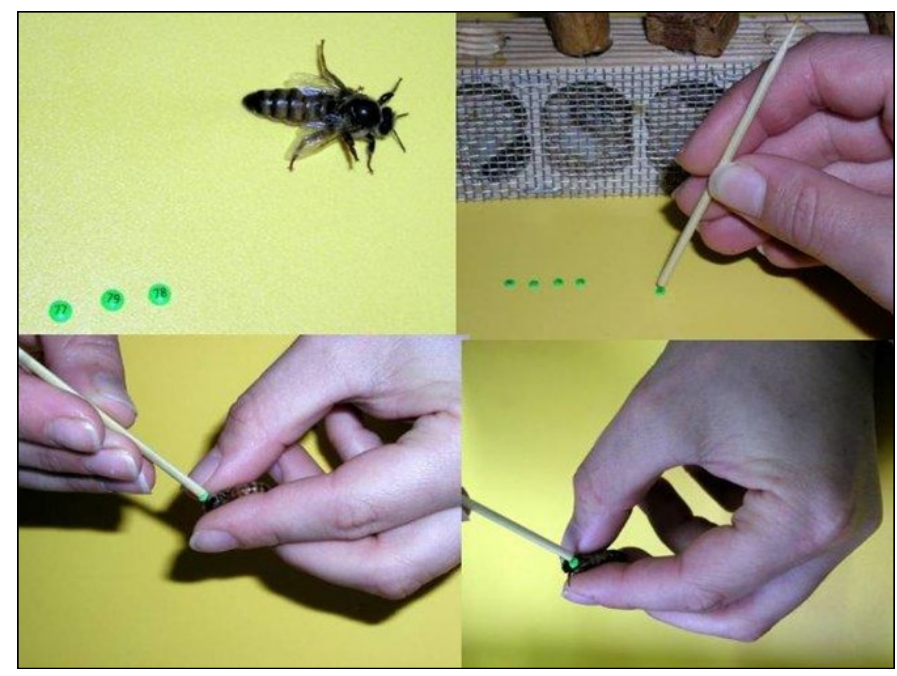

Fig. 3. Step-by-step marking of a queen with numbered plastic disk. Top left - queen with Opalith disks. Bottom left, the marking stick is dipped in glue and touched to the queen's thorax. Top right, the marking stick (the end opposite of the glue) is moistened and touched to the numbered side of an Opalith disk. Bottom Right, the Opalith disk is affixed to the thorax and held in place by the glue.

Photos: J Wilde. 
Table 3. International colour code used for marking queens.

\begin{tabular}{|l|c|}
\hline International queen marking colour code: \\
\hline Colour: & for years ending in: \\
\hline White & 1 or 6 \\
\hline Yellow & 2 or 7 \\
\hline Red & 3 or 8 \\
\hline Green & 4 or 9 \\
\hline Blue & 5 or 0 \\
\hline
\end{tabular}

\subsubsection{Clipping queens' wings}

Queens can be marked by clipping the tip of one forewing. If queens are replaced every two years, the beekeeper can clip the left wing on queens introduced in odd years, and the right wing on queens introduced in even years. The clipping practice may also supplement the paint spot technique as a back-up, should the queen lose her paint mark. Honey bee queens are mated in the air, it should therefore be ascertained that the queen has mated before her wing is clipped.

Another reason to clip the wings of a queen is to prevent her swarming off, besides other methods such as keeping colonies headed by young queens and removing all queen cells. Swarming is the process by which honey bee colonies can reproduce (Seeley, 1986). When swarming occurs, half of the bees will leave the hive. This results in a hive that is unable to rebuild its population before the nectar flow starts, thus decreasing the production of honey.

Therefore, swarm control is a very important part of beekeeping management. When conducting experiments during swarming season, swarm control is even more critical since a swarm may take away half the experimental bees.

From beekeeping experience, it is apparent that queens with fully clipped wings are more prone to fall to the bottom of the hive and are often superseded more quickly than those with unclipped wings. It is recommended to clip less than half of one forewing (Fig. 4) to prevent the queen from flying with a swarm, but not to impair other behaviours. With less than half of one forewing clipped, the queen's

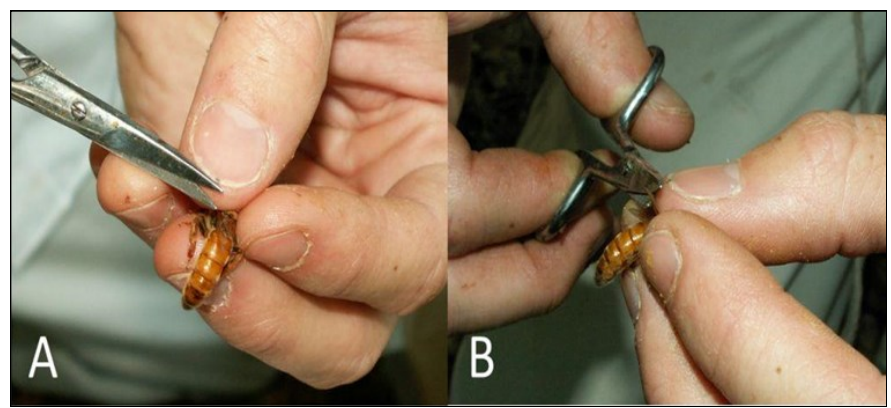

Fig. 4. Clipping the wing of a queen honey bee. The head and thorax of the queen honey bee are lightly grasped between the thumb, index, and middle fingers $(A)$. The wings and abdomen point away from the hand $(A)$. The scissors should be used to tease out the forewing on only one side of the body (B). Using the scissors, clip approximately one fourth, but no more than half of the forewing from the body. ability to function properly inside the colony will not be significantly affected. If the queen tries to fly with the swarm, she will most likely drop in front of the hive. She may then crawl up the leg of the hive stand and re-enter the hive. If not, she can be collected by the beekeeper and put back. The swarming bees will fly away for a short time, but will return to their hive when they are unable to find their queen. Occasionally the clipped queens may fly despite the clipping, but their range is limited, which makes retrieval easier. However, sometimes queens may be lost if they cannot find a way to re-enter the hive after dropping in front of it.

Yet another use of wing clipping is the non-lethal collection of queen DNA. In this case, the purpose is not to prevent flight, since virgin queens that still have to perform a mating flight might be needed for DNA extraction. If a sufficiently small wing piece is clipped (c. $1.3 \mathrm{~mm}^{2}, 7.5 \%$ of each forewing surface is sufficient to genotype them), the mating success of these clipped-wing queens is not affected (Châline et al., 2004).

Wing clipping procedure:

1. Lightly grasp the queen by the thorax between the thumb, index and middle finger of one hand so that the forewing to be clipped points upwards and the abdomen points away from the hand (Fig. 4A).

2. Hold the scissors with the other hand and slide one tip between the fore- and hind wing to separate them (Fig. 4B).

3. Cut approximately one fourth of the forewing without damaging the hind wing.

4. Mark the queen with paint (see section 6.1.2.) when desired.

\subsection{Obtaining brood and adults of known age}

The development of honey bees is divided between egg, larval and pupal stages. Only at the larval stage do immature bees grow, thanks to the abundant food provided by the nurse bees. Their weight increases by a factor of 1,500 during this stage. There are six moults during their development. The timing of moulting and the growth varies according to caste (worker or queen) and sex (drone or queen) of the individual, and to the lineage to which the honey bees of interest belong. Queen development (16 days) is faster than worker's (21 days) and in turn worker development is faster than that of drones ( 24 days). Table 4 summarises the major events and developmental times for $A$. mellifera. Variations of a few hours in developmental time of the various stages can occur between individuals in a colony, but also between subspecies (Michelette and Soares, 1993; Allsopp, 2006). For this reason the measurements given in the following methods are valid only for the subspecies or lineage they have been obtained for. Where known, the subspecies is indicated for relevance of use. When another subspecies is investigated and precise timing of developmental stages is needed, it is recommended to verify

Photos: A Ellis. their timing, for which we give a method (see section 3.5.1.1.). 
Table 4. Development time and events for workers, queens and drones of Apis mellifera (modified from Bertholf, 1925).

\begin{tabular}{|c|c|c|c|c|c|c|}
\hline & \multicolumn{2}{|c|}{ Workers } & \multicolumn{2}{|c|}{ Queens } & \multicolumn{2}{|c|}{ Drones } \\
\hline Day & Stages & Events & Stages & Events & Stages & Events \\
\hline 1 & \multirow{3}{*}{ egg } & & \multirow{3}{*}{ egg } & & \multirow{3}{*}{ legg } & \\
\hline 2 & & & & & & \\
\hline 3 & & hatching & & hatching & & hatching \\
\hline 4 & $1^{\text {st }}$ larval instar & $1^{\text {st }}$ moult & $1^{\text {st }}$ larval instar & $1^{s t}$ moult & $1^{\text {st }}$ larval instar & $1^{\text {st }}$ moult \\
\hline 5 & $2^{\text {nd }}$ larval & $2^{\text {nd }}$ moult & $2^{\text {nd }}$ larval instar & $2^{\text {nd }}$ moult & $2^{\text {nd }}$ larval instar & $2 n^{d}$ moult \\
\hline 6 & $3^{\text {rd }}$ larval instar & $3^{r d}$ moult & $3^{\text {rd }}$ larval instar & $3^{r d}$ moult & $3^{\text {rd }}$ larval instar & $3^{r d}$ moult \\
\hline 7 & $4^{\text {th }}$ larval instar & $4^{\text {th }}$ moult & $4^{\text {th }}$ larval instar & $4^{\text {th }}$ moult & $4^{\text {th }}$ larval instar & $4^{\text {th }}$ moult \\
\hline 8 & \multirow{2}{*}{$5^{\text {th }}$ larval instar } & & \multirow{2}{*}{$5^{\text {th }}$ larval instar } & & \multirow{3}{*}{$5^{\text {th }}$ larval instar } & \\
\hline 9 & & cell is capped & & cell is capped & & \\
\hline 10 & \multirow{2}{*}{ prepupa } & & prepupa & $5^{\text {th }}$ moult & & cell is capped \\
\hline 11 & & $5^{\text {th }}$ moult & \multirow{5}{*}{ pupa } & & \multirow{4}{*}{ prepupa } & \\
\hline 12 & \multirow{9}{*}{ pupa } & & & & & \\
\hline 13 & & & & & & \\
\hline 14 & & & & & & $5^{\text {th }}$ moult \\
\hline 15 & & & & $6^{\text {th }}$ moult & \multirow{8}{*}{ pupa } & \\
\hline 16 & & & \multirow{10}{*}{ imago } & emergence & & \\
\hline 17 & & & & & & \\
\hline 18 & & & & & & \\
\hline 19 & & & & & & \\
\hline 20 & & $6^{\text {th }}$ moult & & & & \\
\hline 21 & \multirow{5}{*}{ imago } & emergence & & & & \\
\hline 22 & & & & & & $6^{\text {th }}$ moult \\
\hline 23 & & & & & \multirow{3}{*}{ imago } & emergence \\
\hline 24 & & & & & & \\
\hline 25. & & $\ldots$ & & $\ldots$ & & $\ldots$ \\
\hline
\end{tabular}

\subsubsection{Obtaining brood of known age}

To obtain brood of known age, a queen can be caged on a frame on a particular day for a few hours. The duration of the caging is determined by the quantity and age range of the brood needed. For example, if more brood is required, the longer the queen is left in the cage. In this case, the age range of that brood increases. For example, the comb area in which the queen laid eggs during $4 \mathrm{~h}$ will hold brood between 20 and $24 \mathrm{~h}$ of age, $24 \mathrm{~h}$ post caging the queen. Given that queens can lay 2,000 eggs per day during the fastest growing stage of the colony, approximately 100 eggs can be obtained every hour. During less beneficial periods, a lower number of eggs can be obtained. If larger amounts of brood of a narrower age range are needed, queens of several colonies need to be caged. This also allows reducing the disturbance of individual colonies in case the brood needs to be collected at frequent intervals. If large amounts of brood of known age are needed from a single colony, several replicates at different times need to be done.

\subsubsection{Procedure to obtain worker or drone brood of known} age

1. Find the queen in a colony.

2. Place an empty comb with worker or drones cells (depending on the needs of the experiment) in a cage with sides made from queen excluder material or purchase a trap cage which encloses the frame and prevents the queen from leaving the comb, but allows workers to move freely in and out to take care of the brood and queen (see Fig. 1 from the BEEBOOK paper on maintaining adult honey bees in vitro under laboratory conditions (Williams et al., 2013)).

3. Place the queen in the cage for a predetermined time. Note: the longer the queen is caged, the larger the range of age of the brood becomes.

4. Remove the comb and queen from the cage.

5. Reintroduce the queen into her colony.

6. Mark on a transparent sheet of acetate the area of comb in which the queen oviposited for future localisation (Fig. 5).

The sheets should be laid over the surface of the comb and the position of cells can be recorded on the sheet using a permanent marker. Be sure to label the sheet and mark it according to its position on the frame (Fig. 5) to be able to place it accurately when using it later and thus avoid confusion.

7. Remove the sheet.

8. Replace the comb in the colony in middle of the brood area. The comb can be placed in the cage again to prevent further ovipositing by the queen (now on the other side of the excluder) in this comb. If done this way, the brood produced while the queen was caged will not be mixed with younger brood produced later.

9. Collect brood when it reaches the desired age or observe developmental stages at regular intervals, according to the purpose of the experiment. 


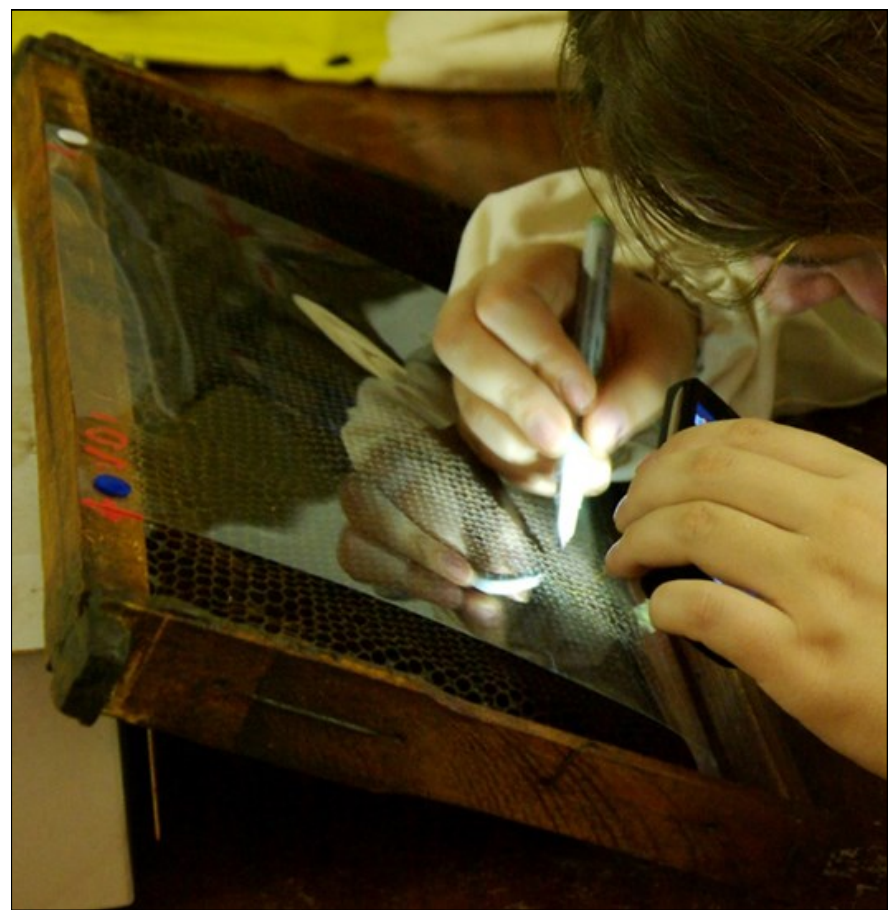

Fig. 5. Marking the cells freshly oviposited in by a queen on an acetate sheet fixed on the frame. The acetate sheet is fixed to the frame with thumb tacks and its position is marked with lines drawn across the sheet and frame (see left side of the image) for precise repositioning on next use.

Photo: V Dietemann.

It is possible to narrow down the age range of the larvae considered for experiments by considering only those that hatched during a chosen period. If larvae are collected for weighing, they should be rinsed in physiological saline to rid them of adhering food.

\subsubsection{Procedure to obtain queen brood of known age}

Follow steps 1 to 8 as described in section 2.5.1.1.

9. Allow for larval hatching approximately 3 days later.

10. Graft larvae of similar age, but younger than $24 \mathrm{~h}$ into queen cups.

11. Follow the instructions given in the BEEBOOK paper on queen rearing and selection for queen rearing (Büchler et al., 2013).

12. Collect queen brood when it reaches the desired age or observe developmental stages at regular intervals, according to the purpose of the experiment.

\subsubsection{Obtaining pupae of known age}

Instead of caging the queen and waiting until pupation to obtain pupae of desired age, freshly capped cells can be identified. This saves time since larval development time can be 'spared' and one need only wait the desired time after capping before obtaining pupae for experiments (see Table 5 for a timeline for worker pupae).

1. Remove frames containing many mature (L5) larvae from the colony.
2. Place an acetate sheet over each frame.

Be sure to label the sheet and mark it according to its position on each frame to be able to place it accurately when using it later and thus avoid confusion.

3. Mark the position of all sealed brood on the sheets of acetate (Fig. 6).

4. Remove the acetate sheets.

5. Replace the frames in the hives.

6. Remove and re-examine frames at regular intervals (as needed for the experiment, usually a minimum of $2 \mathrm{~h}$ ).

7. At each interval, mark the position of cells which have been capped since the last check.

To do this, the acetate sheet is returned to the surface of the frame and aligned with the original point of reference (Fig. 6).

8. Remove the acetate sheet.

9. Replace the comb in the colony.

10. Remove the relevant combs from colonies at pre-determined times and collect pupae of desired age, as indicated by the transparent sheets.

The average duration of the sealed brood stage is 12 days ( $288 \mathrm{~h}$ ) for workers and 14-15 days (340-360 h) for drones in A. mellifera in

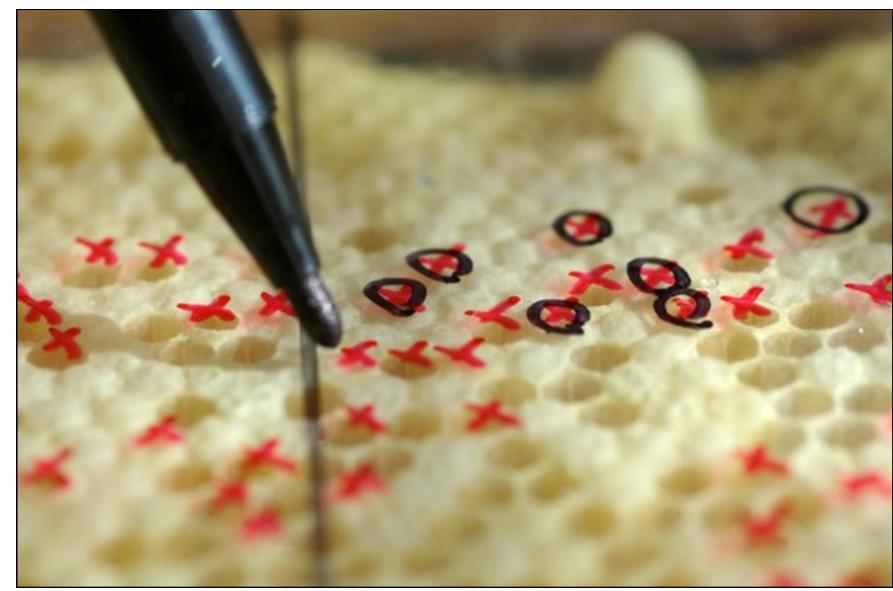

Fig. 6. Marking freshly capped cells on an acetate sheet fixed to the frame.

Photo: V Dietemann.

the U.K. (Martin, 1994, 1995). Relatively high variations are reported for different localities and subspecies (up to $19 \mathrm{~h}$ for worker development, Milum, 1930; Le Conte and Cornuet, 1989; $40 \mathrm{~h}$ for duration of capped stage in A. mellifera capensis workers, Allsopp, 2006). The expected durations should be verified before starting an experiment since these vary from subspecies to subspecies.

The same principle can be used to obtain drone pupae of known age when open drone brood is available. Table 6 gives the timeline for drone pupae development. For queens, follow the procedures described in the $B E E B O O K$ paper on queen rearing and selection for queen rearing (Büchler et al., 2013). Table 7 gives the timeline for queen pupae development. 
Table 5. Colour changes in worker pupae, modified from Jay (1962). Days are counted from cell capping to correspond to Fig. 8. Body parts mentioned in the table are annotated on Fig. 8.

\begin{tabular}{|c|c|c|}
\hline $\begin{array}{l}\text { Number of days } \\
\text { from capping }\end{array}$ & Colour & Body parts \\
\hline 5 & slightly marked light pink & eyes, ocelli \\
\hline \multirow{2}{*}{6} & light pink-purple & eyes \\
\hline & dark pink & ocelli \\
\hline 7 & dark pink-purple & eyes, ocelli \\
\hline \multirow{2}{*}{8} & slightly marked light brown & head, thorax \\
\hline & light brown & tibio-tarsal joints, sutures outlining mesonotum, wing bases \\
\hline \multirow{5}{*}{9} & light yellow & abdomen, legs \\
\hline & light brown & head, thorax \\
\hline & light to medium brown & leg joints, claws, mandibles, antennae, sting, spurs, spines, hair \\
\hline & medium brown & tibio-tarsal joints, wing bases, sutures outlining mesonotum \\
\hline & dark purple & eyes, ocelli \\
\hline \multirow{6}{*}{10} & light grey & wing pads \\
\hline & medium brown & $\begin{array}{l}\text { flagellar segments, leg joints, wing bases, mandibles, claws, sting, spines, spurs, hair, } \\
\text { sutures outlining mesonotum }\end{array}$ \\
\hline & dark yellow & abdomen, scapes, pedicel, tongue, legs \\
\hline & dark brown & head, thorax \\
\hline & brownish-purple & ocelli \\
\hline & black & eyes \\
\hline \multirow{6}{*}{11} & medium grey & wing pads \\
\hline & dark yellow to light brown & abdomen, scapes, pedicel, tongue, legs \\
\hline & dark brown & leg joints, wing bases, claws, sting, spines, spurs, hair, sutures outlining mesonotum \\
\hline & dark grey & head, thorax \\
\hline & dark brownish-black & ocelli \\
\hline & black & eyes, flagellar segments \\
\hline 12 & & pupal moult complete \\
\hline
\end{tabular}

Table 6. Colour changes in drone pupae according to Jay (1962). Days are counted from pupation.

\begin{tabular}{|c|c|c|}
\hline $\begin{array}{l}\text { Number of days } \\
\text { from pupation }\end{array}$ & Colour & Body parts \\
\hline 2 & slightly marked light pink & eyes, ocelli \\
\hline \multirow{2}{*}{3} & light pink-purple & lower parts of eyes, ocelli \\
\hline & dark pink & eyes, ocelli \\
\hline \multirow{2}{*}{4} & dark pink & eyes, ocelli \\
\hline & dark pink-purple & lower parts of eyes \\
\hline \multirow{2}{*}{5} & light pink-purple & eyes, ocelli \\
\hline & dark purple & lower parts of eyes \\
\hline \multirow{3}{*}{6} & light yellow & wing base \\
\hline & dark pink-purple & eyes, ocelli \\
\hline & dark purple & lower parts of eyes \\
\hline \multirow{3}{*}{7} & slightly marked light yellow & abdomen, tongue, antennae, wing pads, head, thorax, legs, wing bases \\
\hline & light brown & tibio-tarsal joints, claws, mandibles, sutures outlining mesonotum \\
\hline & dark purple & eyes, ocelli \\
\hline \multirow{5}{*}{8} & light yellow & abdomen, tongue, scapes, pedicel, legs \\
\hline & light brown & head, thorax, spurs, spines, hair, flagellar segments \\
\hline & light grey & wing pads, tip of abdomen \\
\hline & medium brown & leg joints, wing bases, claws, mandibles, sutures outlining mesonotum \\
\hline & dark purple & eyes, ocelli \\
\hline \multirow{6}{*}{9} & light brown & scapes, pedicel, tongue \\
\hline & light grey & wing pads \\
\hline & medium brown & head, thorax, spines, spurs, hair \\
\hline & dark yellow & abdomen, legs \\
\hline & dark brown & leg joints, wing bases, claws, mandibles, sutures outlining mesonotum, tip of abdomen \\
\hline & purple-black & eyes, ocelli, flagellar segments \\
\hline \multirow{5}{*}{10} & medium to dark grey & wing pads \\
\hline & dark yellow to light brown & abdomen, scapes, pedicel, tongue, legs \\
\hline & dark brown & leg joints, wing bases, mandibles, claws, spines, spurs, hair, sutures outlining mesonotum \\
\hline & dark grey to dark brown & head, thorax \\
\hline & black & eyes, ocelli, flagellar segments, tip of abdomen \\
\hline 11 & & pupal moult complete \\
\hline
\end{tabular}


Table 7. Colour changes in queen pupae according to Jay (1962). Days are counted from pupation.

\begin{tabular}{|l|l|l|}
\hline $\begin{array}{l}\text { Number of days } \\
\text { from pupation }\end{array}$ & Colour & Body parts \\
\hline 1 & light pink & eyes \\
\hline 2 & light pink & ocelli \\
\cline { 2 - 3 } & medium pink & eyes \\
\hline \multirow{3}{*}{3} & light pink-purple & eyes \\
\cline { 2 - 3 } & light yellow & head, thorax, mandibles \\
\cline { 2 - 3 } & dark pink & ocelli \\
\hline \multirow{4}{*}{4} & light yellow & abdomen, legs, antennae \\
\hline & light brown & head, thorax, leg joints, claws, sting, sutures outlining mesonotum \\
\cline { 2 - 3 } & dark pink-purple & eyes, ocelli \\
\hline & dark brown & mandibles \\
\hline \multirow{5}{*}{5} & light grey & wing pads \\
\cline { 2 - 3 } & medium grey & head, thorax \\
\cline { 2 - 3 } & dark yellow to light brown & abdomen, legs, frons, clypeus, tongue, scapes, pedicel \\
\cline { 2 - 3 } & dark brown & leg joints, claws, sting, mandibles, spines, spurs, hair, sutures outlining mesonotum \\
\cline { 2 - 3 } & black & eyes, ocelli, flagellar segments \\
\hline 6 & & pupal moult complete \\
\hline
\end{tabular}

Table 8. Average head diameter and body weight range of workers and queens of $A$. mellifera carnica from Germany and Africanised honey bees from Brazil (after Rembold et al., 1980; Michelette and Soares, 1993).

\begin{tabular}{|c|c|c|c|c|}
\hline & & Instar & Head diameter $(\mathrm{mm} \pm \mathrm{SD})$ & Weight (mg, min. - max.) \\
\hline \multirow{10}{*}{$\begin{array}{l}\text { Apis mellifera } \\
\text { carnica }\end{array}$} & \multirow{5}{*}{ Workers } & L1 & $0.33 \pm 0.018$ & $0.10-0.45$ \\
\hline & & $\mathrm{L} 2$ & $0.47 \pm 0.030$ & $0.35-1.50$ \\
\hline & & L3 & $0.70 \pm 0.051$ & $1.3-6.0$ \\
\hline & & L4 & $1.05 \pm 0.058$ & $4.2-32$ \\
\hline & & L5 & $1.58 \pm 0.078$ & $27-280$ \\
\hline & \multirow{5}{*}{ Queens } & L1 & $0.33 \pm 0.020$ & $0.10-0.45$ \\
\hline & & $\mathrm{L} 2$ & $0.48 \pm 0.026$ & $0.35-150$ \\
\hline & & L3 & $0.72 \pm 0.044$ & $1.3-7.0$ \\
\hline & & L4 & $1.11 \pm 0.072$ & $3.8-44$ \\
\hline & & $\mathrm{L} 5$ & $1.69 \pm 0.097$ & $31-360$ \\
\hline \multirow{5}{*}{$\begin{array}{l}\text { Africanised } \\
\text { honey bees }\end{array}$} & \multirow{5}{*}{ Workers } & L1 & $0.32 \pm 0.026$ & $0.11-0.30$ \\
\hline & & $\mathrm{L} 2$ & $0.44 \pm 0.032$ & $0.31-1.05$ \\
\hline & & L3 & $0.65 \pm 0.045$ & $1.50-4.45$ \\
\hline & & L4 & $0.92 \pm 0.094$ & $4.80-24.8$ \\
\hline & & L5 & $1.49 \pm 0.048$ & $24.30-126.7$ \\
\hline
\end{tabular}

\subsubsection{Recognising the instar of larvae}

Rembold et al. (1980) and Michelette and Soares (1993) described the different larval instars based on head diameter for $A$. mellifera carnica from Germany (workers and queens; Table 8) and Africanised honey bees form Brazil (workers; Table 8 ), respectively. These measures provide a reliable method to identify larval instars, since head size of the various stages grow in a stepwise manner at each ecdysis. These authors also give the weight range of the different instars, which can also help identify them. However, the weight of the heaviest larvae of an instar can overlap with that of the lightest larvae of the next instar.

\subsubsection{Recognising the age of larvae}

When queen caging is not an option to obtain larvae of known age, the age of worker larvae can be assessed visually or by weighing. Visual recognition can be done based on Fig. 7. This however, only allows for a rough estimate of age. Because the growth is exponential, visual estimation of age is error prone. A more accurate way is to weigh the larvae after having cleaned them from jelly residues and absorbed the excess water from their surface. Table 5 gives equations that allow the calculation of larva age for workers, queens and drones. Given the exponential growth of larvae, Thrashyvoulou and Benton (1982) divided the larval development of honey bees of Italian origin in several phases that could be described with regression equations for workers, queens and drones (Tables 9 and 10). The high coefficient of correlations obtained (between 92.3 and 99.7) shows that their formulas are reliable for the population measured. An equation was also produced to describe the complete development, but with lower precision and is therefore not given here (coefficient of correlations between 81.7 and 90.6). Despite the good fit of these equations, deviations might occur according to variations between bee populations and subspecies and they should be recalculated for different populations or subspecies. 
Table 9. Regression equations for weight categories of honey bee workers and queens. $X$ designate age and $Y$ the measured weight within the category given in the second column (after Thrashyvoulou and Benton, 1965).

\begin{tabular}{|l|c|c|c|c|}
\hline & \multicolumn{2}{|c|}{ Workers } & \multicolumn{2}{c|}{ Queens } \\
\hline Age (h) & Weight $(\mathrm{mg})$ & Regression equation & Weight $(\mathrm{mg})$ & Regression equation \\
\hline $\mathbf{6 - 3 0}$ & $0.20-0.80$ & $\mathrm{X}=(\mathrm{Y}-1.41) / 32.60$ & $0.12-0.69$ & $\mathrm{X}=(\mathrm{Y}-4.79) / 51.40$ \\
\hline $\mathbf{3 1 - 5 4}$ & $0.81-7.00$ & $\mathrm{X}=(\mathrm{Y}-31.90) / 2.71$ & $0.70-8.50$ & $\mathrm{X}=(\mathrm{Y}-33.50) / 3.29$ \\
\hline $\mathbf{5 5 - 9 0}$ & $7.10-46.00$ & $\mathrm{X}=(\mathrm{Y}-50.60) / 0.87$ & $8.60-37.90$ & $\mathrm{X}=(\mathrm{Y}-48.80) / 1.12$ \\
\hline $\mathbf{9 1 - 1 2 0}$ & $46.10-140.00$ & $\mathrm{X}=(\mathrm{Y}-73.30) / 1.69$ & $38.00-186.00$ & $\mathrm{X}=(\mathrm{Y}-85.10) / 0.16$ \\
\hline
\end{tabular}

Table 10. Regression equations for weight categories of honey bee drones. $X$ designate age in hours and $Y$ the measured weight in $\mathrm{mg}$ within the category given in the second column (after Thrashyvoulou and Benton, 1965).

\begin{tabular}{|l|c|c|}
\hline Age (h) & weight $\mathbf{( m g )}$ & regression equation \\
\hline $9-54$ & $0.29-3.50$ & $\mathrm{X}=(\mathrm{Y}-8.82) / 11.60$ \\
\hline $55-98$ & $3.51-42.00$ & $\mathrm{X}=(\mathrm{Y}-52.80) / 1.09$ \\
\hline $99-120$ & $42.10-129.00$ & $\mathrm{X}=(\mathrm{Y}-64.30) / 0.47$ \\
\hline $121-163$ & $129.42-311.54$ & $\mathrm{X}=(\mathrm{Y}-91.6) / 0.23$ \\
\hline
\end{tabular}

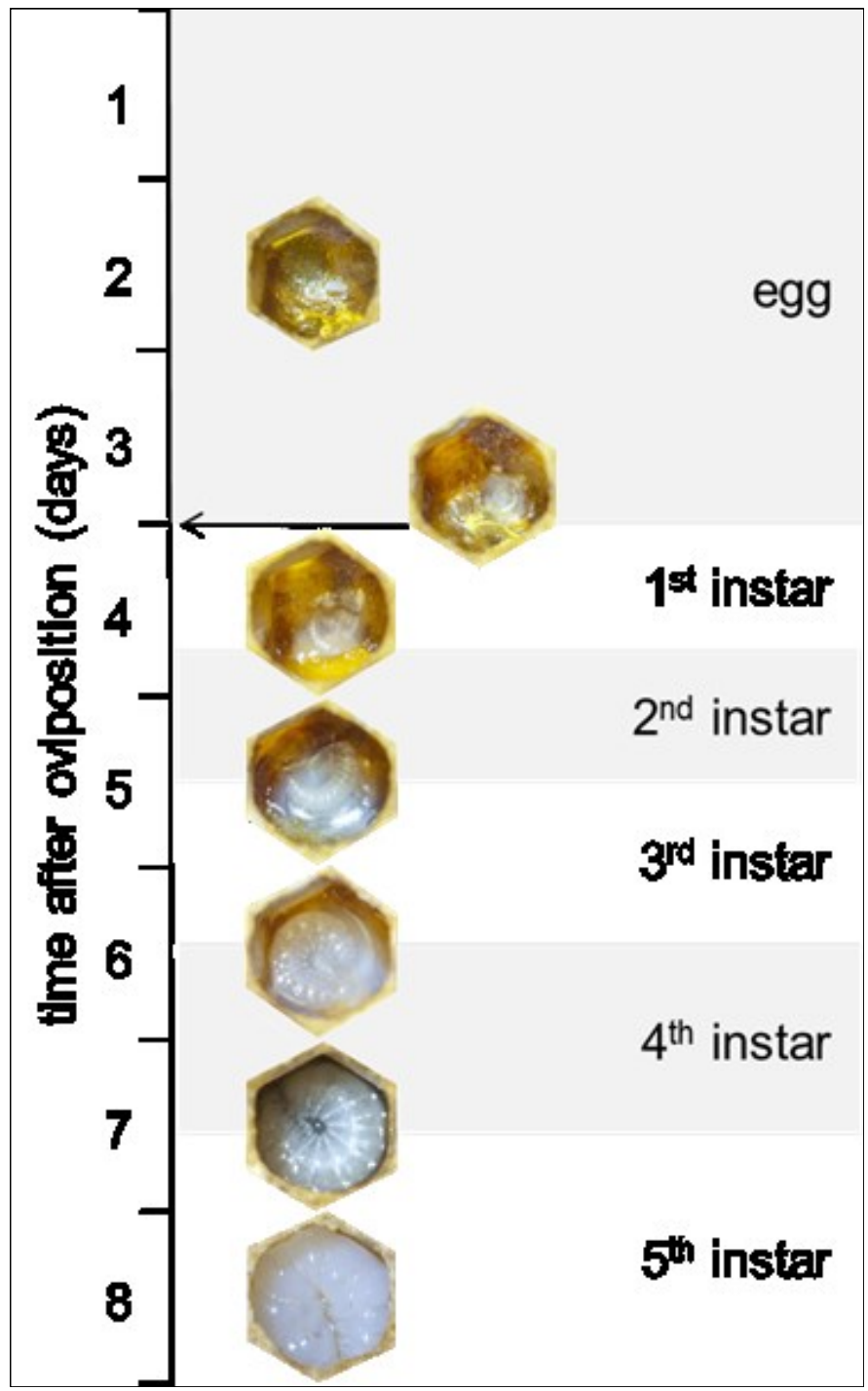

Fig. 7. Development of a worker larva, starting from egg-laying by the queen. A rough assessment of larva age can be obtained by observing the space occupied by the larva in the cell. Larval instars are represented by greyed areas.

\subsubsection{Recognising the age of pupae}

When queen caging or marking freshly capped cells are not an option, it is possible to recognise the approximate age of pupae based on their morphology and colouration of body parts. Figure 8 can be consulted for identification of worker pupa age as well as Table 5, compiled from the observations of Jay (1962) on pupa appearance. Jay (1962) also describes the appearance of immature drone (Table 6) and queen (Table 7) pupae. The body parts described by Jay (1962) are annotated on Fig. 9. The work of Jay is presented here since it describes the appearance of pupae according to days of development. Others describe colour changes more precisely since they base their description on colour standards, but they only mention the appearance of different stages without linking it to age (Rembold et al., 1980; Michelette and Soares, 1993).

\subsubsection{Obtaining workers of known age}

Obtaining workers of known age (counted from emergence) can be accomplished by having them emerge in an incubator, marking them and replacing them in their colony for the desired duration. Refer to the $B E E B O O K$ paper on 'maintaining adult honey bees in vitro under laboratory conditions' by Williams et al. (2013) for more details on incubator conditions.

1. Select a brood comb with capped cells.

2. Inspect the comb for emerging workers.

If none are observed, uncap a few cells to determine the age of the pupae (see section 2.5.5. 'Recognising the age of pupae'). The presence of late stage pupae (dark eyes) indicates that workers will begin emerging within a few days.

3. Place the selected frame in a frame cage (see Fig. 12 of the $B E E B O O K$ paper on maintaining adult honey bees in vitro under laboratory conditions by Williams et al. (2013)).

4. Place in the incubator at $35^{\circ} \mathrm{C}$ and $60-70 \% \mathrm{RH}$.

5. Inspect daily (or when needed) and remove freshly emerged workers.

6. Collect workers when a sufficient amount can be collected at once; discard or reintroduce the workers into colonies if their number is insufficient and wait until enough young workers have emerged.

7. Mark an excess of workers with colour paints (see section 2.3. 'Marking individual bees' of the BEEBOOK paper on behavioural methods by Scheiner et al., 2013). 


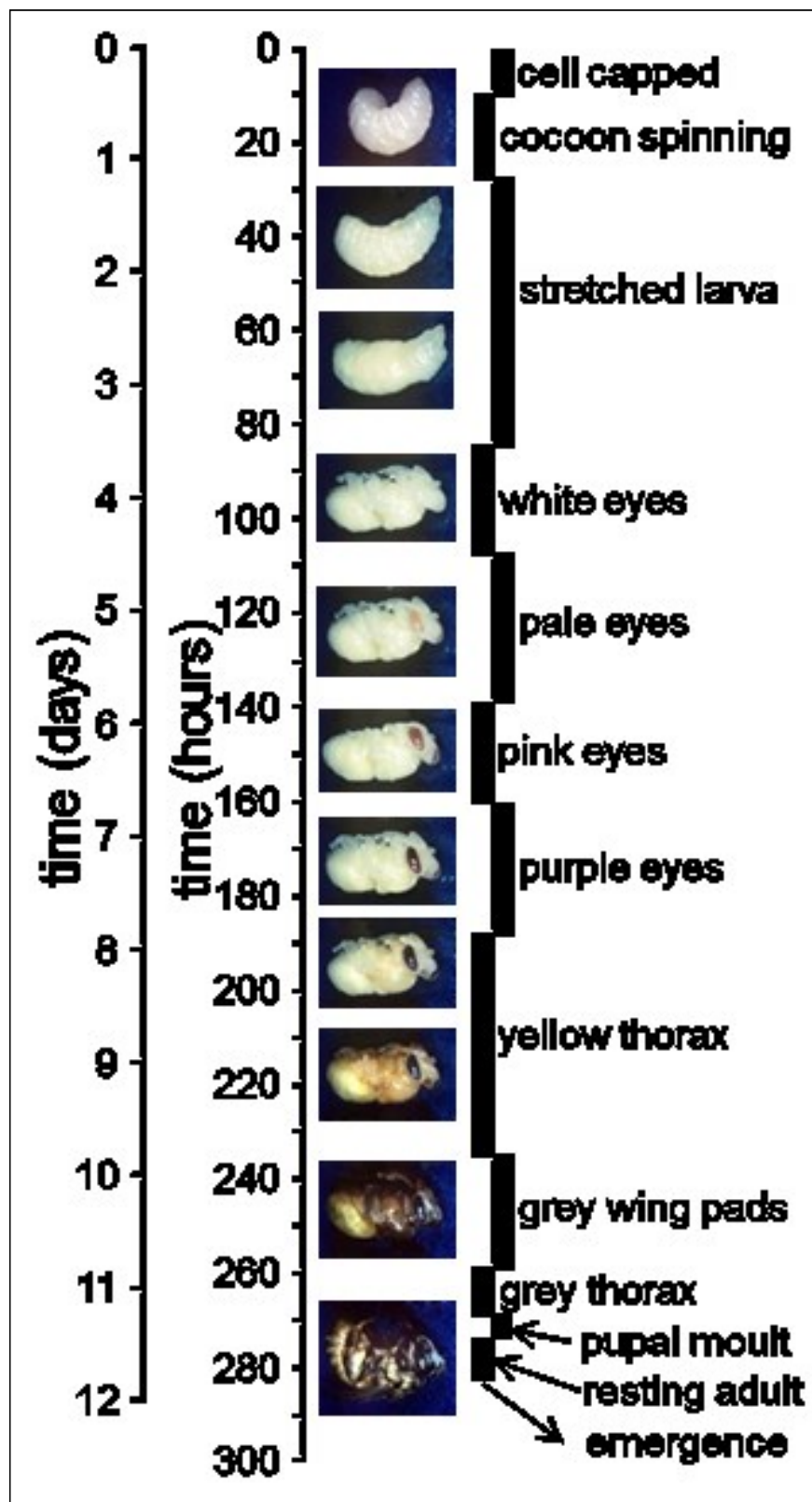

Fig. 8. Timing and duration of sealed worker brood development. Y-axis starts at capping time. Morphological categories after Martin (1994) for UK honey bees. For simplicity black vertical bars are represented without overlap, but developmental time of each stage can vary.

Photo: S Camazine.

Different colours or marking codes can be used to mark workers of the same colony on different days.

8. Allow some time for the paint to dry.

9. Reintroduce workers into their colonies.

If workers are attacked by nest mates, spray them with sugar water or reintroduce them in a cage plugged with candy (for a recipe, see the $B E E B O O K$ paper on 'maintaining adult honey bees in vitro under laboratory conditions' by Williams et al. (2013)) so that they can eat their way out. This will increase their acceptance.

10. Inspect colonies and collect marked workers at the desired time.

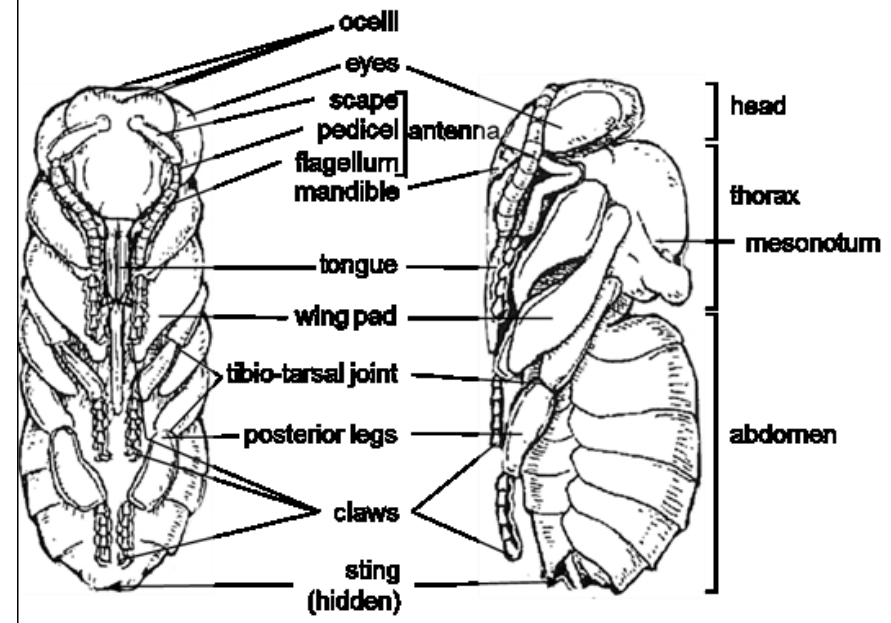

Fig. 9. Anatomy of the worker honey bee pupa with annotations corresponding to Tables 5, 6 and 7. Adapted from Dade (2009).

\subsubsection{Conclusion}

The possible variation in developmental time between different lineages should be taken into account when designing experiments in which the age of immatures or adult is important. In the literature, development times can be given in hours or days and counted from different starting points (oviposition by the queen, hatching, emergence). This makes the body of work available difficult to rely on and should be considered to avoid mistakes in experimental design. The margin of error when considering development time in days is rather large ( $24 \mathrm{~h}$ ) and makes it challenging to set boundaries between developmental stages.

\section{Other equipment used in the}

\section{laboratory}

\subsection{Using a haemocytometer to estimate the concentration of cells, spores or sperms}

In fields of quantitative experimental research e.g. cell culture and microbiology (including bee pathology), it is important to determine the exact concentration or number of bacteria, cells, or spores and even small organisms (hereafter referred to as particles) to guarantee accuracy and reproducibility of experiments (Hefner et al., 2010). The quickest reliable method is direct microscopic or total cell counts of a culture or a suspension through the use of a counting chamber or haemocytometer (Cantwell, 1970; Paul, 1975; Strober, 1997). This method takes into account all cells or spores, cultivable or not, as long as they have a recognisable shape or trait and are not confused with other material in the sample. Further methods can be used to detect culturable (i.e. viable) particles. The plate count method allows for the counting of clonal unicellulars that form colonies and can be cultivated on an appropriate medium (see the European foulbrood paper of the 
BEEBOOK (Forsgren et al., 2013)). It is also possible to use spore germination test (see BEEBOOK paper on fungi (Jensen et al., 2013)) or fluorescence staining, Fenoy et al. (2009) for this purpose.

\subsubsection{Total or microscopic count}

A haemocytometer (Fig. 10) is used to determine the number of particles found within a demarcated region of a slide haemocytometer containing a known volume. The number of cells counted in this volume is used to extrapolate the number of cells in the total sample. There are several kinds of haemocytometers, but they all consist of a microscope slide with a grid etched into the bottom of a cavity (the counting chamber, Fig. 11). The size of the counting chambers can vary with model and manufacturer (e.g. Helber Z30000, FuchsRosenthal, Neubauer, Neubauer improved, Thoma, Thoma new). A typical chamber depth is $0.1 \mathrm{~mm}$, but to be able to count smaller particles (bacteria) a smaller depth $(0.02 \mathrm{~mm}$, e.g. Petroff-Hausser) is required. The grid is divided in squares of different sizes that allow for the counting of particles of different sizes. The number of squares also depends on the model (Neubauer: $3 \times 3$; Neubauer improved $5 \times 5$; Thoma $4 \times 4$ ) as is the number of lines separating the squares (Figs. 12 and 13). A cover glass closes up the top of the cavity, determining a specific chamber volume. It is possible to obtain disposable counting chambers (e.g. Fastread, UK), which have the advantage of not requiring cleaning between measurements.

Procedure to follow when using a haemocytometer

1. Carefully clean haemocytometer and cover glass with lens paper with sterilised distilled water to avoid contamination or counting errors.

2. Dry with lens paper.

3. Slightly moisten the edges of haemocytometer.

4. Apply cover glass.

Make sure to use the provided cover glasses - these glasses are thicker than the standard cover glasses so that surface tension will not deform them.

5. Press firmly until the Newton rings appear where slide and cover come into contact.

This is important for accuracy of the measurement since only a proper placement ensures a correct volume and therefore counting.

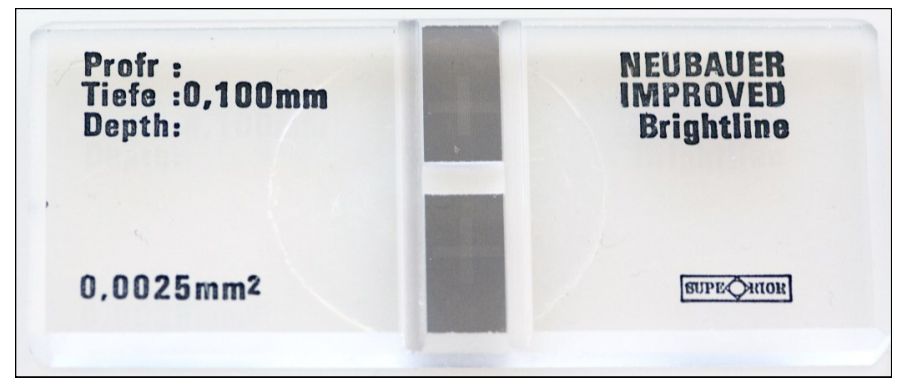

Fig. 10. A haemocytometer.

Photo: V Dietemann.

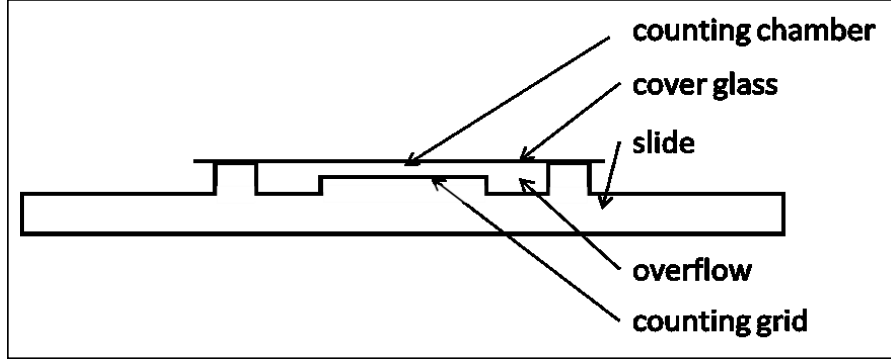

Fig. 11. Section of a haemocytometer. Drawing by V. Dietemann.

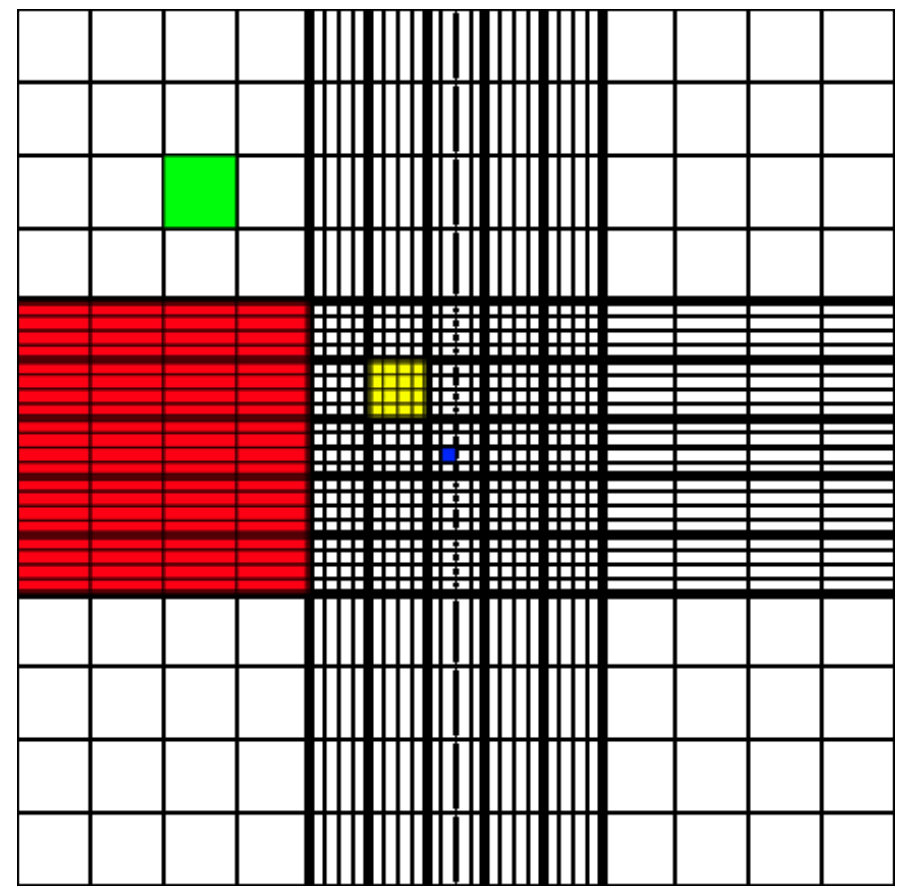

Fig. 12. Haemocytometer grid: red square $=1 \mathrm{~mm}^{2}, 100 \mathrm{nl}$, green square $=0.0625 \mathrm{~mm}^{2}, 6.25 \mathrm{nl}$, yellow square $=0.04 \mathrm{~mm}^{2}, 4 \mathrm{nl}$, blue square $=0.0025 \mathrm{~mm}^{2}, 0.25 \mathrm{nl}$, at a depth of $0.1 \mathrm{~mm}$. Source: Wikipedia In an improved Neubauer haemocytometer total number of cells can be determined by number of cells found in grid (red square) $\times 10^{4}(10,000)$.

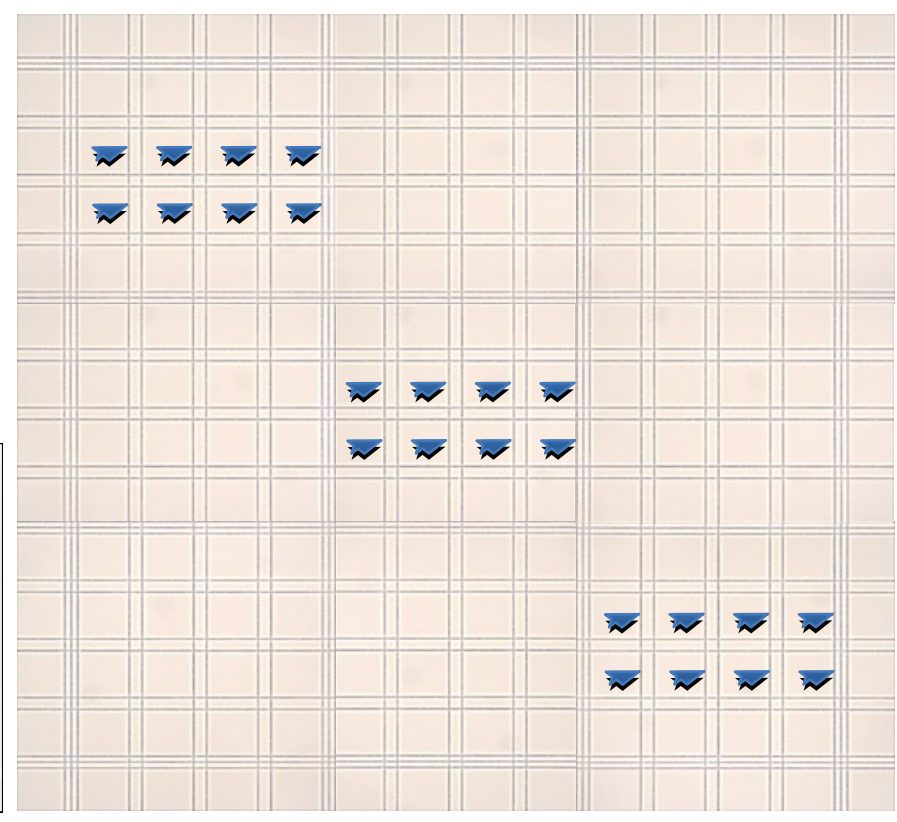

Fig. 13. Suggested counting of 24 squares in a haemocytometer. 
6. Prepare your sample according to description in other papers of the BEEBOOK (American foulbrood, De Graaf et al., 2013; European foulbrood, Forsgren et al., 2013; fungi, Jensen et al., 2013; Nosema, Fries et al., 2013; queen rearing and selection, Büchler et al., 2013; instrumental insemination, Cobey et al., 2013).

The samples, especially if they include bees or bee parts, should be carefully ground or dissected and mixed with water. The solution should contain 5-50 particles per square. If stock solution has more particles, it can be diluted until values in this range are obtained. This determines the dilution factor. To facilitate calculations of the dilution factor, it is recommended to use one $\mathrm{ml}$ of water per sample or bee that has to be counted or to use 10 times dilution series. In this case, mixing the samples by vortexing during the dilution process is necessary to ensure a homogeneous suspension of the particles. Vortexing is also necessary to homogenise the solution before each counting.

7. Mix sample properly to ensure uniform/ homogenous suspension before introducing the suspension to the periphery of one of the v-shaped wells with pipette. The area under the cover slip fills by capillary action.

8. Place haemocytometer under microscope, adjust to appropriate magnification.

9. Use a weak magnification to facilitate localisation of the grid.

10. Adjust to appropriate magnification for counting (see the BEEBOOK papers on Nosema, European foulbrood and fungi for more details, Fries et al., 2013; Forsgren et al., 2013; Jensen et al., 2013, respectively).

Do not crash the objective into the cover glass when focusing! Remember the haemocytometer is much thicker than regular slides.

11. Allow 2 min for the particles to settle in the chamber before counting.

12. Count the particles in the appropriate squares depending on the size of the particles to be counted, making sure that different areas of the chamber are counted (e.g. for Nosema spore sized particles, Fig. 13).

Count at least 300 particles in order to minimise errors. Particles that are only partially inside a particular square must be dealt with in a systematic manner to prevent double counting when the neighbouring square is counted. Count only those particles which are entirely within a square and only those crossing over the top and left boundaries, Fig. 14 (or bottom and right, if you prefer). If squares are separated by several lines, chose one as a boundary.

13. Calculate the number of particles per $\mathrm{ml}$ of the original sample from the known volume of the counting chamber.

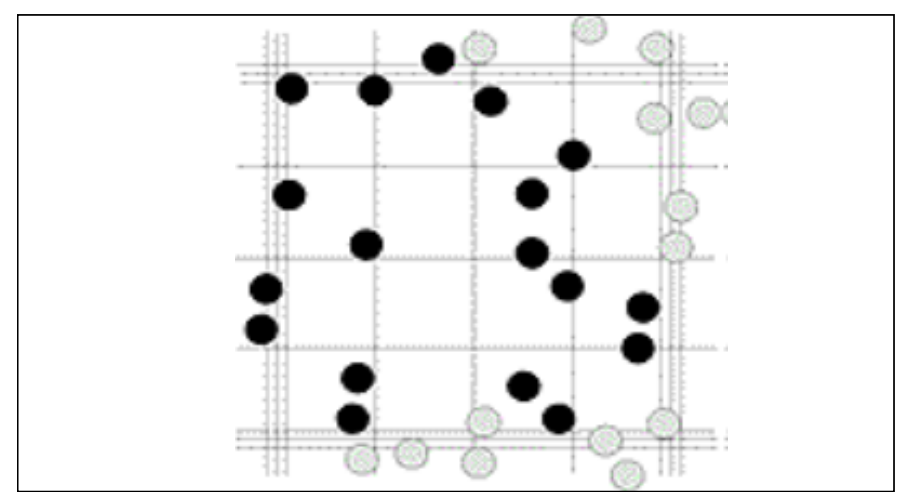

Fig. 14. To avoid double counting, spores that are only partially inside a particular square must be dealt with in a systematic manner. In this example, only the particles which are entirely within a square and only those crossing over the top and left middle lines are counted.

Formula:

$$
\frac{\text { total number of counted particles } \times \text { dilution factor }(\delta)}{\text { area of squares counted }\left(\mathrm{mm}^{2}\right) \times \text { chamber depth }(\mathrm{mm})}
$$

14. To obtain the total number of particles in the sample, multiply the concentration obtained by the initial sample volume.

Example:

total number of counted particles: 288

area of small squares counted: $24 \times 0.04=0.96 \mathrm{~mm}^{2}$

chamber depth: $0.1 \mathrm{~mm}$

dilution: $1: 200$ (dilution factor $(\delta)=200$ )

$$
\frac{288 \times 200}{0.96 \times 0.1}=600,000
$$

Say total sample volume was $0.5 \mathrm{ml}$, there are $0.5 \times 600,000=$ 300,000 particles in the samples.

Pros: Haemocytometers are inexpensive and commonly used. They are long-lasting and versatile and a very effective way to count particles.

Cons: Using a haemocytometer requires a phase contrast microscope. Statistical robustness is lacking when counting low concentrations. In addition subjectivity may be a problem among users and it is a tedious and time consuming method (Hefner et al., 2010). It is a monotonous and time consuming task, only reliable for clearly recognisable particles or in samples without structures looking similar to the particles of interest. The viability of the particles counted is unknown.

The automated cell counting method, including flow cytometry, Scepter cell counters and vision based counters, may be a more reliable alternative method to use for particle counting. Not only is it less time consuming, it eliminates subjectivity and it also provides counting algorithms. In future it may even become a necessity in laboratories. 
Table 11. Examples of application of hive scale networks: honey meters in different countries.

\begin{tabular}{|c|c|c|c|}
\hline Name & Country & Webpage & Info \\
\hline \begin{tabular}{|l|} 
Trachtmeldedienst der Landesverbände \\
Badischer und Württembergischer Imker
\end{tabular} & Germany & $\begin{array}{l}\text { http://lbi.volatus.de/trachtmeldedienst/ } \\
\text { Trachtmeldedienst.html }\end{array}$ & $\begin{array}{l}\text { Restricted website. } \\
\text { Only for members of the associations. }\end{array}$ \\
\hline Nordic/Baltic honey meter & Denmark & $\begin{array}{l}\text { www.stadevægt.dk } \\
\text { you can also use: http://biavl.volatus.de/bsmo/ } \\
\text { BSM.html\# } \\
\text { if the Danish letter 'æ' is not available on your } \\
\text { keyboard }\end{array}$ & $\begin{array}{l}\text { Open website. } \\
\text { Access for all beekeepers. }\end{array}$ \\
\hline \begin{tabular}{|l|} 
Apistische Beobachtungen - Waagvölker \\
Verein deutschschweizerischer und \\
rätoromanischer Bienenfreunde
\end{tabular} & Switzerland & http://www.vdrb.ch/service/waagvlker.html & $\begin{array}{l}\text { Open website. } \\
\text { Access for all beekeepers } \\
\text { (scales offline in winter) }\end{array}$ \\
\hline US honey beenet & $\begin{array}{l}\text { United States of } \\
\text { America }\end{array}$ & $\begin{array}{l}\text { http://honey beenet.gsfc.nasa.gov/Sites/ } \\
\text { reg_map_button.htm } \\
\text { example single scale: http://honey } \\
\text { beenet.gsfc.nasa.gov/Sites/ScaleHiveSite.php? } \\
\text { SiteID=MD003 }\end{array}$ & $\begin{array}{l}\text { Presumably the oldest available hive scale data } \\
\text { on the internet. } \\
\text { Most of the scales are manual scales. }\end{array}$ \\
\hline
\end{tabular}

Table 12. Comparison of four different scales. The design of the electronic scales follows the same basic concept.

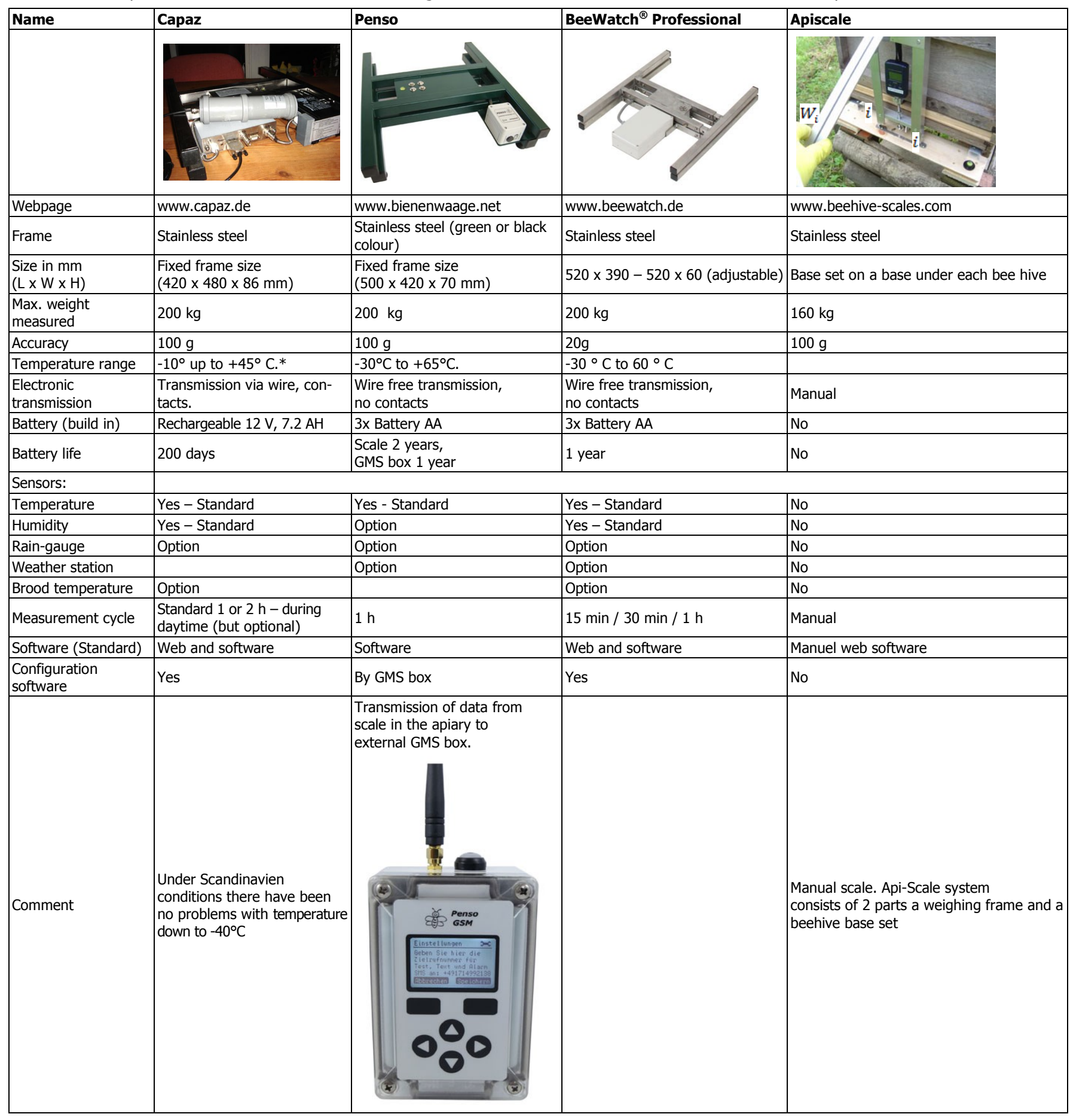




\section{Research methods at the colony}

\section{level}

\subsection{Weighing full hives}

\subsubsection{Introduction}

Over the last few years, new technology has been taken into use in modern beekeeping. For example, electronic hive scales can easily supply the beekeeper/ scientist with important information on several important events from honey bee colonies' life cycles (McLellan, 1977; Buchmann and Thoenes, 1990; Meikle and Holst, 2006). The weight of full colonies (i.e. the summed up weight of the box, combs with food stores and the bees) can be measured to monitor: 1 . the occurrence of nectar flow during the foraging season (for examples see Table 11) or daily gain in nectar stores (Meikle et al., 2008; Okada et al., 2012), 2. the reduction of food stores during nonforaging periods (Seeley and Visscher, 1985) and 3. the occurrence of swarming events (Meikle et al., 2008).

All electronic scales are designed following the same basic concept namely to function as a honey meter, much like a weather forecast with which beekeepers can get vital information on the nectar flow, food consumption, but also humidity, temperature, rainfall and brood temperature. Some hive scales also measure wind velocity or sun hours. A state of the art hive scale is designed to automatically transmit these data either directly via internet, to the beekeepers cell phone or to personal computer software.

Since there is an increasing number of scales available on the market, we give a short comparison of three different commercially available electronic and one manual scales in Table 12 and focus on the most widely used Capaz hive scale and its application as a honey meter.

\subsubsection{The Capaz hive scale}

The first prototype of the Capaz hive scale was developed in 1997. In 2003 , it was ready to be put on the commercial market. The scale is a $420 \times 480 \times 86 \mathrm{~mm}$ platform made of aluminium and stainless steel (Fig. 15). The scale can weigh up to $200 \mathrm{~kg}$ with a precision of 100 grams. Weight, ambient temperature, humidity are measured by default. The amount of rain collected and brood temperature can be added to the parameters measured. The number of measurements per unit time can be adjusted and depends on the topic of the study (Seeley and Visscher, 1985; Meikle et al., 2008). A very easy way to change the setup of the scale is by connecting the scale to the configuration software that accompanies the scale (Fig. 16). The battery lasts for approximately 200 days, but has a shorter life in the wintertime due to low temperature extremes. So far, no problems due to cold Nordic winter conditions (down to $-40^{\circ} \mathrm{C}$ ) have been reported (Flemming Vejsnæs; pers. comm.).
The scale will send an SMS that is transformed to an e-mail. Using SMS limits the quantity of data that can be sent per unit time (Fig. 17). As standard the scale records data every second or every hour during the daytime. It is possible to change the setup of the scale, sending more SMSs per day, thus increasing the number of daily data. Every day, at a time determined by the user, the scale will send the data.

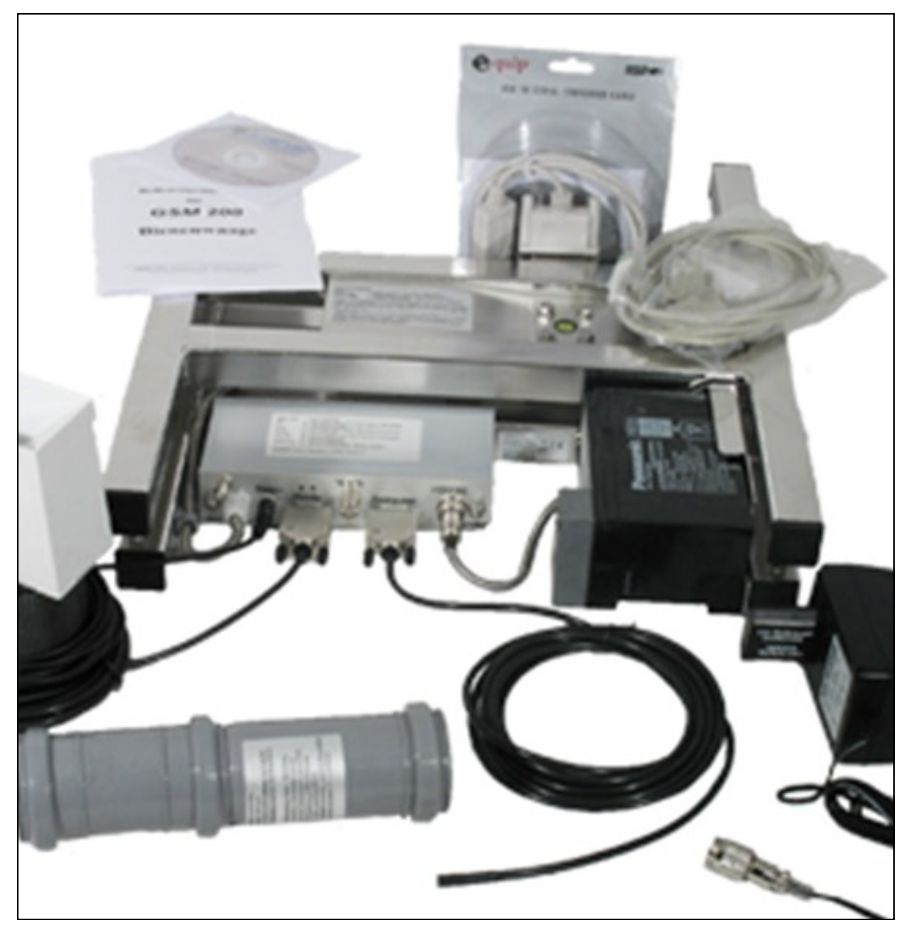

Fig. 15. The Capaz scale is an $\mathrm{H}$-shaped platform made from aluminium and stainless steel, with the dimensions $420 \times 480 \times 86 \mathrm{~mm}$ (long $\mathrm{x}$ wide $x$ high). Data are transmitted by cell phone. The rechargeable battery (12 V) lasts for 200 days. Ambient temperature and humidity are measured by default. Additional equipment is the rain collector and brood temperature sensor. Changes of the standard setup of the scale are done via the computer software.

Photo: Capaz.

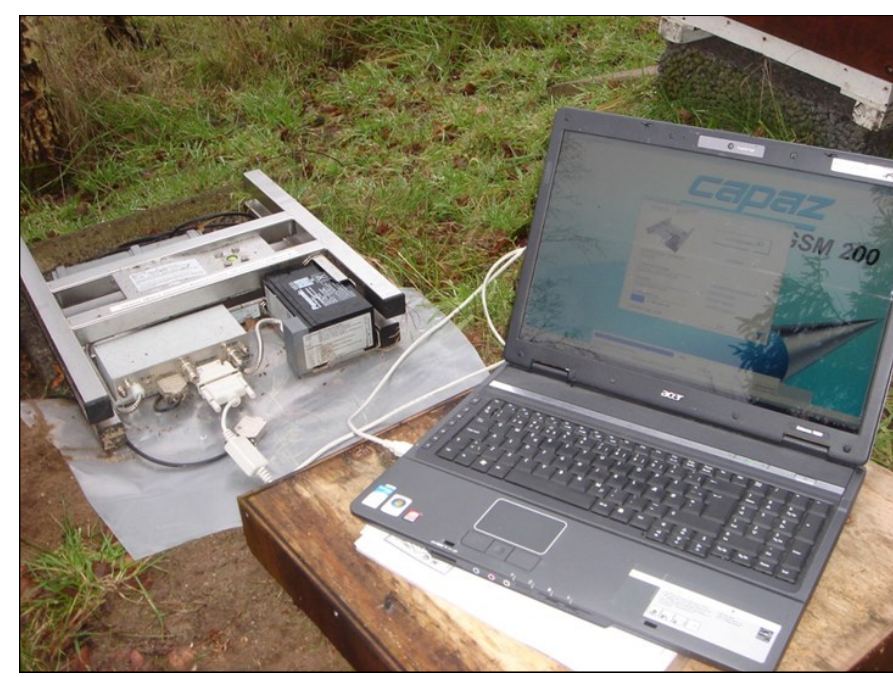

Fig. 16. Configuration of the Capaz scale directly in the apiary.

Photo: F Vejsnæs. 


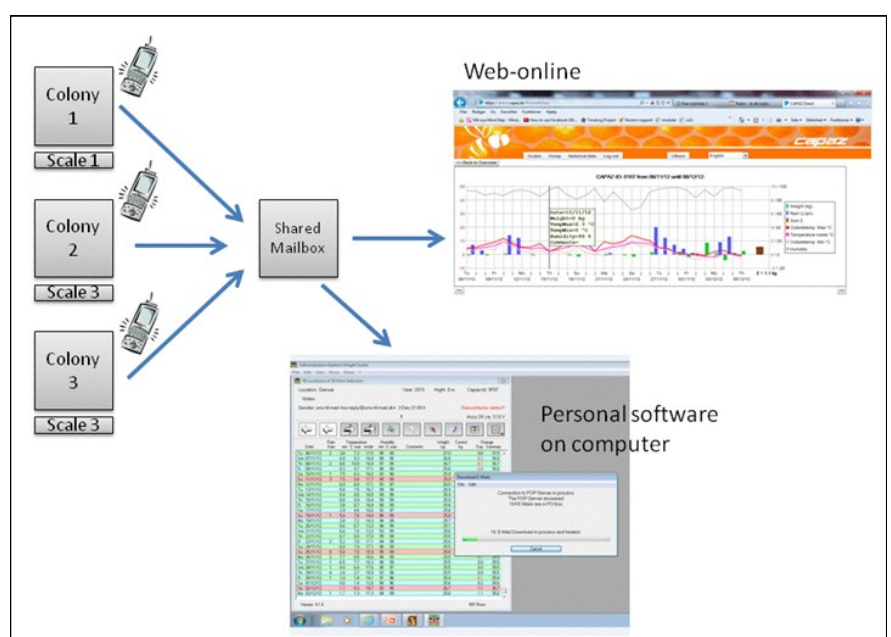

Fig. 17. With the Capaz scale, all data are sent by a cell phone, as an SMS. The SMS is converted to an e-mail sent to an e-mail account. From here, it can be uploaded on the internet and/or downloaded by the software. A sample output received via e-mail follows the format: !33H74F71301122XXXX\#0601+027033891+1970800+025033890+ $1961200+029033791+1961400+035033690+1931600+042033683+$ $1952000+042033682+1962200+040033580+198$ !

Together with the scale, well developed software (Fig. 18) is provided, where all data can be downloaded directly from the e-mail mailbox.

Data can easily be exported to excel spreadsheets. In addition, a web application can upload data directly to the internet. Different scale companies offer different online web applications.

\subsubsection{The honey meter}

One of the most important and widely used applications of hive scales is the so called 'honey meter', a nectar flow tracking or honey forecasting system. In other words, the aim of the honey meter is to monitor the timing and potential honey harvest of healthy colonies of a local area, based on the entering amount of nectar. It is of course an open discussion as to how representative data from single colonies are. The best solution is to place all colonies in an apiary on scales, but this is not feasible due to economic reasons. The Capaz Company has therefore designed a pallet scale for existing metal pallet system, having four load cells, thus providing average data for four colonies. The four load cells can measure up to $1.200 \mathrm{~kg}$. Some examples of scale networks functioning as honey meter are given in Table 11. An example dataset for the weight changes of a colony in Jutland, Denmark are shown in Fig. 19.

\subsubsection{The use of the data from an electronic scale}

Very often it is difficult to judge what is going on in honey bee colonies. The hive scale is an important tool and gives a good assessment if food consumption has been high over a longer period and whether there is a need for feeding. In most countries, it is important to know how big the winter storage is since it will tell if spring feeding of carbohydrates is needed. In addition, it gives a very good assessment of periods without any flow in the summertime and hence can warn of starvation danger. Finally, it gives a very good evaluation of how intense the nectar flow is, in other words, if there is a need to provide the colonies with additional supers. Commercial beekeepers use hive scales to save unnecessary visits to the apiary when they do long-distance migration. Examples are German commercial beekeepers having colonies for pollination of white clover in Denmark. With the scale, such migration has become profitable, since the driven kilometres can be kept to a strict minimum. The German hive scale system (see Table 12) is especially a warning system for the start of honeydew flow. It tends to start suddenly and

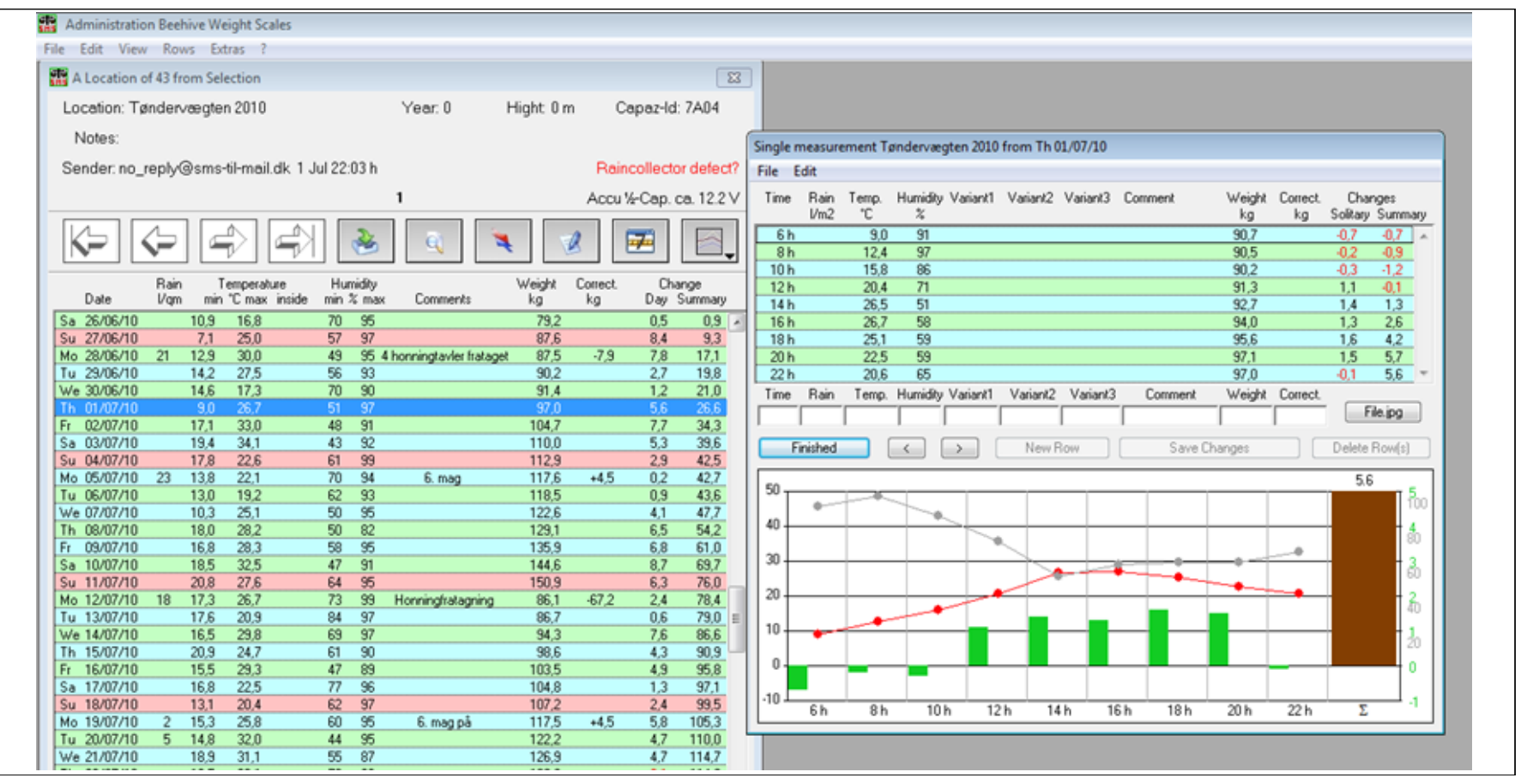

Fig. 18. The well designed software that comes with the Capaz scale allows easy exporting of data to spreadsheets. 


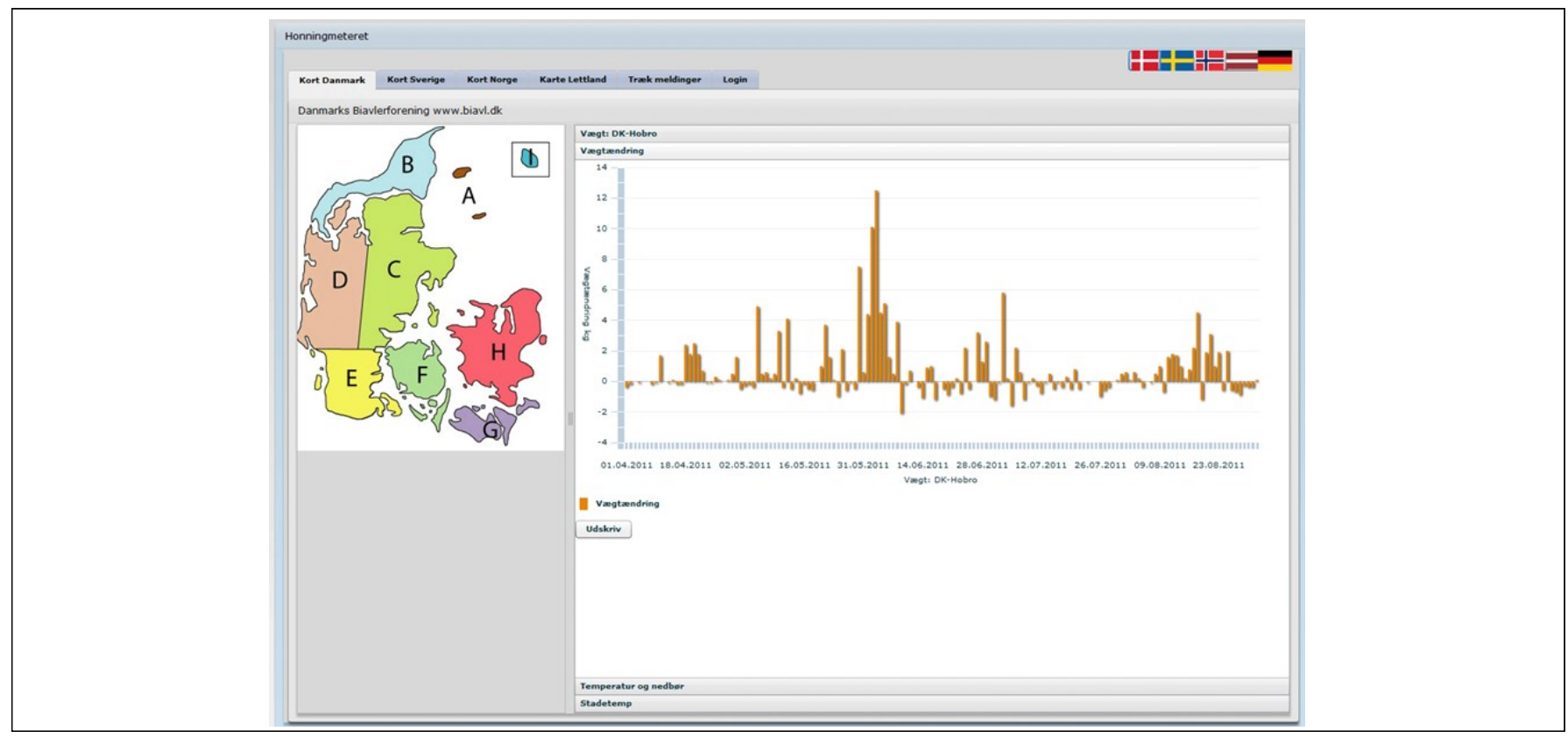

Fig. 19. The Nordic/baltic honey meter. Over 66 scales are distributed in four countries (Denmark, Sweden, Norway, Latvia). Here food/ honey consumption/weight gain for the period 1.4.2011-1.9.2011 is shown for a scale located close to the town Hobro in Jutland, Denmark.

can be massive. The scales also give very good information about when the nectar flow stops. In Denmark, information from the honey meter has shown that the main nectar flow stops, in general, earlier than the beekeepers expect. Some Danish beekeepers make all their varroa treatments according to the figures of the honey meter with the positive result of earlier and therefore more efficient varroa summer treatments.

Measuring brood temperature indicates when there is no brood in the colonies. This is the optimal time of the year for varroa-treatment with oxalic acid. But note that since there is only one temperature sensor, one has to ensure correct sensor placement in the centre of the winter cluster. With scales, obtaining an indication of colony swarming through a decrease in its weight (Meikle et al., 2008) is also possible. A necessary requirement for accurate measurements and predictions is to monitor good/ well running colonies on the scales.

Having colonies on hive scales is providing very important complementary data on colonies used for experiments. The disadvantage of the system is that the figure of increasing/ decreasing bees and brood in the colonies are influenced by variation in food stores. A very nice experiment is that of Meikle et al. (2008) who used precise bench scales ( \pm 10 grams) that measured every hour. They weighed separately the bees, brood and food, showing that the main part (76\%) of the colony weight throughout 2005 was food. However using scales with a precision of 10 grams in the field entails large errors due to the accumulation of rain or even due to wind pressure on the hive body. It is important to use Styrofoam boxes, since wooden boxes absorb moisture and thereby bias weight measurements.
In wintertime, it is important to have the colonies protected from snow and ice in order to have reliable day to day measurements. Procedure to follow when using a hive scale (Capaz scale)

1. Place the hive scale on a levelled platform - to protect against moisture from the ground.

2. Connect all plugs. Test for cell phone connection according to manual.

3. Secure a protection cover for the scale, protecting against debris from the colony, from precipitation, driving rain etc.

4. Check battery charge regularly - recharge at least every spring and fall.

5. Keep all plugs clean and dry - otherwise rust problems will arise.

6. Use Styrofoam boxes, since wooden boxes will absorb moisture.

7. Ensure that water runs of the hive cover, otherwise water can accumulate or be absorbed, biasing results. In countries experiencing snowfall, scales and colonies should be protected in a house, external cover or shed. Otherwise winter measurements will be biased.

8. If using the Capaz brood chamber sensor, ensure that the sensor is placed in the centre of the winter cluster during winter.

9. Refer to scale manuals for data downloading.

10. Download the data regularly and make backups, since it is an enormous amount of data that is collected. 


\subsection{Using beelines to locate wild honey bee colonies}

\subsubsection{Introduction}

Locating honey bee colonies is obviously essential for any researcher wishing to collect data from naturally occurring or feral populations.

This is important for a variety of research interests whether they are determining nest site selection, population densities (see section 4.3 on bee density), collecting samples of bees and other nest constituents, determining parasite loads, studying colony strength, etc. Locating colonies is also important for people who utilise the various nest constituents of honey, pollen, brood, wax, and propolis for food, medicine, or craft. Different cultures throughout history have developed and utilised methods of tracking and 'hunting' honey bee colonies that vary from random searching for colonies to following honeyguide birds (Crane, 1999). Most methods, however, including those used in current academic research, follow the flight paths of honey bees to their colony of origin, known as beelines.

A beeline is defined in this section as the direct flight path taken by foraging honey bees to and from their colony's nest, to and from any particular foraging resource (e.g. flowers, water, propolis, etc.). Beelines are established first by worker honey bees called scouts that locate the resource. Using the waggle dance in the nest, these scouts will communicate the location of the resource to other foragers in the colony (von Frisch, 1967; Seeley, 1983). Once foragers have located and travelled to and from the resource enough times, remembering its location, they fly the most optimal path; and this same path is taken by many foragers. Thus, the beeline is established and can be present for as long as the foraging source is available. Beelines are often quite direct and are essentially a straight line to and from the colony's nest.

There are essentially only three steps associated with locating wild honey bee colonies by beelining. They are 1) establishing a beeline, 2) following the beeline, and 3) locating the honey bee nest. This section details these steps from practiced methods used in Vaudo et al. (2012 $a, b)$ and references listed below. This method has been optimised to potentially locate multiple colonies from a single foraging source.

\subsubsection{Suggested materials}

1. Feeding station.

Detailed instructions for creating feeding stations are provided in section 4.2.3.1.

2. Mobile feeding station, bee box.

Detailed descriptions are provided in section 4.2.4.3. and 4.2.6.2. Bait - 1:3:3 honey:sugar:water by volume. Handheld GPS and/ or map and compass. Field proof laptop or note pad. Binoculars.

Camera.

Personal protective equipment:
a. epinephrine autoinjector (e.g. EpiPen, Twinject, etc.).
b. bee suit (veil, gloves, and long clothing).
c. water and food for a day in the field.

\subsubsection{Establishing a beeline}

The most essential step of tracking bees using this method is to establish a beeline. The easiest way to establish beelines is to provide a highly attractive foraging source or feeding station, for honey bees and allow the foragers time to locate the source. This requires minimal effort for the observer to attract foraging honey bees. It also allows the observer to place a foraging source in a location that will make it easy for him or her to track the beelines. Once beelines are established, the foraging source can be replenished and beeline maintained. Beelines can also be established in locations where foraging honey bees are already located such as flower patches or water sources (see sections 4.2.6.1 and 4.2.6.2).

\subsubsection{Setting up a feeding station}

The feeding station is the honey bee tracker's means to establishing and maintaining beelines and is composed of two parts, a stand and foraging source. A feeding station consists of a $10 \mathrm{~cm}^{2}$ iron plate welded to a $2 \mathrm{~m}$ tall iron rod that is angled to a point at the bottom (Fig. 20). A $10 \mathrm{~cm}$ iron crosspiece is welded $0.5 \mathrm{~m}$ from the bottom of the station at $90^{\circ}$ from the main rod. The crosspiece and angled bottom facilitate station insertion into hard ground. The iron plate at the top of the station has a $5 \mathrm{~mm}$ hole drilled through each corner. A plastic container ( $11.5 \times 17 \times 4 \mathrm{~cm}, \mathrm{~L} \times \mathrm{W} \times \mathrm{H})$ is affixed to a 25 $\mathrm{cm}^{2}$ wooden platform using a nail or screw through the centre of the container. The wooden plate then can be mounted to the iron stand with bolts through each of the holes on the iron plate. Less complex feeding stations can be made and other construction materials used in case sturdiness is not an issue.

1. Construct the stand.

The stand can be made of any material, such as wood or iron, so long as it will not be knocked over in the field. It is important that the plate of the stand sets high $(\sim 1.5-2 \mathrm{~m})$ so that is easily found by the foraging honey bees and the observer can easily view the beelines.

2. Place the feeding station in an open field so that the observer can easily see beelines against the sky and they can be tracked without difficulty. It can also be placed in the sunlight, so that bees can be spotted against a dark background.

3. Produce the bait.

The bait can vary from scented sugar water to honey filled comb. A volume of $0.5 \mathrm{~L}$ to $1 \mathrm{~L}$ of a mixture of $1: 3: 3$ honey:sugar:water (by volume) in a plastic container should be sufficient for attracting a large numbers of bees as they tend to be readily attracted to the scent and taste of honey. 


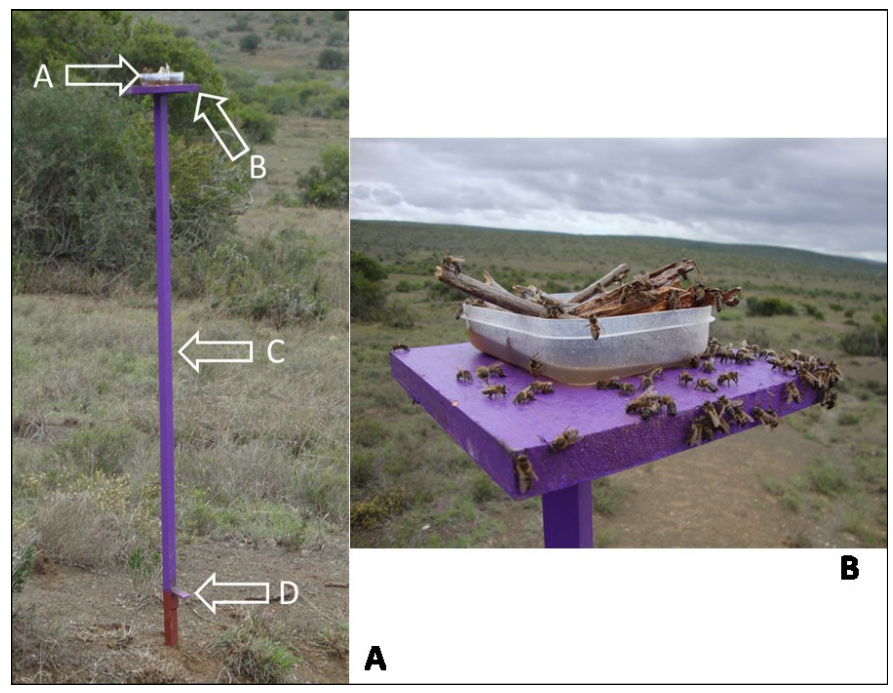

Fig. 20. A honey bee feeding station. Arrow A points toward the container which is partially filled with bait (see photograph $B$ at the right for a close view). Arrow $B$ indicates the removable feeding plate. Arrow $\mathrm{C}$ shows the main iron rod that can be driven into the ground using the crosspiece (Arrow D).

Photos: A Vaudo.

Scented sugar syrup, using only a few drops of $\sim 50 \%$ anise extract per litre of solution (Seeley; pers. comm.) will attract fewer honey bees. This can be useful if one needs to reduce the number of honey bee arrivals to the feeding station in order to obtain accurate round trip times more easily (Wells and Wenner, 1971; see section 4.2.6.4).

4. Place the bait in a container on top of the plate.

5. Place sticks and twigs in the feeding container so the bees do not drown in the liquid bait.

6. Record the location of your feeding station on a handheld GPS (by creating a new waypoint) or map so you may find it easily in the future.

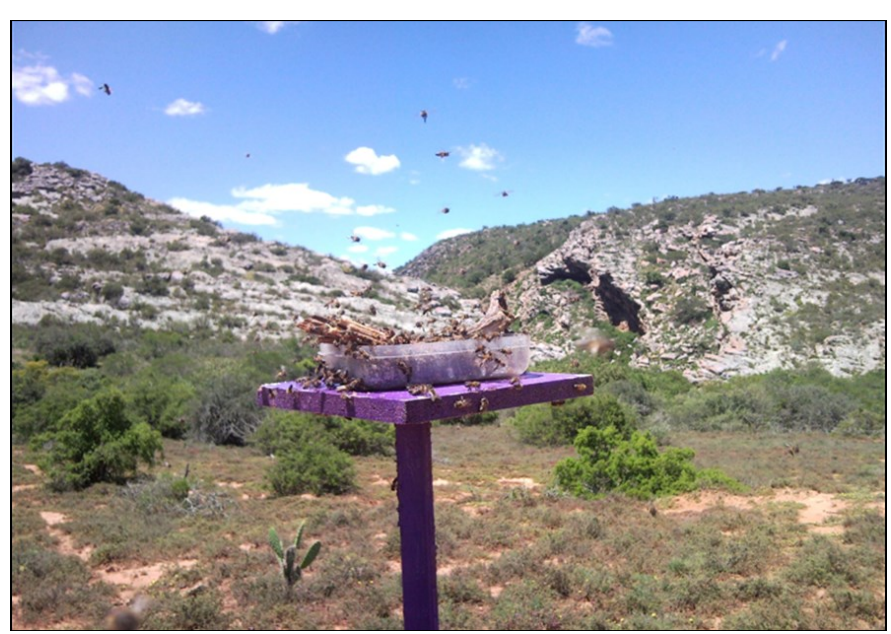

Fig. 21. An example of foraging honey bees feeding from a feeding station used to establish beelines. Note how the bees are easily observable against the blue sky and the bees are lost against the mountains and shrubs.
7. Once the feeding station is baited, leave it overnight to allow the honey bees to locate the foraging source and establish their beelines. Usually, scouting foragers will locate the feeding station the morning after it is erected. Foraging bees may not find the feeding station the day it is placed in the field because they have already established foraging sources for the day.

\subsubsection{Following the beeline}

\subsubsection{Observing beelines}

1. Take position a few meters beyond the feeding station to accurately observe the beeline. The observer should be able to see many bees flying. It is helpful to squat below the feeding station to see the contrast of the dark bees against the sky (Fig. 21).

2. Look at the group of bees above the station.

At the feeding station, it will appear that the bees are landing and taking flight in random directions from the bait. When forager bees leave the station, they often will circle up in the air to orient themselves then quickly dart off in a straight direction into the beeline and toward their nest. When one observes a strong beeline, it appears as a 'highway' of bees flying both directions.

3. Note the direction of bees leaving the feeding station to return to the colony and not those approaching the station.

4. Circle around the feeding station to determine the directions of all beelines established.

5. Use a GPS or compass to determine and record the direction that each beeline is heading. Stand at the feeding station and record the direction that the beeline is heading from the station.

\subsubsection{Tracking the beeline}

Once beelines are established at your feeding station, it is now time to follow the beeline toward the honey bee nest. This can be time consuming and require some energy. Be prepared to walk through wild vegetation and traverse difficult terrain. The beeline is very direct, so it will transverse over buildings, dense woods, cliffs, marshes, lakes, etc. One should bring ample water and food to spend the day in the field.

1. Refill the feeding station so the bees continue to maintain the original beelines prior to moving in the direction of the beeline.

2. Walk a short distance in the direction determined as that of the bees flying to their colony.

3. Look for the beeline.

Bees are recognisable from other insects by their direct line of flight.

4. If you are correct in locating the beeline and the direction it is 
heading, continue walking that direction in a straight path. One may not see the beeline any longer while moving away from the feeding station. However, one can reasonably trust that the honey bee nest is in that direction.

5. Keep track of one's path with a map or GPS device if there are obstacles that have to be circumvented or scaled. A handheld GPS with a tracking option is useful so that you can visualise your path and return to it if you have to deviate temporarily or return to the feeding station.

6. If the path is followed directly, one should be lead straight to the location of the colony.

However, there it is difficult to determine the exact distance between your feeding station and the colony (usually less than a $1 \mathrm{~km}$ but potentially up to $5 \mathrm{~km}$ ). One could estimate the distance by using the techniques outlined in sections 4.2.6.3 and 4.2.6.4.

7. Look for the colony nest entrance as you follow the beeline (section 4.2.5).

8. If you reach an obstacle that prevents travelling further, set up a feeding station and establish a new beeline on the other side of your obstacle. From this point, you can pick up the beeline again and continue your search.

\subsubsection{Using a mobile feeding station}

One may not be successful locating the honey bee nest on the first attempt. You may have lost the beeline, the beeline could have terminated, or you could have reached an obstacle preventing you from continuing on your path. If you get lost while following the path and fail to find the nest, one possible solution is to carry a mobile secondary feeding station with you. Examples of mobile feeding stations include a bee box (see section 4.2.5.2) or another transportable container filled with bait (e.g. a bucket used as a stand and another feeding container like that used for the feeding station).

1. Return to the original feeding station, set up your mobile feeding station beside it and allow the bees to start foraging from the bait. The bees should begin foraging from it quickly.

2. Carry the station with the bees with you in the direction of the beeline once you have many foragers on your mobile station.

3. Stop and let the bees establish a new beeline that you can follow once you reach a considerable distance from the original feeding station. This point can be where you previously lost the beeline.

4. Repeat this process with your mobile feeding station as many times as necessary until you get close enough to locate the nest.

Sometimes you may even travel beyond the colony and see the beeline from your mobile station heading back the way you came. Now you know that the colony is located between the last stations' and your current location. It is advisable to carry a bottle of bait while tracking the bees so the mobile feeding station can be replenished.

\subsubsection{Locating the honey bee nest}

Honey bee nests can be located in cavities ( 40 l by volume) at any height, in the ground, or high in a building, tree, or cliff, depending on the environment (Vaudo et al., 2012a) (Fig. 22). Many African subspecies of honey bees also nest in the open, hanging on branches, or overhangs of cliffs and buildings. Generally, wild bees will be located in a wooded or at least covered area. Consequently, their

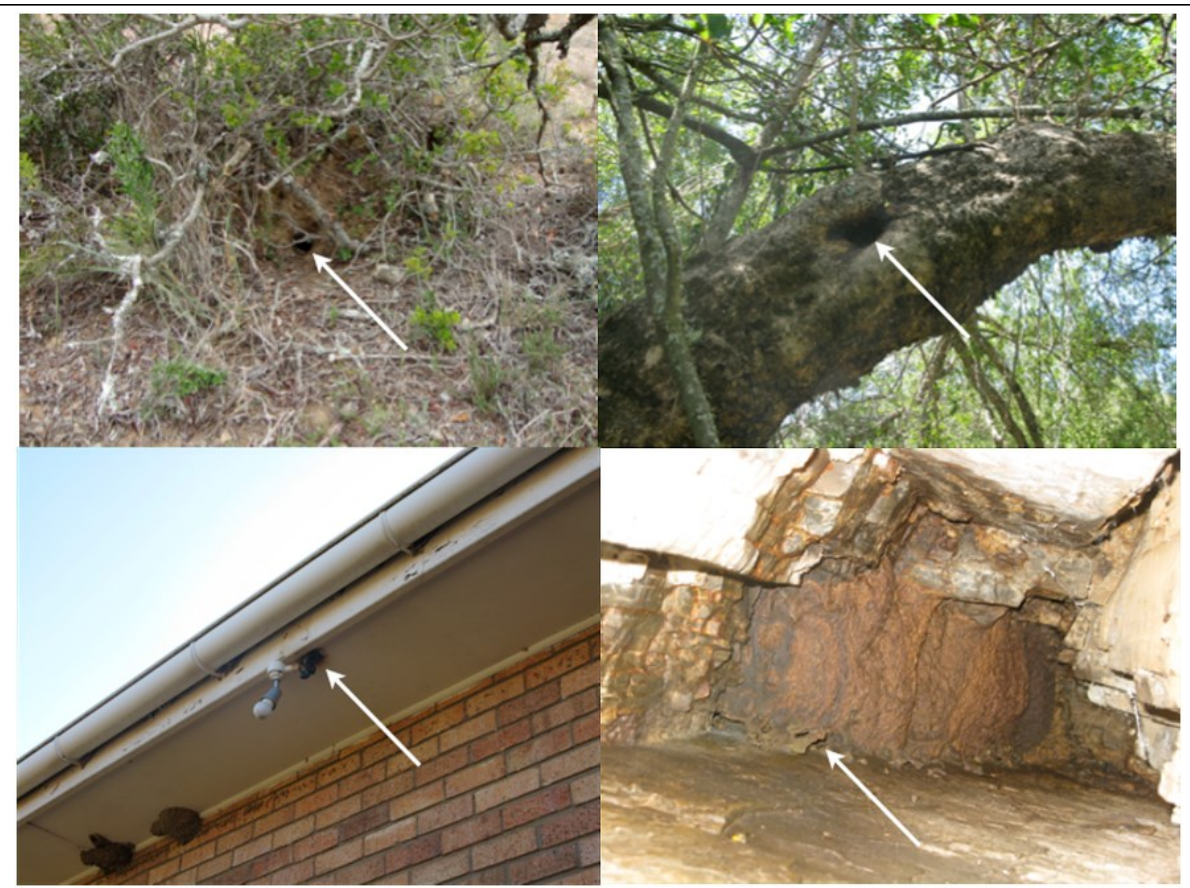

Fig. 22. Examples of honey bee nest site locations. The white arrows indicate the entrances of the colonies. 
nests can be difficult to find. Locating the exact position of the nest requires both your sense of hearing and sight. One must constantly listen and look for the honey bee nest and look at every potential nest site along one's path. This is why it is good to place the feeding station in an open area. It will allow you to determine a definitive direction to head (use landmarks visible from the defined path) prior to entering a wooded or otherwise congested area.

It is advisable to bring personal protective equipment (a bee suit or veil, gloves, and long clothing) when locating a nest in case the honey bee colony is defensive or if one plans on investigating the nest closely. One should keep an epinephrine autoinjector (e.g. EpiPen, Twinject, etc.) at all times in case an allergic reaction is experienced if/ when stung.

1. Look for the activity of insects flying in, out, and around a specific location.

One can see almost a 'funnel' or cloud of bees in an open area close to their colony as they fly in and out of the nest (similar to the activity of bees taking off and landing from your feeding station). This activity can be seen against the sky where their black bodies and glistening wings will be apparent. Nest entrances can be quite small, so follow this activity as it narrows to where the nest entrance is located.

Active colonies tend to be obvious with many workers flying in and out and a number hanging outside the entrance.

Consequently, nests can be easy to find in late or mid-to-late spring when colonies typically are large and actively foraging on available pollen and nectar. Additionally, using a highly attractive bait at your feeding station as suggested can assist in making a colony more active.

2. Use the sound of the bees.

If the beeline is strong and the colony is active, you should be able to hear a distinct hum of honey bees (similar to the sound of a swarm) once close to the nest.

3. Approach the location and confirm that you have located the entrance to the colony.

Having binoculars could be useful to confirm the colony's location if it is high.

4. Make sure you have located a nest hosting a live colony. The occurrence of pollen foragers shows that there is no ongoing robbing of the nest of a dead colony and that the activity witnessed is not that of scouts looking for a new nest site.

5. Mark the exact location of the colony with a GPS or on a map once it is found.

6. Mark the nest to make it easier to locate in the future (Fig. 23).

7. Take a photograph of the area so you can easily find it again.

\subsubsection{Alternative methods}

\subsubsection{Following bees from water sources}

Usually in hot conditions, honey bees forage for water to be used for nest temperature regulation. They can be found at fresh water sources,

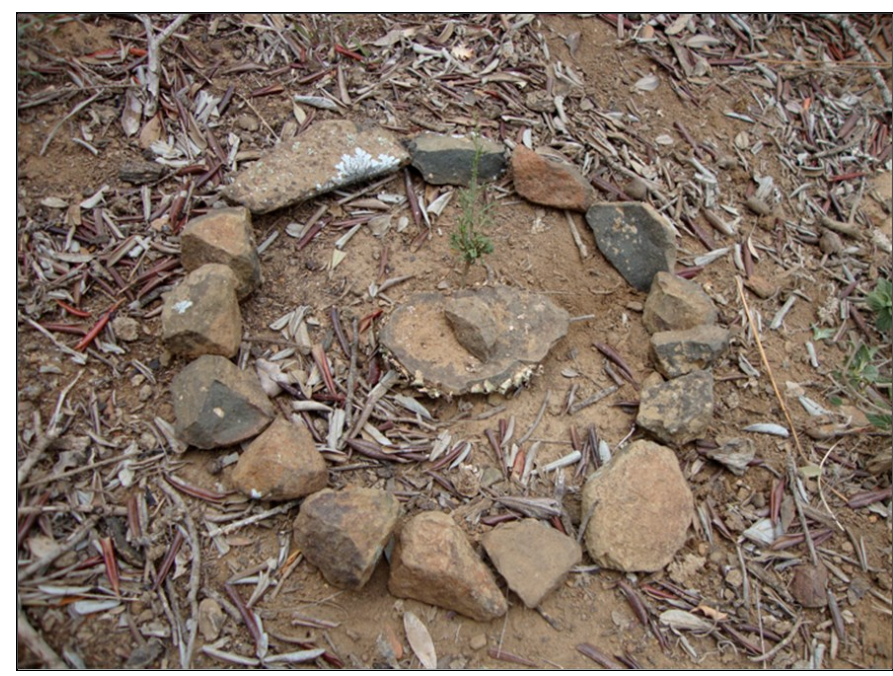

Fig. 23. Marking a honey bee nest. The nest entrance (not shown) is in the ground nearby.

Photo: A Vaudo.

such as water troughs, small pools of water, and edges of ponds, lakes, and rivers. Colonies tend to nest close to water sources, so following bees from these sources can reduce one's search time. Similar to beelining from a bait station, one can follow the direction of the bees leaving the water source. They will travel directly to the colony.

Another technique is using water to honey foraging conversion as suggested by Wenner et al. (1992). Simply, a few drops of undiluted honey can be placed on a stick upslope and close to where individual bees are foraging for water. If the bees switch to imbibing the honey, they will begin to recruit other foragers to the water source and soaked sponges of honey water placed in the area (Wenner et al., 1992). You can now follow the beelines to the colony.

Pros: no installation necessary, water foragers always come to the same place; colonies usually nearby, reducing the search time.

Cons: no easy triangulation done; few water foragers for each colony so finding the water foragers may be difficult.

\subsubsection{Beelining with a bee box}

Several authors described methods to locate nests using a portable device called a bee box (Edgell, 1949; Visscher and Seeley, 1989). Locating a honey bee colony using a bee box (Fig. 24) uses the same basic concepts outlined in section 3.2.3 and 3.2.4. However, the main difference is that the bee box allows you to trap individual honey bees off of flowers rather than allowing bees to find a feeding station. One can trap a number of bees in a section of the box and using glass and trap doors manipulate them into a second section in the box, a section that contains bait material, be it honey, sugar water, or a combination of both, placed in a small sponge or piece of honey bee comb (Fig. 24). When a beeline is established, one can close the lid of the box and carry the bees trapped with the bait along the path to the 
colony then stop, open the box, and allow the bees to establish new beelines. Refer to the procedure described below and Fig. 24 for the methodology of using the bee box.

1. Trap individual bees off of flowers in chamber $A$.

2. Darken chamber $A$, open divider (D), open window $(F)$, and allow bee into chamber $E$.

3. Close divider and repeat until enough bees are captured into chamber $\mathrm{E}$.

4. Place bait in chamber $A$.

5. Close window to chamber $E$, allow light into window (C) to chamber $A$, and open divider (D). The bees will eat from the bait. Allow 10-15 min for bees to consume the bait.

6. Open lid (B) to chamber $A$ and allow bees to travel to their colony and back.

7. Replenish bait and wait for enough bees to visit so that a beeline is established.

8. Close foraging bees in chamber A and follow path of bee line.

9. When needed, stop and open chamber A and allow a new beeline to form.

10. Repeat and keep following the beeline to the colony's nest.

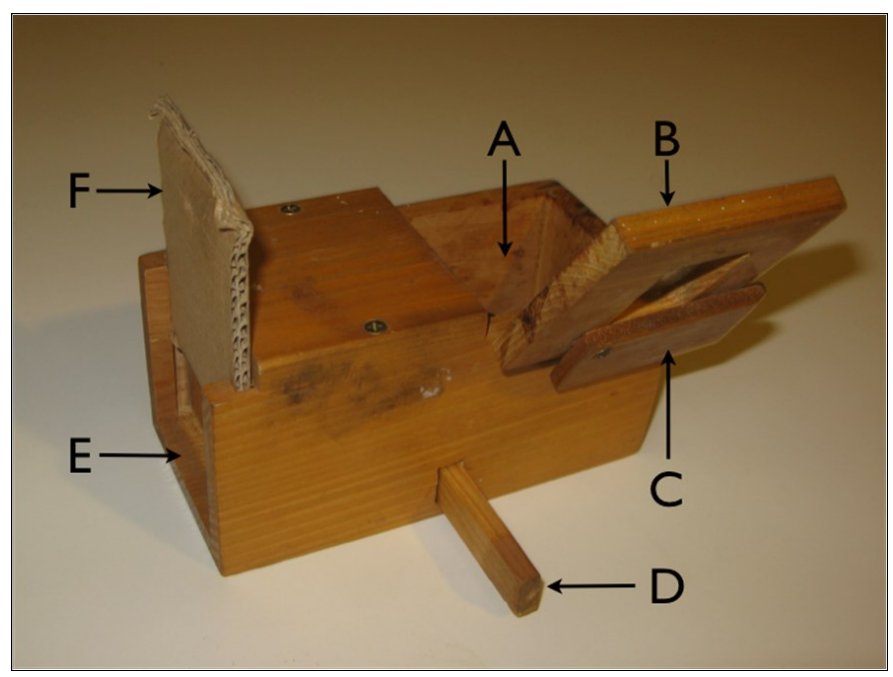

Fig. 24. An example of a bee box. (A) Chamber used to trap bees off of flowers and establish bee lines using bait. (B) Lid to chamber $A$ to trap bees. (C) Window cover to allow light in or darken chamber $A$. Allowing light in will attract bees toward chamber $A$ while chamber $E$ is darkened. (D) Sliding divider between chambers A and E. Opening and closing the dividers allows or blocks bees from moving between chambers. (E) Chamber to store bees while trapping individuals in chamber A. (F) Sliding window cover to allow light or darken chamber E. Allowing light in will attract bees to chamber $E$ while chamber $A$ is darkened. Refer to Edgell, 1967 and Visscher and Seeley, 1989 for specifications.

Photo: A Vaudo.
Pros: bees can be caught directly from foraging sources; the box is transportable and bees can be carried along and new beelines can be established during your search for the nest.

Cons: the major limitation to this technique is the size of the bee box and quantity of bait that can be provided to the bees, limiting the number of bees that will establish a beeline. If there is ample forage in the field, the bees will not readily recruit to the small amount of comb and bait used for the bee box. This technique does work in times prior to or after major blooming periods.

\subsubsection{Triangulating with feeding stations}

Visscher and Seeley (1989) described a method to locate the approximate location of a honey bee colony by triangulation using multiple feeding stations. Refer to Fig. 25 for the following methodology.

1. Place two feeding stations at an arbitrary distance from one another ( $c$, baseline) and mark each one's location on a map or GPS and calculate the distance between the two using the map legend or GPS function. If you are placing the feeding stations in the same open area or forest clearing, place them at least a couple hundred meters from each other. It may also be useful to find two different clearings in a forest to set up the feeding stations.

2. Calculate the angles ( $A$ and $B$ ) of the beelines from the baseline with a compass or GPS. This can be done easily on a handheld GPS or compass by recording difference in degrees between the direction of the opposite feeding station and the beeline.

3. Calculate the angle from the honey bee nest $(C)$ to each feeding station.

$$
180^{\circ}-A-B=C
$$

4. Using the 'law of sines', calculate the distances from each feeding station ( $a$ and $b$ ) to the nest.

$$
\frac{c}{\sin C}=\frac{a}{\sin A}=\frac{b}{\sin B}
$$

5. Mark the approximate location of the nest on a map or as a new waypoint on the handheld GPS

6. Follow the beeline from either feeding station toward the colony for the calculated distance and search the area for the nest.

Pros: potentially reduce searching time by calculating the approximate location of the bee nest, especially in a heavily wooded area.

\footnotetext{
the same location.
} 


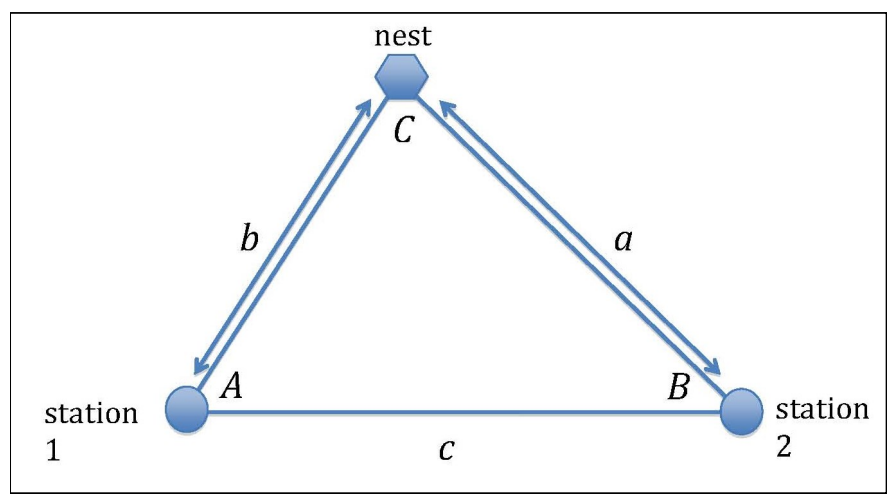

Fig. 25. Triangulating the location of a honey bee nest using two feeding stations. $A, B$, and $C$ represent angles and $a, b$, and $c$ represent the length of the sides opposite their respective angle. Arrowed lines represent beelines to and from each feeding station.

\subsubsection{Calculating the distance between a honey bee nest and feeding station by timing a forager's round trip}

Visscher and Seeley (1989) calculated the round trip time it takes for a forager to return to its colony and back to a feeding station in order to determine the distance of the colony from the feeding station. This round trip time is calculated as the time from when a forager leaves a feeding station until the time it returns. They found that a $5 \mathrm{~min}$ round trip time indicated that the colony was approximately $0.9 \mathrm{~km}$ away. A 10 min round trip indicated that the colony was approximately $1.4 \mathrm{~km}$ away. Finally, a 15 min round trip indicated that the colony was approximately $1.7 \mathrm{~km}$ away. These values, however, can vary based on the environment (e.g. vegetation cover, wind conditions etc.).

Wenner et al. (1992) suggested using the following formula to approximate the distance to a colony from a feeding station:

$$
x=150 y-500
$$

The distance in yards or meters $(x)$ is approximated by the time between arrivals at the feeding station $(y)$. Note the difference between this measurement of round trip time and that of Visscher and Seeley (1989). The constant (500) represents the approximate amount of time the forager takes to fill at the feeding station and unload in the colony (Wenner et al., 1992).

1. Mark foraging bees (3-6 bees) while they are feeding from the feeding station.

This can be done by placing a dot of paint on the thorax of the forager bee, between its wings. See section 2.3 of the $B E E B O O K$ paper on behavioural methods for marking technique (Scheiner et al., 2013).

2. Record each bee's round trip time ( $~ 10$ times per individual bee).

Use the time from when a forager leaves the feeding station until it returns for Visscher and Seeley's (1989) approximation.
Use the time between landings at the feeding station for Wenner et al. (1992) formula.

3. Select the third or fourth shortest time for each bee as its representative round trip time.

4. Use the appropriate calculation suggested above to estimate the distance to the nest.

5. Repeat with several foragers marked differently to obtain an average distance.

Pros: optimise search time; distinguish colonies located in the same direction, at different distances.

Cons: the presence of wind can increase flight time, flight times are variable and distance approximation is not exact; marked foragers may not return to feeding station if they have been predated or recruited to another foraging source.

\subsection{Honey bee colony density estimations}

It can be difficult to determine the number of wild honey bee colonies per unit area (colony density) due to the cryptic nature of honey bee nesting sites. Consequently, research involving data collection on colony density can be complex and time consuming. There are a number of instances where knowing colony density would be beneficial. For example, one can employ GIS technology (Geographic Information System, see the BEEBOOK paper on the topic, Rogers and Staub, 2013) to determine how colony density varies over land use patterns or within/ between various ecosystems. Furthermore, one could track population size and health over time, monitor migration patterns, determine disease spread within a population, etc. Yet, these applications seem out-of-reach because of our inability to determine colony density accurately.

Currently, the only way to determine true colony density is to search a landscape thoroughly and locate all of the colonies in a given area by bee lining (identifying the direction of home flight and finding the colony on this line, see section 4.2. (Using beelines to locate wild honey colonies) or extensive search for nests (e.g. Oldroyd et al., 1997). This seems challenging due to the cryptic nature of some

nesting sites or in areas where accessing colonies is difficult or dangerous such as on cliff faces or high in trees. As a result, researchers have turned to indirect methods for assessing colony density.

Herein, we present two methods that can be used to assess the density of honey bee colonies in an area. The first method (using feeding stations) assesses the relative density of honey bee colonies in an area through indexing while the second method (using genetic markers) provides a direct estimate of colony density. 


\subsubsection{Determining a colony density index using feeding stations}

It is not known if density indices can be used to provide accurate estimates of the actual number of colonies present, and this should be a subject of future investigation. However, it is believed that the indices are useful for determining relative colony density. The indices rely on approximating the number of forager honey bees that visit established feeding stations spaced throughout a landscape. The indices' reliability rests on the assumption that colony density is positively correlated with the number of bees visiting the feeding stations. The following method is based on Vaudo et al. (2012a, b).

\subsubsection{Material used}

See section 4.2.2. 'Setting up a feeding station' in the beelining method for a description of the feeding station and food container required.

\subsubsection{Procedure}

1. Place feeding stations along a transect $\sim 2 \mathrm{~km}$ from one another and throughout the study site about $24 \mathrm{~h}$ before monitoring.

The reason for the $2 \mathrm{~km}$ recommendation stems from the necessity to minimise the possibility that one colony will be attracted to two stations. The $24 \mathrm{~h}$ gives bees time to navigate the unique environmental conditions in an area, find the stations and reach maximum foraging activity prior to station monitoring.

2. Bait feeding stations with $\sim 600 \mathrm{ml}$ of a $1: 3: 3$ mixture of honey:water:sugar respectively and by volume; alternatively, pure honey can be used.

Pure honey is likely more attractive to bees than a mixture with water and sugar. The choice of bait does not compromise the index when all stations are stocked with the same bait. The honey used should be from a single source to control for possible differences in the attractiveness of honey from varied sources. The honey can be irradiated to kill all pathogens and eliminate the risk of disease spread to wild colonies (see the section 7.6. 'Food sterilisation and detoxification' of the $B E E B O O K$ paper on maintaining adult Apis mellifera in cages under in vitro laboratory conditions (Williams et al., 2013).

3. Place sticks, twigs, or other floatation devices on the bait to provide foraging bees a surface on which to land.

This minimises the chance that bees will drown in the bait.

4. Monitor feeding stations at similar weather, time and season points.

For example (1) only during sunny weather, (2) with little or no wind, and (3) between the hours of 09:00 and 15:00.

5. Visit feeding stations in the order and about the same time that they were erected the day before, thus keeping the time of bee acclamation to stations as close to a standard $24 \mathrm{~h}$ time period as possible.

6. Refill the stations prior to data collection in instances where bees removed all of the bait from the feeding stations within $24 \mathrm{~h}$.

Vaudo et al. (2012b) reported that bees are attracted to reprovisioned stations almost immediately.

\subsubsection{Index data}

Three types of index data can be collected from bait stations:

1. Establish the number of bee lines to each station - $A$ beeline is defined as 'the flight path taken to and from a food source and the colony' (see section 4.2. on bee lines).

They can be determined best when a foraging bee is leaving the food because it takes a more direct flight to return to its colony than when landing on the station. Individual stations should be monitored until all beelines are recorded. The working assumption is that more beelines will be formed to a feeding station when more colonies are nesting in an area, though this assumption needs to be verified.

2. Field rating of bee density on feeding stations - Rate each station on a scale of 0 (no bees foraging) to 3 ('many' bees foraging).

The rating is based on the intensity of the foraging visits on a station. This is a qualitative and subjective rating but it provides a quick index of visiting intensity, working on the assumption that higher field ratings indicate more colonies nesting in the area.

3. Photograph rating of bee density on feeding stations - Rather than making a subjective rating of foraging intensity at feeding stations, one can take a picture of each feeding station and assign a station rating per the number of bees counted feeding at each station, for example: $(0)=$ zero foraging bees, $(1)=1-50$ foraging bees, $(2)=51-200$ foraging bees, (3) > 200 foraging bees (Fig. 26). It is assumed that higher ratings indicate more colonies present in the environment.

\subsubsection{Statistical analyses}

The number of bee lines per feeding station can be analysed by an assigned independent variable using a weighted one-way ANOVA. The ANOVA is weighted for the number of feeding stations within an independent variable. For example, Vaudo et al. (2012b) looked at land use effects on the number of bee lines, with land use being recognised as stations on (1) game reserves or (2) livestock farms. Since the authors did not place the same number of feeding stations at locations of both types, the ANOVA analyses were weighted for the number of feeding stations used, giving greater weight to sites having more stations. The field and photograph indices of numbers of bees at 


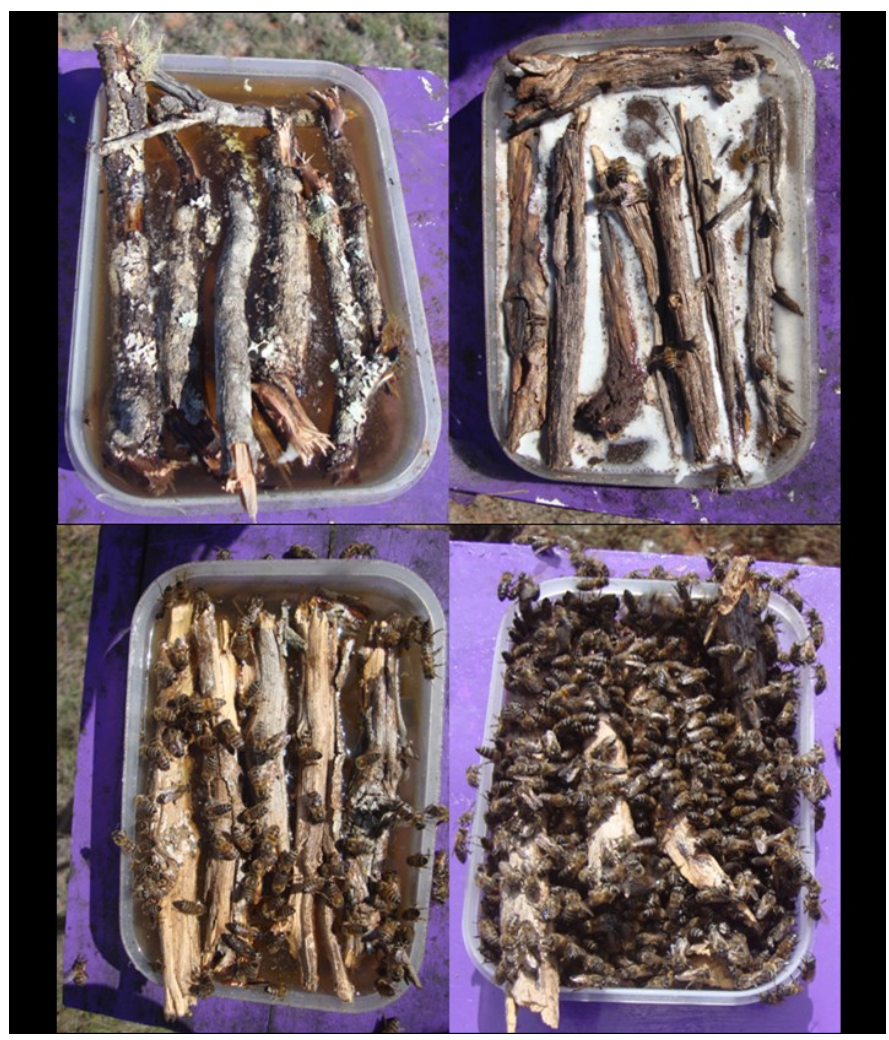

Fig. 26. Photograph Field Ratings. $(A)=$ Rating 0 ( 0 foraging bees); (B) = Rating 1 (1-50 foraging bees); (C) = Rating 2 (51-200 foraging bees); (D) = Rating 3 (> 200 foraging bees). $\quad$ Photos: $A$ Vaudo.

feeders can be analysed by Pearson's $x^{2}$ tests to determine if there is a difference in the distribution of ratings between feedings stations categorised in two or more independent variables.

Pros: this is a relatively inexpensive method.

Cons: time consuming, reliability not established.

\subsubsection{Determination of honey bee colony density using genetic markers}

The difficulty of locating cryptic honey bee nests for density estimation can be overcome by exploiting their mating behaviour. Drones fly to drone congregation areas (DCAs) to find sexual partners. It is thus possible to locate these DCAs to which colonies in an area contribute drones and queens instead of locating all the nests these come from. DCAs can be located by observing the terrain or transecting it with a pheromone trap, which can then be used to samples drones (Williams, 1987). Using genetic tools, it is then possible to genotype the drones and infer the genotype of their mothers. Because drones are produced parthenogenetically and only carry alleles from their mother, genotyping drones allows for their easy assignment to specific queens. Similarly, by genotyping workers of a single queen, it is also possible to deduce the genotype of the queen and that of her mates (honey bee queens mate with many haploid drones). Since honey bee colonies are headed by a single queen, obtaining the number of queens in an area equals counting the number of colonies in this area (Baudry et al., 1998; Jaffé et al., 2009a). A recent model verified the validity of using locally mated queens to estimate colony densities based on the genotype of their brood. They conclude that at least 10 mated queens are needed to detect order of magnitude differences in colony density estimates (Arundel et al., 2012).

\subsubsection{Sampling}

\subsubsection{Drone sampling}

Honey bee drones can be lured by synthetic queen pheromone into a trap kept aloft by a weather balloon. See section on trapping drones in the BEEBOOK paper on behaviour (Scheiner et al., 2013).

- Capture drones (ideally between 100-200 individuals) from a previously identified DCA by flying the pheromone trap between 12:00 and 17:00 hours (depending on the region and season), above $17^{\circ} \mathrm{C}$, under sunny and windless conditions, during the swarming season. See section 13.4. on locating DCAs in the BEEBOOK paper on methods to study behaviour (Scheiner et al., 2013).

\subsubsection{Worker sampling}

- Identify at least 10 colonies headed by locally mated queens.

- Collect freshly emerged workers (ideally between 12-24 workers per colony) directly from brood combs upon opening of the hives in order to avoid sampling workers that drifted from a foreign colony into the sample hive.

Using this approach, failing to detect some fathers in a colony would be equivalent to failing to sample some drones at a DCA

\subsubsection{Genotyping}

See section (6.3.1.) on microsatellite markers in the BEEBOOK paper on molecular methods (Evans et al., 2013) for the method to determine individual genotypes. The use of independent sets of tightly linked microsatellite markers (Shaibi et al., 2008, Table 15) to reconstruct queen genotypes from a sample of drones has been shown to result in a very high detection power (see section 4.3.3.5. on non-detection errors below), even allowing the identification of closely related queens (Jaffé et al., 2009a). For the details of the linked markers refer to Shaibi et al. (2008).

\subsubsection{Genetic diversity measures and reconstruction of queen genotypes}

The drone genotypes are obtained either directly, by genotyping drones caught in a DCA, or indirectly, by inferring their genotype from the worker offspring of a single queen.

1. Construct tables with the genotypes of all drones for each sample set (see Tables 13 and 14). 
Table 13. Genotypes obtained from genotyping drones.

\begin{tabular}{|c|c|c|c|}
\hline Drone ID & Locus 1 & Locus 2 & Locus 3 \\
\hline 1 & $\mathrm{a}$ & $\mathrm{c}$ & $\mathrm{a}$ \\
\hline 2 & $\mathrm{a}$ & $\mathrm{b}$ & $\mathrm{b}$ \\
\hline 3 & $\mathrm{~b}$ & $\mathrm{a}$ & $\mathrm{c}$ \\
\hline
\end{tabular}

Table 14. Genotypes inferred from genotyping workers of a single queen.

\begin{tabular}{|c|c|c|c|}
\hline Worker ID & $\begin{array}{c}\text { Locus 1 } \\
(\mathbf{b} / \mathbf{b})\end{array}$ & $\begin{array}{c}\text { Locus 2 } \\
(\mathbf{a} / \mathbf{b})\end{array}$ & $\begin{array}{c}\text { Locus 3 } \\
(\mathbf{c} / \mathbf{c})\end{array}$ \\
\hline 1 & $\mathbf{a} / \mathbf{b}$ & $\mathbf{c} / \mathbf{a}$ & $\mathbf{a} / \mathrm{c}$ \\
\hline 2 & $\mathrm{a} / \mathrm{b}$ & $\mathbf{b} / \mathrm{a}$ & $\mathbf{b} / \mathrm{c}$ \\
\hline 3 & $\mathbf{b} / \mathrm{b}$ & $\mathbf{a} / \mathrm{b}$ & $\mathbf{c} / \mathrm{c}$ \\
\hline
\end{tabular}

Table 15. Characteristics of the microsatellite DNA toolkit of Shaibi et al. (2008). DNA was Chelex-extracted (Walsh et al., 1991) from one leg of each bee. Multiplex PCR solutions contained $10 \mu \mathrm{l}$ of 10-100 ng DNA, $1 \times$ PCR-Master-Mix (Promega), and $0.2 \mu \mathrm{m}$ of each primer ( $5^{\prime}$-label). PCR programme: denaturation for $5 \mathrm{~min}$ at $95^{\circ} \mathrm{C}, 35 \mathrm{cycles}$ of $30 \mathrm{~s}$ at $95^{\circ} \mathrm{C}, 30 \mathrm{~s}$ of annealing at $55^{\circ} \mathrm{C}$, extension for $1 \mathrm{~min}$ at $72^{\circ} \mathrm{C}$, final elongation of $20 \min$ at $72^{\circ} \mathrm{C}$.

\begin{tabular}{|c|c|c|c|}
\hline Locus & $\begin{array}{c}\text { PCR } \\
\text { reaction }\end{array}$ & Primers sequence $\left(5^{\prime}-3^{\prime}\right)$ & Repeat motif \\
\hline HB-SEX-01 & 2 & $\begin{array}{c}\text { F: HEX-AGTGCAAAATCCAAATCATC } \\
\text { R: ATTCGATCACCCAAAGAA }\end{array}$ & (A)15 \\
\hline UN351 & 2 & $\begin{array}{c}\text { F: FAM-AGCATACTTCTTCACCGAACCAC } \\
\text { R: TCCGTTTATGCTTCATTITCGA }\end{array}$ & (AT) 13 \\
\hline HB-SEX-02 & 1 & $\begin{array}{l}\text { F: HEX-ACGCATTGAAGGATATTATGA } \\
\text { R: AATTTGAACATTCGATCACC }\end{array}$ & (A)16 \\
\hline HB-SEX-03 & 2 & $\begin{array}{l}\text { F: TET-AACGTGGAAGATAACTITAACAA } \\
\text { R: ACAATGTTATGATITITCACGA }\end{array}$ & $(\mathrm{TA}) 12$ \\
\hline HB-THE-01 & 1 & $\begin{array}{l}\text { F: FAM-GACGATTTACGAGGTTTCAC } \\
\text { R: TCGATTTCGTTTCGTITAT }\end{array}$ & $(\mathrm{TA}) 9$ \\
\hline HB-THE-02 & 2 & $\begin{array}{l}\text { F: TET-GGGAAAGATATTAGGGAGGA } \\
\text { R: CGACGAAAAATTACAAGGAC }\end{array}$ & $(\mathrm{TA}) 12$ \\
\hline HB-THE-03 & 1 & $\begin{array}{l}\text { F: FAM-TAACTGGTCGTCGGTGTT } \\
\text { R: CACGTAGAGAATCCCATTGT }\end{array}$ & $(\mathrm{TA}) 11(\mathrm{TC}) 12$ \\
\hline HB-THE-04 & 2 & $\begin{array}{l}\text { F: HEX-GCTGGAAGGGAACTGTAGA } \\
\text { R: GGACGCGTITTAATATCTCA }\end{array}$ & $(\mathrm{GA}) 9$ \\
\hline HB-C16-01 & 2 & $\begin{array}{l}\text { F: HEX-AAAATGCGATTCTAATCTGG } \\
\text { R: TTGCCTAAAATGCTTGCTAT }\end{array}$ & $(\mathrm{GA}) 35$ \\
\hline AC006 & 1 & $\begin{array}{l}\text { F: TET-GATCGTGGAAACCGCGAC } \\
\text { R: CACGGCCTCGTAACGGTC }\end{array}$ & (ТCT)5 (ТTC)10 \\
\hline HB-C16-02 & 2 & $\begin{array}{l}\text { F: TET-TAGTATCGTGCTGTTCATCG } \\
\text { R: ACATACATCTCTTGGCGAGT }\end{array}$ & $(\mathrm{TA}) 23$ \\
\hline HB-C16-05 & 1 & $\begin{array}{l}\text { F: FAM-ATTTTATGCGCGTTTCGTA } \\
\text { R: CATGGCTCCTCCATTAAATC }\end{array}$ & (TC)23 \\
\hline A079 & 2 & $\begin{array}{l}\text { F: HEX-CGAAGGTTGCGGAGTCCTC } \\
\text { R: GTCGTCGGACCGATGCG }\end{array}$ & $(\mathrm{CCT}) 10(\mathrm{GA}) 10$ \\
\hline AP043 & 2 & $\begin{array}{l}\text { F: TET-GGCGTGCACAGCTTATTCC } \\
\text { R: CGAAGGTGGTTTCAGGCC }\end{array}$ & (CT)24 \\
\hline A113 & 2 & $\begin{array}{l}\text { F: FAM-CTCGAATCGTGGCGTCC } \\
\text { R: CCTGTATITTGCAACCTCGC }\end{array}$ & (TC) $2,5,8,5$ \\
\hline A024 & 1 & $\begin{array}{l}\text { F: TET-CACAAGTTCCAACAATGC } \\
\text { R: CACATTGAGGATGAGCG }\end{array}$ & (CT) 10 \\
\hline A107 & 1 & $\begin{array}{l}\text { F: HEX-CCGTGGGAGGTTTATTGTCG } \\
\text { R: CCTTCGTAACGGATGACACC }\end{array}$ & (CT)23 \\
\hline A007 & 1 & $\begin{array}{l}\text { F: FAM-GTTAGTGCCCTCCTCTTGC } \\
\text { R: CCCTTCCTCTTTCATCTTCC }\end{array}$ & $(\mathrm{CT}) 3(\mathrm{~T}) 7(\mathrm{CT}) 24$ \\
\hline
\end{tabular}

Note: Queen genotypes inferred from worker genotypes are given in parenthesis. Drone genotypes inferred from workers and queens are highlighted in bold.

2. When using unlinked markers, rearrange the tables by grouping all individuals sharing allelic combinations in three or more loci to facilitate the identification and counting of their colonies of origin. The more loci the individuals share, the higher the probability they share a mother queen (see section 4.3.3.5. on non-detection errors below). When using linked markers (Shaibi et al., 2008, Table 15), first group all individuals sharing the same allelic combination at all loci within each linkage group. The haplotypes found in each linkage group are equivalent to individual alleles.

2. Exclude individuals that showed two or less successfully amplified loci, or that could not be assigned to a specific haplotype in at least one linkage group (because of low polymorphism or misamplifications at some loci).

4. Introduce the alleles/ haplotypes into a sibship reconstruction software (e.g. COLONY, Wang, 2004) to reconstruct the genotype of individual drone-producing queens. 


\subsubsection{Non-detection and non-sampling errors}

Two kinds of errors affect estimated number of drone-producing queens:

1. Non-detection errors (the probability of obtaining two identical genotypes in two different individuals by chance). Non-detection errors (NDE) are determined by the number of markers employed and their level of polymorphism and are an indicator of the resolution of these markers. It should always be reported along with the results, but there is no need to correct the results. To calculate NDE the following formula can be used:

$$
N D E=\left(\sum q_{i}^{2}\right)\left(\sum r_{i}^{2}\right) \ldots\left(\sum z_{i}^{2}\right)
$$

where

$q_{i}$ are the allele/ haplotype frequencies at the first locus, $r_{i}$ are the allele/ haplotype frequencies at the second locus, and $z_{i}$ are the allele/ haplotype frequencies at the last locus. This calculation assumes all loci/ linkage groups are unlinked and under Hardy-Weinberg equilibrium.

2. Non-sampling errors (the number of queens remaining undetected because of an insufficient sample). In contrast to $\mathrm{NDE}$, the final number of queens detected should be corrected for non-sampling errors (NSE). In other words, the number of undetected queens should be accounted for. The following procedure describes how to account for NSE.

2.1. Construct a frequency distribution table with the number of drones found to be assigned to each colony (see Fig. 27).

2.2. Fit a Poisson distribution to the real data by calculating the expected frequency for each category.

Expected frequencies of a Poisson distribution can be calculated using most commercial statistical packages (e.g. STATISTICA or SPSS).

2.3. Obtain the expected frequency for the zero or less than one category.

2.4. Add the undetected colonies (or colonies with an expected frequency of zero, see Fig. 27) to the detected ones to correct result for non-sampling errors.

\subsubsection{Density estimation}

1. Exclude colonies represented by less than a median number of drones in all density calculations in order to overcome the limitation that distant colonies will contribute fewer drones than colonies located in the vicinity of a DCA.

2. Quantify the number of colonies represented by an equal or higher than median number of drones.

3. Divide this number by the mean mating area of drones (for the drone samples, $2.5 \mathrm{~km}^{2}$, Jaffé et al., 2009a) or queens (for the worker samples, $4.5 \mathrm{~km}^{2}$, Jaffé et al., 2009a) to obtain an estimate of the local density of colonies at the sampling location (see Fig. 28).

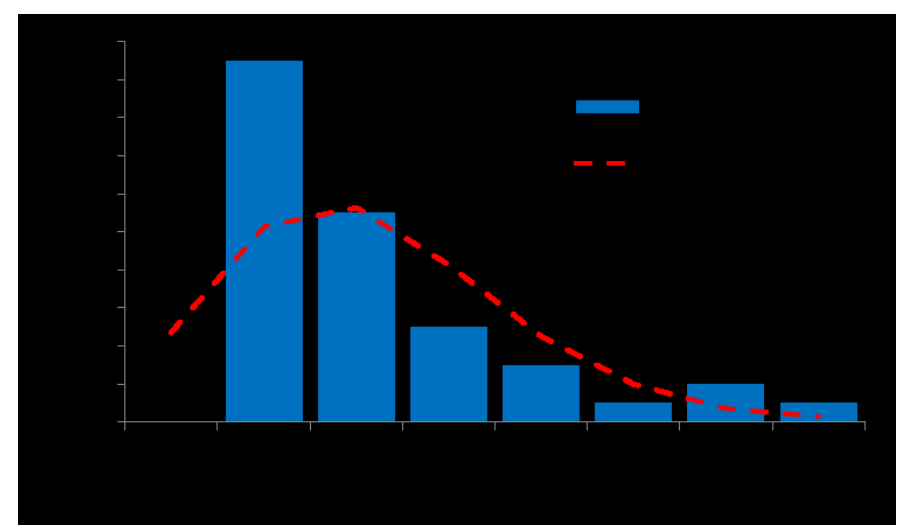

Fig. 27. Estimating the number of non-sampled colonies through a fitted Poisson distribution. While observed frequencies are plotted with blue bars, expected frequencies (fitted Poisson distribution) are shown in a red dashed line. In this example, the number of nondetected colonies is 4.7 .

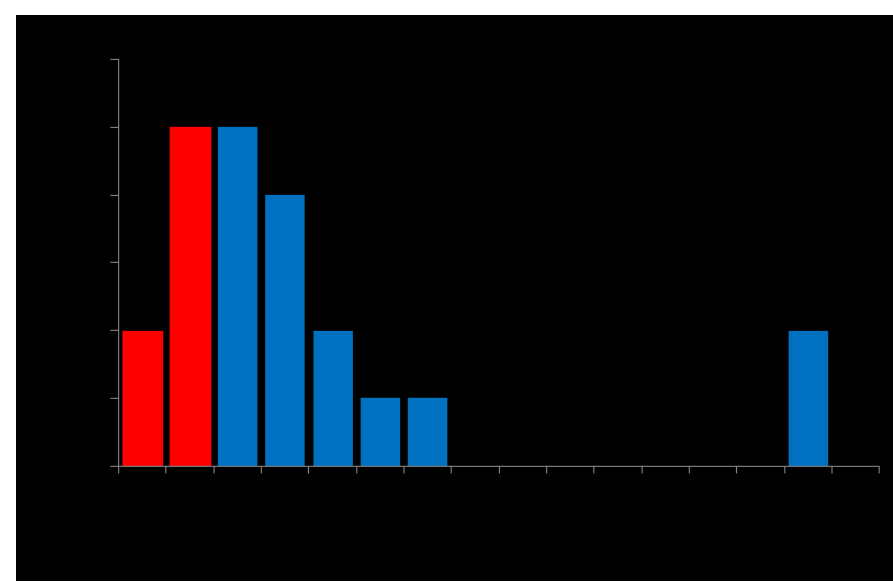

Fig. 28. Schematic representation of the approach to estimate honey bee colony densities based on the frequency distribution of drones among the reconstructed colonies. For a given sample of drones from a specific location, the median number of drones per colony is first calculated. In order to estimate the local density of colonies, those colonies represented by less than a median number of drones (red columns) need to be discarded. The number of remaining colonies (blue columns), are then divided by the mean mating area of drones or queens. This approach aims to avoid the overestimation of colony densities due to the inclusion of low-represented colonies, likely to be located beyond mean flight distances of drones or queens.

Pros: less tedious than finding all nests in an area. Method independent of nest spatial distribution (Arundel et al., 2012).

Cons: Fails to detect colonies that do not produce drones. Season dependence when based on drone trapping, and thus a relevant density figure can only be obtained during mating season when most colonies produce drones. Assumes a similar drone investment by all colonies. Inaccuracy due to variable/ non predictable size of mating areas of drones and queens, which can be different between regions and honey bee populations. High costs involved in genetic analyses, and a suitable lab space and equipment is needed. 


\subsubsection{Future research needs and perspectives}

1. The set of linked markers described in Table 15 might not prove useful for some honey bee populations because of misamplifications or low polymorphism. Additional genetic markers should be identified and tested to create a larger set of tightly linked markers located on different chromosomes.

2. A model accounting for a variable drone production per colony might increase accuracy of the method based on genetic markers.

3. Further studies on the mating area of drones and queens in different regions and populations might also increase accuracy of the method based on genetic markers.

4. The method based on genetic tools should be calibrated against populations of known absolute density.

5. One needs to determine the number of feeding stations that should be deployed per unit area before a site can be considered 'adequately represented'. For example, determining an index for colony density with 10 feeding stations on a 10,000 hectare area hardly seems accurate.

6. Because honey bees can forage $4-6 \mathrm{~km}$ from the nest (Winston, 1987), the distance between feeding stations necessary to limit the chances of one colony going to more than one site needs to be determined.

7. The accuracy of the indices should be confirmed by comparing the results from the indices to the actual colony density in an area (determined by methodical search and location of wild colonies in a landscape) and to other published colony density estimation methods (Oldroyd et al., 1997; Baum et al., 2005; Moritz et al., 2008; Jaffé et al., 2009a).

8. Reliability - Vaudo et al. (2012b) suggest that the field and photograph ratings provide more reliable indices than counting the number of bee lines, though this assumption needs to be validated.

\subsection{Estimating the number of dead honey bees expelled from a honey bee colony with a trap}

\subsubsection{Aim of using dead bee traps}

The assessment of intra hive mortality through dead bee traps is useful for acquiring data on honey bee survival when exposed to pesticides, environmental pollution, or honey bee diseases (Gary, 1960; Atkins et al., 1970; Perez et al., 2001; Porrini et al., 2003).

For determination of bee mortality the removal of dead and sick honey bees (undertaking behaviour) needs to be considered (Gary, 1960; Perez et al., 2001). Heavier objects e.g. bee bodies are usually dropped below the hive opening by bees and dragged away (several metres), while lighter objects are carried by the bees and disposed of at a good distance (several hundred metres) away from the hive (Gary, 1960; Porrini et al., 2002a). Dead bee traps provide an obstacle to this behaviour and allows for the collection and counting of the majority of the discarded bodies at hive entrance.

\subsubsection{Limitations of using dead bee traps}

The use of dead bee traps unfortunately does not account for the bees that have died in the field or on their way home (Porrini et al., 2002a). Originally dead bee traps, e.g. the Gary trap, was intended to be used for short periods of time, but ever since bees have become biological indicators, traps are now being used throughout the year (Accorti et al., 1991). These traps can become a problem when bees begin to treat them as an integral part of the hive that also needs to undergo the same cleaning processes as the rest of the hive (Accorti et al., 1991). We therefore recommend, first to clean the trap on a regular basis and second to ensure that the trap is not continuously attached to the colony.

In general, studies tend to report the efficiency of traps, but not the effect on the colonies (Stoner et al., 1979). In their study Stoner et al. (1979) reported the negative effect of a modified Todd trap on colonies showing less adult bees were present in colonies with dead bee traps. One should keep in mind when designing experiment using dead honey bee traps that the efficiency and suitability of a trap is not only depending on its design, but also on other factors like season, colony strength and environmental conditions (Porrini et al., 2002a).

\subsubsection{Types of dead bee traps}

Many dead bee traps have been designed for Langstroth and Dadant type hives but currently the Todd, Gary, Münster and underbasket dead bee traps are the most frequently used (Table 16) (Illies et al., 2002; Porrini et al., 2002a). However, preliminary data on the performance of an experimental dead bee trap called the barrier trap indicates high efficiency (Porrini et al., 2002b). In addition to existing traps, Hendriksma and Härtel (2010) constructed an entrance trap made of plastic ice cream containers that can be used for risk assessment in small hives.

There are several fundamental requirements for the design of a dead bee trap. They are reported in the Table 16 for each trap model and in section 4.3.4. for the general case.

\subsubsection{Dead bee traps requirements as gathered from the literature}

- Traps have to be well designed to allow for easy sample collection.

- Traps have to be very efficient at trapping only dead bees.

- Dead bee traps should not obstruct the normal behaviour productivity and flight of bees.

- Predators/ scavengers should not be able to enter the dead bee traps.

- Traps have to be resistant to adverse weather conditions.

- Small, drainage holes for rain water should be present 
- The dead bee trap should allow for straightforward construction and cleaning.

- The attachment and removal of the traps from the hives should be uncomplicated.

- Dead bee traps should be as cost-effective as possible.

\subsubsection{Recommended dead bee traps to use}

We recommend using the Münster trap (Illies et al., 1999, 2002), the underbasket trap (Accorti et al., 1991) and the trap for small hives (Hendriksma and Härtel, 2010). No negative interference with colony activity was reported in these traps. The recovery rates of dead bees in the Münster trap (Illies et al., 1999, 2002) were somewhat lower than some of the other traps (Table 16), but the artificial honey bee mortality resulting from the use of this trap was lower. As a cheaper alternative, the underbasket trap can be used since it does not interfere with the normal activity of the hive and reportedly has a very good recovery rate of dead bees (Table 16). The small hive trap (Hendriksma and Härtel, 2010) is fairly new in the bee research field, but it has a high potential of being a very successful dead bee trap that is also cost-effective in terms of both construction and maintenance.

\subsubsection{Building a dead bee trap}

For exact measurements please refer to the articles describing the original traps and their modifications.

\subsubsection{Protocol for calibrating dead bees in traps}

Before using the selected bee trap, it needs to be calibrated to establish its recovery rate. The following calibration protocol is derived from the work of Gary (1960), Illies et al. (2002) and Hendriksma and Härtel (2010).

1. Connect the trap to the hive for several days before the experiment begins, to allow the bees to become accustomed to the new addition.

2. Collect a known number of bees (e.g. 100) from the colony on which the trap is mounted.

3. Kill these workers (see section 2.1.3.).

4. Mark these workers (see the section 2.3. of the BEEBOOK paper on behavioural studies (Scheiner et al., 2013).

5. Open the hive on which the trap is mounted.

6. Place the dead workers on top of the frames

7. Close the hive.

8. Record the number of recovered bees every $15 \mathrm{~min}$ during the first hour, then again after 2, 4, 8 and $24 \mathrm{~h}$ (e.g., 2, 5, 1, 10, 22, 35, 6, 12).

The efficiency can then be calculated based on 8 data points.

9. The percentage recovery rate of these marked dead bees is calculated to get an estimate of trapping efficiency.
Recovery rate $=$ (number of recovered bees/ number of dead bees introduced) $\times 100$.

In our example, recovery rate $=(93 / 100) \times 100=93 \%$

\subsubsection{Protocol for using a dead bee trap}

1. Equalise colony size or assess colony size (see the BEEBOOK paper on colony strength (Delaplane et al., 2013) to obtain a mortality rate. Do regular size assessment if it is a long term experiment.

2. Connect the trap to the hive for several days before the experiment begins, to allow the bees to become used to the new addition.

3. Remove and count the number of dead bees at regular predetermined intervals

4. Clean the trap if necessary after counting.

5. Calculate the corrected mortality rate based on the recovery rate determined in section 4.4.7.) (Gary, 1960):

Corrected mortality $=\frac{1}{\% \text { recovered controls }} \times$ obs body recovery

\subsubsection{Dead bee trap trade-offs}

The most important trade-off among the different trap designs is that of a high recovery of dead bees versus interference with normal colony activity, in particular with undertaker bees and foragers. Another trade-off is the ease to attach and clean the traps versus the exposure of the trap content to the environment and potential predators which could utilise the trap as a feeding ground.

\subsection{Creating multiple queen colonies}

Recently, a method to create multiple queen honey bee colonies composed of young workers was created by clipping part of the mandibles of queens (Figs. 29 and 30). The crucial part of the method is the clipping of part of their mandibles. This operation does not significantly affect the general activity and mandibular gland profile of queens (Dietemann et al., 2008; Zheng et al., 2012). Queens with their mandibles ablated refrain from lethal fighting, resulting in cohabitation of queens (Dietemann et al., 2008).

This procedure is described in section 4.4.1. In the following sections $(4.4 .2,4.4 .3$.), the preparation and maintenance of multiple queen colonies is described. Multiple queen honey bee colonies (Fig. 31) are of significance both in beekeeping and research. In some areas of China, these colonies are used in beekeeping as supporting colonies to: (1) build up populous colonies faster in spring prior to major nectar flows and to maintain the population year-round when needed (2) provide the 1-day-old larvae necessary for grafting larvae in queen cells for royal jelly production and (3) provide replacement queens when necessary. Furthermore, they can contribute to package bee 
Table 16. Different types of dead bee traps being used in honey bee studies with their main characteristics, their pros and cons.

\section{GARY TRAP (Gary, 1960)}

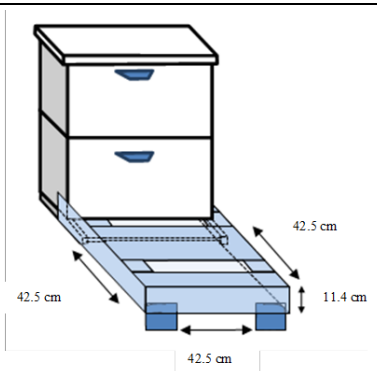

Front view of Gary trap, modified from Gary (1960)
According to Gary (1960) the trap can be used for long-term experiments without affecting colony activity and/or the consistency of the information recorded.

Pros: Efficient collection (84.6\%) of dead bees (Gary, 1960).

Cons: This trap unfortunately detains large numbers of live bees resulting in increased mortality rates and it modifies the behaviour of the undertaker bees (Illies et al., 2002).

\section{TODD TRAP (Atkins et al., 1970; Stoner et al., 1979)}

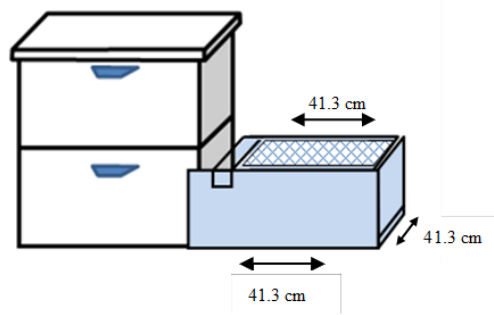

Side view of Todd trap, modified from Atkins et al. (1970)
Modifications were made to the trap that permitted the drainage of rain and irrigation water (Atkins et al., 1970).

Pros: This trap is reported to be efficient $(90-95 \%)$ at preventing the elimination of dead bees (Atkins et al., 1970; Herbert et al., 1983).

Cons: Compared to other traps the Todd trap seems to be more difficult to clean from debris by the experimenter.

\section{MÜNSTER DEAD BEE TRAPS (Illies et al., 1999, 2002)}

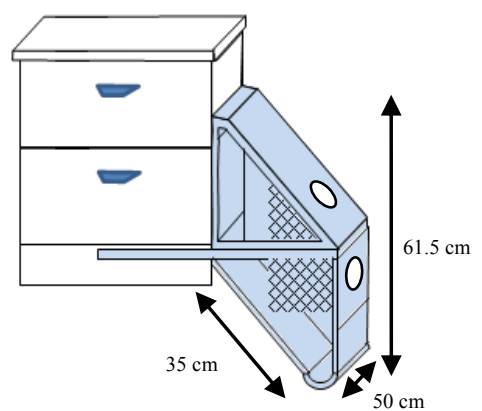

Side view of Münster trap, modified from Illies et al. (2002)
Pros: The entrance of this trap does not interfere with normal flight behaviour and bees adjust quickly to this trap (Illies et al., 1999, 2002). Recovery amounts to $76.4 \%$ of dead bees (Illies et al., 2002). The trap also prevented predators from removing dead bees and provided shelter from wind (Illies et al., 1999).

Cons: The recovery rate is relatively low compared to the other traps mentioned here.

\section{UNDERBASKET (Accorti et al., 1991; Porrini et al., 2002a)}

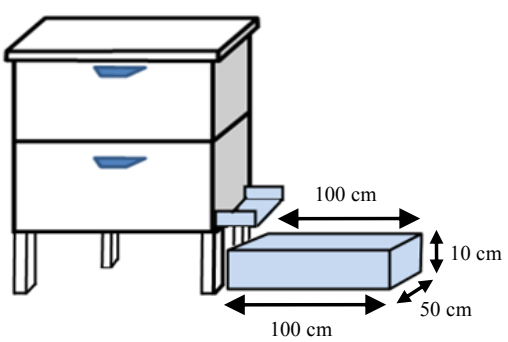

Side view of underbasket modified from Porrini et al. (2003)
The trap does not form part of the hive and is located on the ground underneath the hive opening (Accorti et al., 1991; Porrini et al., 2002a).

Pros: Underbasket traps are easy to attach and clean. They seem to be highly efficient and do not interfere with undertaker bees' activities (Accorti et al., 1991). A dead bee recovery rate of $71-96 \%$ was recorded in this trap (see Porrini et al., 2002a).

Cons: The trap is very exposed to the environment and predators.

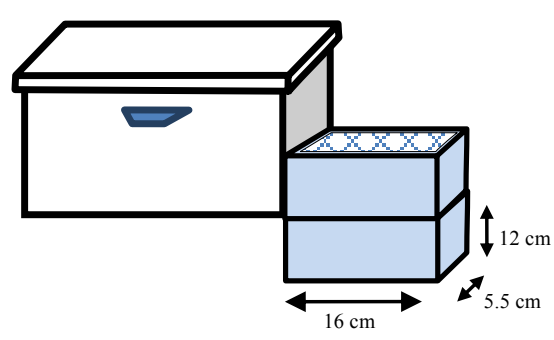

Side view of small trap modified from Hendriksma and Härtel (2010)
Pros: This is the first trap developed for small hives. Hendriksma and Härtel (2010) recorded a dead bee recovery rate of $93 \%$. It seems easy to attach and clean, sounds highly efficient and does not interfere with normal hive behaviour. Most of all, it is very cheap to construct (Hendriksma and Härtel, 2010).

Cons: This hive needs further testing 


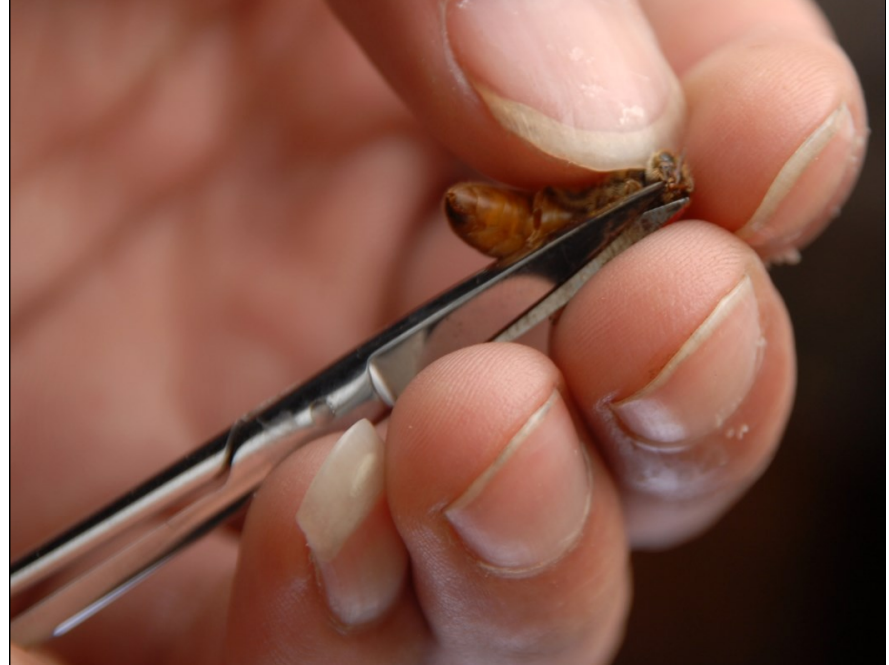

Fig. 29. Clipping mandibles of a queen. The queen's thorax is held between the thumb, index finger and middle finger of one hand while one third to half of mandibles on both sides is cut with small scissors held in the other hand.

Photo: W Wei.

production by providing large numbers of workers. In research, theyare helpful to deepen our understanding of basic questions on the evolution of sociality, such as division of reproductive labour and the evolution of polygyny (Dietemann et al., 2009b).

\subsubsection{Mandible clipping procedure}

1. Hold the queen lightly by the thorax between the thumb, index- and middle finger of one hand (Fig. 29).

2. Hold the scissors with the other hand.

3. Cut approximately one third to half of both mandibles. Take care not to hurt other appendages of the queen.

4. Mark the queen with paint (see section 2.4.1.2.) when desired.
4.5.2. Preparation of colonies destined to host the multiple queens

The method that follows was described by Zheng et al. (2009a).

1. Mark the queens (see section 2.4.1) to allow future identification.

2. Select combs of emerging brood for the receiver colony.

3. Slightly shake the combs to trigger flight in the older bees, while young bees tend to remain on the comb.

4. Place the combs in a hive box with the young bees still clinging to them

Alternatively, combs with emerging brood can be kept in an incubator, if available, at $34^{\circ} \mathrm{C}$ for two days to collect young bees. One to three-day-old workers are preferred to freshly hatched individuals, which may not be able to care for the queens efficiently enough. The amount of combs and bees to be used in the multiple-queen colony depends on the number of queens to be introduced. Four to six combs are used for three to six queen colonies.

5. Add combs of honey and pollen beside the brood combs to provide enough food.

Providing stored food is necessary because the colony is deprived of foragers at the beginning.

6. Place the hive $5-10 \mathrm{~m}$ away from their original location to ensure that all remaining foragers (older bees) do not re-enter.

7. Two days after the receiving colonies were prepared, take the queens out of their original colonies.

To increase the chance for successful introduction, select queens older than six months since younger queens are more aggressive towards each other. The large abdomens of the egg laying queens might further reduce their ability to fight.
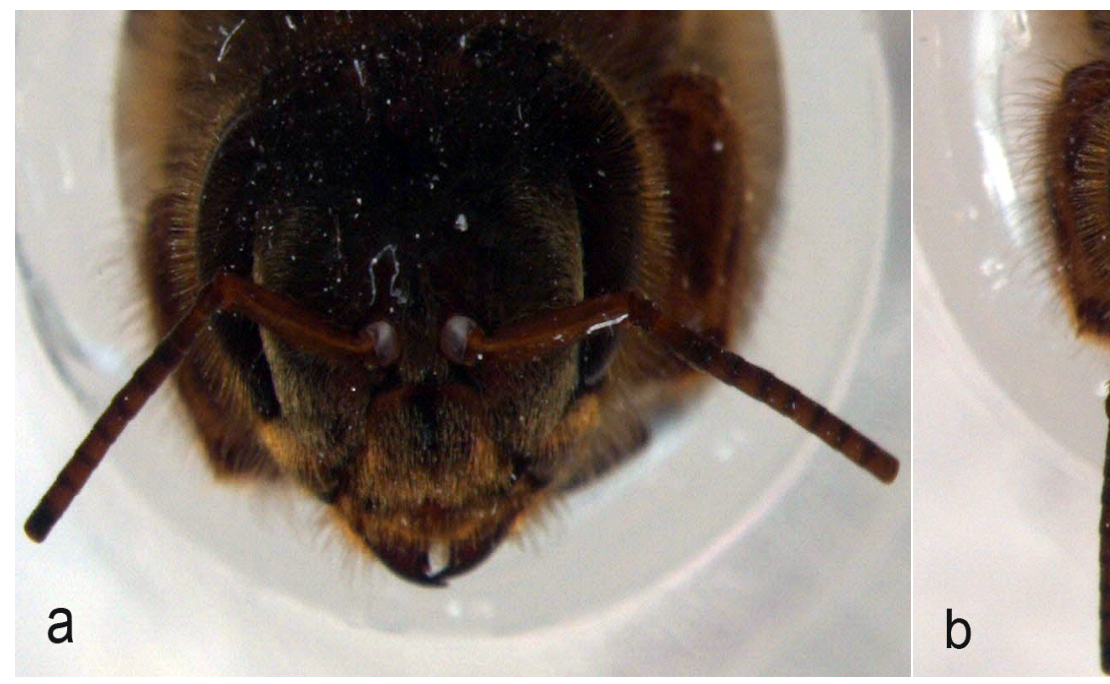

Fig. 30. (A) A queen with intact mandibles; (B) A queen with mandibles clipped.

Photo: H-Q Zheng. 


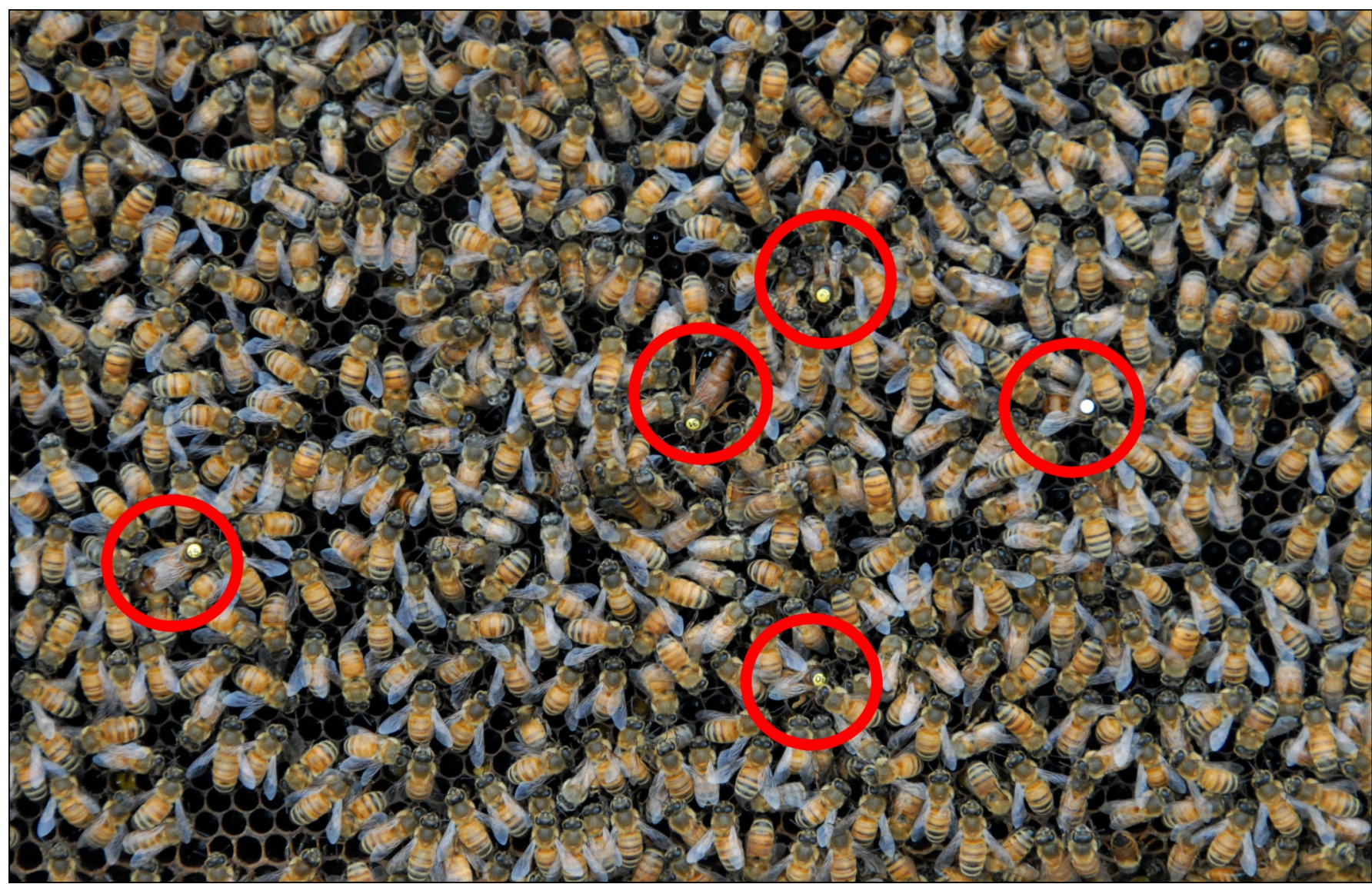

Fig. 31. Five queens on one side of a comb.

Photo: W Wei.

8. Cut off a third to a half of both the queens' mandibles with small scissors.

A good quality pair of small or micro scissors is necessary. Great care should be taken to avoid hurting other appendages of the queens, specifically their antennae, proboscises and forelegs. It is recommended to practice with workers before clipping queens.

9. Introduce the queens on different frames in the host hives. Observe the queens for a minute after their introduction. If the queens are attacked by workers, take them out and spray some honey water on both the workers and queens and then reintroduce the queens into the hive. If the queens are attacked, which may occasionally happen if some of the workers are too old to accept multiple queens, host colonies should be reorganised, making sure that the majority of the workers are young.

To ensure the multiple queen social structure, great care should be taken to maintain the receiver colonies. The necessary steps are described in the next section.

\subsubsection{Steps for maintenance of an artificially established multiple-queen social organisation}

The method that follows was described by Zheng et al. (2009b).

1. Supply the multiple queen colony with sufficient food at regular intervals.
The strong egg laying capacity of a multiple queen colony results in most of the combs being occupied by brood, decreasing the space available for food storage and increasing the need for food to rear the brood. Consequently, these colonies must be fed more frequently compared to single queen colonies when there is decreased nectar flow, especially when no supers have been added.

2. Prevent robbing of the multiple queen colonies and drifting by placing food away from other colonies. Regularly monitor the occurrence of robbing.

3. Destroy newly built queen cells.

This is to ensure that one or more queens are not killed after the occasional production of young queen(s).

4. Abandon foragers before migration.

The agitation of old bees resulting from the transport during migration may lead to queen elimination. To reduce the possibility of queen losses, these old workers must be removed before migration. For this, the hive hosting the multiple-queen colony should be moved during an active foraging period a short distance away from its original location two days before the migration takes place. A hive with one comb should be placed at the original location to collect the old forager bees that will fly back. 


\subsection{Digital monitoring of brood development via location recognition}

Jeker et al. (2011) designed a method to record subsequent development stages in a fixed number of cells selected on a frame at the start of a study following a (pesticide) treatment or other environmental impact. This technique is used as a digital documentation and an automation of the data evaluation according to the OECD guidance document 75 (2007). The method is used for GLP-compliant ecotoxicity tests, focused on subsequent recording of the content of marked cells during brood development. Besides studying the impact of pesticides it can be applied to follow brood development in studies about the impact of pathogens e.g. virus, brood pathogens and in-hive conditions.

\subsubsection{Introduction}

The development of the bee brood is assessed in individually-marked brood cells of all colonies within a study. At the assessment before the application of a treatment (BFD = Brood Fixing Day), one or more brood combs are taken out of each colony and identified with the study code, treatment group, hive number, comb number and comb site. The frames are photographed with a high-quality digital photo camera (full frame CMOS chip with a resolution of 20 megapixels or more) controlled via a laptop computer. In the laboratory, all photos are transferred to a personal computer and cells to be analysed, are chosen on the screen. Cells with any type of cell content can be selected, although for a typical evaluation according to Oomen et al. (1992), only egg-containing cells would be selected. The exact position of the markers and of each cell and its content are stored in a computer file that serves as a template for later assessments. The same cells are assessed on each of the following assessment dates (see Table 17). Thus, the development of each individually marked cell can be determined throughout the duration of the study (pre-imaginal development period of worker honey bees typically averages 21 days). For studies focussing on specific brood development stages e.g. young/ old larvae, the BFD may start at this stage and the assessment days are adjusted automatically to the expected development time of the specific brood stage. Following the OECD guideline 75, the brood development is checked 5 times: start with eggs, five days later these eggs have turned from young to old larvae, sixteen days after the start the brood in the marked cells are in the pupal stage and 22 days later the cells should be empty or contain again eggs. The program can cope with any number of observation days, meaning that frames, if necessary in the scope of the study, can be analysed each day. All data evaluation and files (with results), are adapted automatically. The program will generate additional result files for each of the starting stages (or starting contents). Depending on the study objective it is possible to start with other brood stages and with more frequent check dates. On brood fixing day 0 (BFD 00) cells with any brood stage can be selected. If egg-containing cells are selected and if in addition
Table 17. Assessment of the development of the bee brood starting with the brood stage "egg".

\begin{tabular}{|c|c|}
\hline Assessment days & $\begin{array}{l}\text { Determination brood stage in } \\
\text { marked cells }\end{array}$ \\
\hline BFD & egg \\
\hline Assessment days & $\begin{array}{l}\text { Expected brood stage in marked/ } \\
\text { selected cells }\end{array}$ \\
\hline+5 days ( \pm 1 day) after BFD & Young to old larvae \\
\hline+10 days ( \pm 1 day) after BFD & Capped brood \\
\hline+16 days ( \pm 1 day) after BFD & Capped brood shortly before hatch \\
\hline+22 days ( \pm 1 day) after BFD & Empty cells or egg containing cells \\
\hline
\end{tabular}

to the standard data evaluation, images BFD 01 or BFD 02 or BFD 03 are analysed, the presumed age of the egg is calculated accordingly and the time resolution of the study is improved from four days to a maximum of one day.

When photographing the brood containing frames, the bees of the frames to be checked need to be brushed gently from the combs. The combs should not be shaken since too harsh handling might disturb the brood. In order to prevent drying out of the brood and so disturbing the normal development, the frames are taken from the colony, photographed immediately and transferred back to the colony as quickly as possible. Using fixed apparatuses the taking of the photograph requires only minutes.

For the European honey bee, the egg stage varies and is approximately 3 days $(70-76 \mathrm{~h}$ ). The larval stage (unsealed stage is considered as the larval stage) can varies between 5 and 6 days, with an average of 5.5 days and the pupal stage (capped cells) is 12 days (Winston, 1987; Jean-Prost and Médori, 1994; refer also to the section 1.5 on obtaining adults and brood of known age in this paper). Working with, for instance African honey bees, the assessment days must be adjusted to the duration of the development stages of the brood (see Fletcher, 1978).

\subsubsection{Procedure for data acquisition}

\subsubsection{Software requirements}

In order to apply the "Bee Brood Analyser", two programs must be installed on the computer:

- FIJI, a freeware image analysis program. (http://pacific.mpi-cbg.de/wiki/index.php/Fiji)

- NEXTREAT Bee Brood Analysis Software Package. (NEXTREAT, email: info@nextreat.ch) This software is regularly updated for optimal performance. Along with the Bee Brood Analysis Software Package, a User Manual is provided.

The user manual provides detailed instructions. Therefore here, only an outline is presented of the subsequent steps and results. 


\subsubsection{Before starting the project}

Put orientation hallmarks (coloured thumbtacks) in the middle of the upper and lower long side of the frame.

\subsubsection{Image acquisition.}

1. Take out a frame.

2. For GLP reasons it is advised to label the frames with an identifier. Preferentially the ID should be used, which corresponds to the ID-System used by the software. The ID pattern is the following "AAAAAA_BB_CCD_EE", whereas "_ " is a mandatory separator.

2.1. AAAAAA: ID of the study in six characters,

2.2. BB: ID of the hive in two numeric characters, e.g. "05",

2.3. CC: ID of the frame in two numeric characters, e.g. "03",

2.4. D: ID of the side of the frame e.g. "a" or " $b$ ",

2.5. EE: ID of the BFD, e.g. 00 for BFD 0 (the day of study start).

An example of a label on the frame would look like:

"Study1_01_02a" for a permanent label or

"Study1_01_02a_00" for a label made specifically for the day of image acquisition.

3. For unequivocal identification of the image, the label is attached on the front side of the frame and must be visible and to be photographed at every recording.

4. Make a picture of the frames using a fixed distance.

4.1. The minimal photographic distance is calculated in order to allow visibility of at least $75 \%$ of the bottom of a cell at the outermost rim of the image. The calculation is based on an average cell diameter of $5.3 \mathrm{~mm}$ and an average cell depth of $11 \mathrm{~mm}$. The photographic distance fulfilling of the above requirement is $11 /(5.3 * 0.25) / 2=4.15$ fold the long axis of the frame.

4.2. The camera to be used should be connected to and controlled by a computer.

The control software is necessary for a number of reasons: It enables triggering of the camera without the need to touch it. It enables a magnified live-view of the image allowing the directed focusing on the eggs. The camera's autofocus will always focus on the upper rim of the cell wall.

4.3. Ideally, a setup should be created, allowing keeping the fixed distance, defined illumination and minimal vibrations.

4.4. Illumination should be optimised to minimise reflections.

5. After the pictures are made, download the pictures from the camera to the computer.
5.1. The images have to be re-named according to the pattern "AAAAAA_BB_CCD_EE.jpg".

5.2. The image files of the same frame should be stored in the same folder.

\subsubsection{Image analysis}

\subsubsection{Analysis of the first image (BFD 00)}

1. Use the command keys in the User's Manual

1.1. Standardise the size of the cell

1.2. Position the mouse and press on the number-pad 0 - empty cell

1 - -an egg

2 - a young larva

3 - an old larva

4 - a pupa

5 - nectar

6 - pollen

7 - a dead larva

8 - non characterised cell (nc)

A circular mark will be set at the cell area, generating a circular region of interest (ROI).

1.3. Do so for the number of cells required for the study.

1.4. Once the selection of the cells is completed, define the two hallmarks.

The hallmarks should always be the last ROI.

2. Once the ROI and both hallmarks have been selected, the process is finalised by automated saving the ROI file (AAAAAA_BB_CCD_EE_ROI.zip).

3. Simultaneously a copy of the ROI file is saved in the folder AAAAAA_BB_CCD_Archive with a time-stamped name (AAAAAA_BB_CCD_EE_ROI yymmdd_hhmmss.zip; yymmdd_hhmmss corresponds to a date and time of the saving).

4. An image file is generated with all selected cells, hallmarks and additional GLP-relevant information is "burned" into the image (AAAAA_BB_CCD_EE_selections.jpg).

\subsubsection{For all consecutive images (BFD $+05,10,16,22)$}

Consecutive images are processed by:

1. Selecting the hallmarks.

2. Letting the program transpose the selections from BFD 0 . The program re-classifies the content of all cells to " $\mathrm{nc}$ " (not classified), ensuring that previous classifications are not carried forward. The user is forced to a re-classification of the cells. If a cell is classified as "nc" at any of the observation days, than the data of this cell are excluded of all of the subsequent analyses. The event of exclusion is documented, the data are not deleted. 
3. Re-classification of the ROI's by the user.

By presenting one cell after the other, the user has to reclassify the cells with the same keys on the number-pad as used for the selection of the cells on the image from BFD00 (see step 3.1. above), with the difference, that the cells are presented by the program and not chosen by the user.

\subsubsection{Finalisation of the analysis.}

The data evaluation is based on a developmental described by the following pattern: 1111222333444444444444 , with the digits representing the expected developmental stage on consecutive days during larval development, i.e. the first four digits (1) correspond to days 0 to 3 with egg stage, the fifth to the seventh digits (2) correspond to days 4 to 6 with young larva stage, etc. If necessary, the user has the possibility to change this pattern and/ or to assign a maximum of two days of tolerance for either delayed or accelerated development. Once all images of a frame have been processed the analysis is finalised by pressing F6 or choosing the menu "Make gallery". The program will then run the analyses.

1. The program creates a folder with the name AAAAAA_BB_CCD Results yymmdd_hhmmss", where all results files of the evaluation are saved to ("yymmdd_ hhmmss" corresponds to a date and time of the analysis). Copies of all ROI files used for the analysis are saved into this folder.

2. The ROI data from subsequent days of the same frame are pooled into one tab-delimited file and saved as AAAAAA_BB_CCD_RawData.xls.

3. The program populates the classification data of each individual cell from the different observation days as numeric values (data of one cell are in one row; data of the same day are in columns "BFDnn"; e.g. BFD05 for the fifth brood fixing day).

4. The program rates the development as normal or terminated by comparing the set developmental pattern to the developmental stage expected for that cell on that day. These data are populated to the others in columns "BTRnn" (BTR $=$ Brood Termination Rate). Brood termination-rate: Based on the brood termination-rate the failure of individual eggs or larvae to develop is quantitatively assessed. For the calculation of the brood termination-rate the observed cells are split into 2 categories:

a. The bee brood in the observed cell reached the expected brood stage at the different assessments days or was found empty or containing an egg after hatch of the adult bee on BFD +22 = successful development.

b. The bee brood in the observed cell did not reach the expected brood stage at one of the assessment days or termination of the bee brood development.
For the final calculation the number of cells, where a termination of the bee brood development was recorded, is summed up for each treatment and colony, is multiplied by 100 and divided by the number of cells observed in order to obtain of the brood termination-rate in $\%$.

5. The program determines the brood index (BI) for each cell and each day and populates the data to the previous ones in the columns "BInn".

Brood Index:

The brood-index is an indicator of the bee brood development and facilitates a comparison between different treatments. The brood-index is calculated for each assessment day and colony. Therefore the brood development in each cell will be checked starting from BFD 0 up to BFD +22 . The cells are classified from 1 to 5 (1: egg stage, 2: young larvae (L1 - L2), 3: old larvae (L3 - L5), 4: pupal stage (capped cell), 5: empty after hatching or again filled with brood (eggs and small larvae) if the cells contain the expected brood stage at the different assessment days. If a cell does not contain the expected brood stage or food is stored in the cell, the cell has to be counted 0 at that assessment day and also on the following days, irrespective whether the cell is filled again with brood. For the final calculation the values of all individual cells in each treatment, assessed at the same day, are summed up and divided by the number of observed cells in order to obtain the average brood-index.

6. The program determines the compensation index (CI) for each cell on each observation day and populates the results to the previous ones in the columns "CInn".

Compensation index:

The compensation-index is an indicator for recovery of the colony and will also be calculated for each assessment day and colony. The cells are classified from 1 to 5 (see brood index), solely based on the identified growth stage on the assessment days. By that the compensation of bee brood losses will be included in the calculation of the indices. For the final calculation the values of all individual cells in each treatment, assessed at the same day, are summed up and divided by the number of observed cells in order to obtain the average compensation-index.

7. The program does a frequency analysis for each day and parameter and populates the results below all the other data.

8. The program summarises all data by calculating the brood termination rate (BTR), BI and CI for each observation day and populates the results below the other data.

9. Finally, the developmental pattern and the tolerances used in the analysis are written at the end of this file. This file is saved as a tab-delimited file under the name "AAAAAA_BB_CCD_FinalData.xIs". 
10. If on BFD00 other than egg-containing cells are selected, then the program separates the cells based on their developmental stage or content and performs the above analyses (steps 5.6. to 5.9.) for each of the developmental stage or content separately and creates additional files with the names according to the following examples:

"AAAAAA_BB_CCD_StartAge_00_03.xls" for cells containing egg on BDF00,"AAAAAA_BB_CCD_StartAge_10_21.xls" for capped cells on FD00,

"AAAAAA_BB_CCD_StartContent_empty.xls" for cells empty on BFD00.

11. The program creates a gallery, where the images of the individual cells on the different observation days are assembled together side-by-side (similarly to a stampcollection). This allows the user to have a visual verification of the assessment at a glance. This file is saved as a multi-page TIF file under the name "AAAAAA_BB_CCD_gallery.tif".

The temporal resolution of a standard study (observation on BFD00 followed by observation on BFD05, etc.) is four days, because the egg stage is four days-long. Insertion of an additional observation day before the end of the egg-stage allows the refinement of the calculated age of the eggs. This can enhance the temporal resolution of the study by a maximum of four fold. If an additional observation before BFD04 was inserted (e.g. on BFD02), than the program separates the egg containing cells according to their expected age into separate files and performs the above analyses (steps 4 to 9) for each age separately and creates additional tab-delimited files with the names according to the following examples:

"AAAAAA_BB_CCD_StartAge_00_01.xls" for egg containing cells, where the eggs had a calculated age of 0 to 1 days.

\subsubsection{Conclusion}

This program is a sophisticated tool for further study of stressors on brood development and the impact of stressors on colony level in field situations. The parameter "brood development" provides additional information about the vitality and plasticity of honey bee colonies confronted with stressors. Stressors are not restricted to pesticides but can also be read as the impact of pathogens and the environmental, both in terms of feed and pollution.

\subsection{Collecting pollen and nectar from bees and flowers}

\subsubsection{Introduction}

Pollen and nectar (Fig. 32) are produced by flowers as rewards for pollinators in exchange for pollination. Pollen is essential in the reproduction of plants while nectar, a sugary solution, secreted by glands called nectaries, is a product that is not part of the sexual system of plants (Dafni, 1992), but attracts pollinators to ensure the spread of the pollen. Both pollen and nectar are collected for various

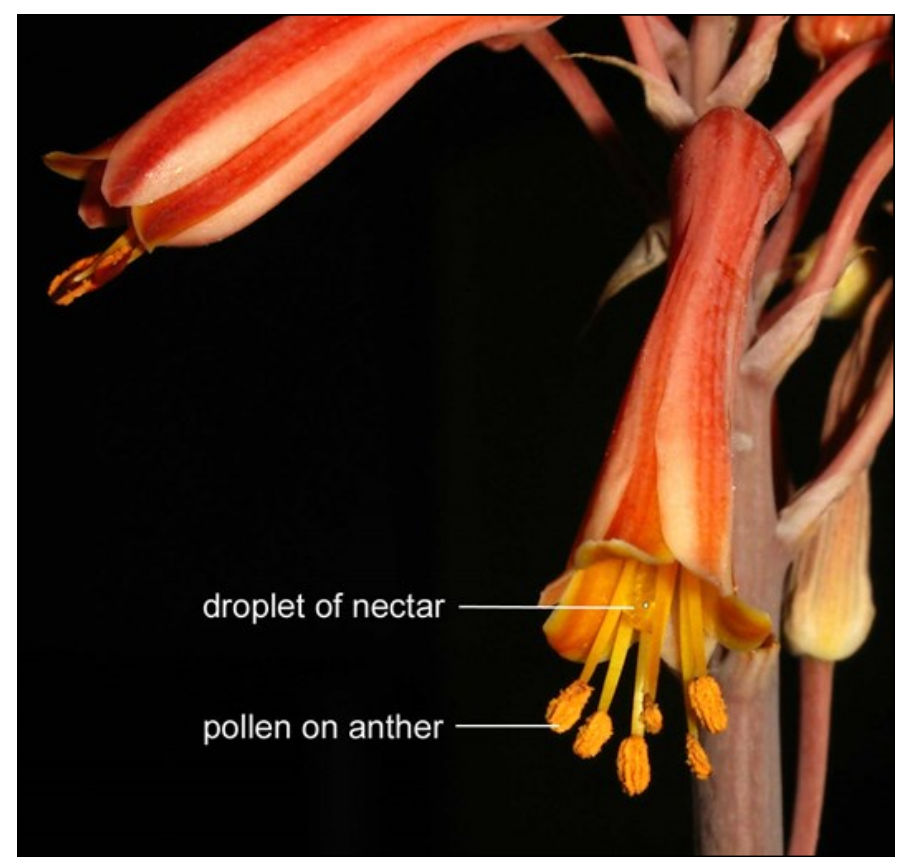

Fig. 32. Aloe greatheadii var davyana flower showing pollen on anthers and a droplet of nectar.

Photo: V Dietemann

reasons in honey bee research, particularly in studies addressing foraging biology, pollination research and exposure risks to environmental pollutes (Sammataro and Avitabile, 2011; see also the BEEBOOK paper on toxicology, Medrzycki et al., 2013).

Studies have shown a change in both appearance and nutritional composition of pollen during collection and storage by honey bees (Fig. 33) (Human and Nicolson, 2006). Through the addition of nectar and glandular secretions (Winston, 1987; Roulston and Cane, 2000) and certain bacterial flora associated with stored pollen the digestibility and nutritional value of the beebread/ stored pollen is increased (Herbert and Shimanuki, 1978). The sampling and collection methods depend upon the intended use of the floral source and the specific endpoints of measurements. However, it is important to know that quality of pollen decreases over time and should be stored appropriately and preferably be used within a year of sampling (Pernal and Currie, 2000). Here we describe methods to collect pollen (from the flowers, from the bees and stored in their combs) as well as various methods to collect nectar.

\subsubsection{Methods for pollen collection}

These methods are mostly used for studies on pesticide residues (Dively and Kamel, 2012, see also the BEEBOOK paper on toxicology, Medrzycki et al., 2013) and nutritional content of pollen (e.g., Human and Nicolson, 2006; see references therein). Fresh pollen can be collected directly from flowers where the bees are foraging. There are three basic examples of fresh pollen collection; using bags over the flowers (section 4.7.2.1.1.), by physically shaking the flowers over plastic trays (section 4.7.2.1.2.) or by gently brushing off the pollen from the male anthers with a paint brush (section 4.7.2.1.3.). 


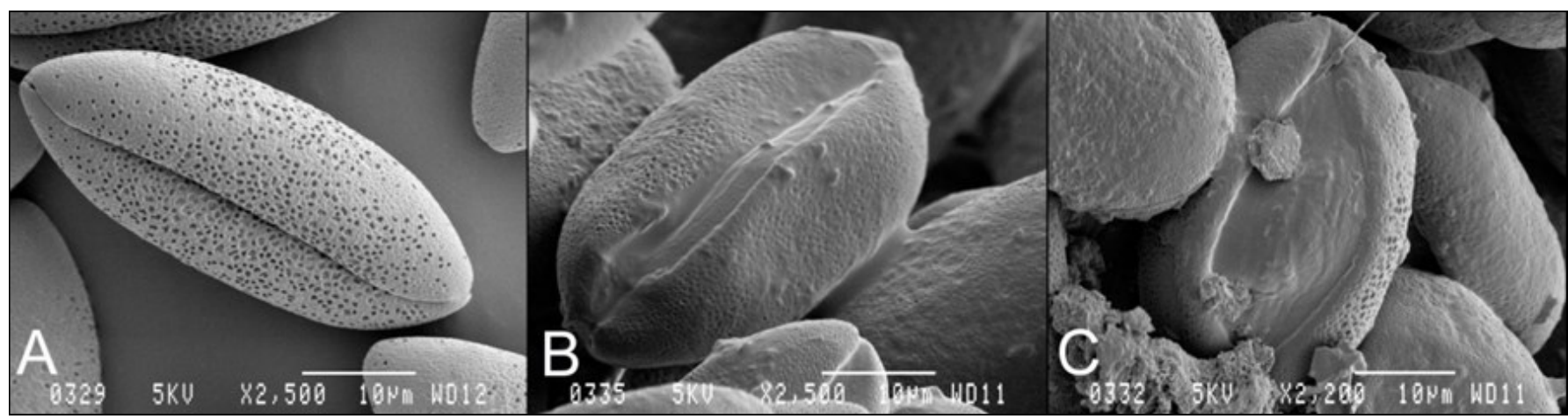

Fig. 33. Scanning electron microscopy pictures of Aloe greatheadii var. davyana pollen showing physical differences occurring in pollen grains after addition of nectar and glandular secretions; (A) Fresh pollen, (B) Bee collected pollen and (C) Stored pollen.

Photos: H Human.

Whenever fresh pollen is to be collected, flower buds that are open and ready to start shedding pollen, need to be covered with fine gauze or pollination bags the day before collection in order to prevent insect visitation and thus possible contamination. Bee collected pollen can be collected with pollen traps at the hive entrance or manually from the combs in which it has been stored (as bee bread).

\subsubsection{Nectar collection}

Foraging behaviour of honey bees is closely linked to colony needs and nectar production (volume and quality/ sugar concentration). Plants not only display particular rhythms of nectar secretion, but also nectar reabsorption (Nicolson et al., 2007). In general nectar secretion is influenced by a variety of environmental factors e.g. humidity and temperature (Pacini and Nepi, 2007). Knowledge of these factors is essential for a proper understanding of the relationship between plants and volume. and honey bees.

Nectar secretion varies between plants, time of day and is even influenced by age of flowers (Pacini and Nepi, 2007). Nectar volume varies enormously between species; from less than a microlitre to thousands of microlitres (Pacini et al., 2003). Similarly there is an extreme variation in nectar sugar concentration of plants (between and within species); from 7-70\%. An example for between species variation is the low sugar concentration of less than $10 \%$ in $A / o e$

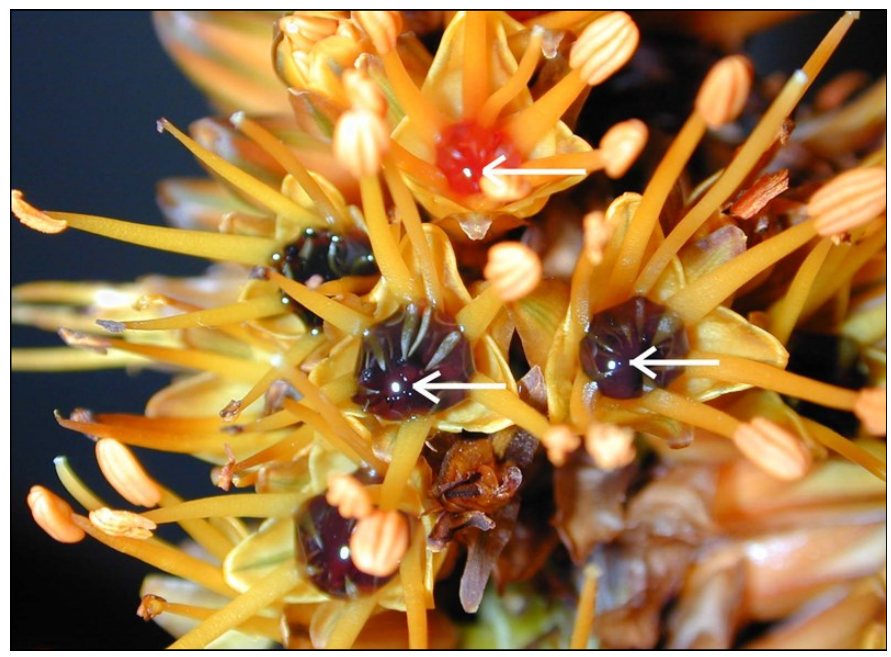

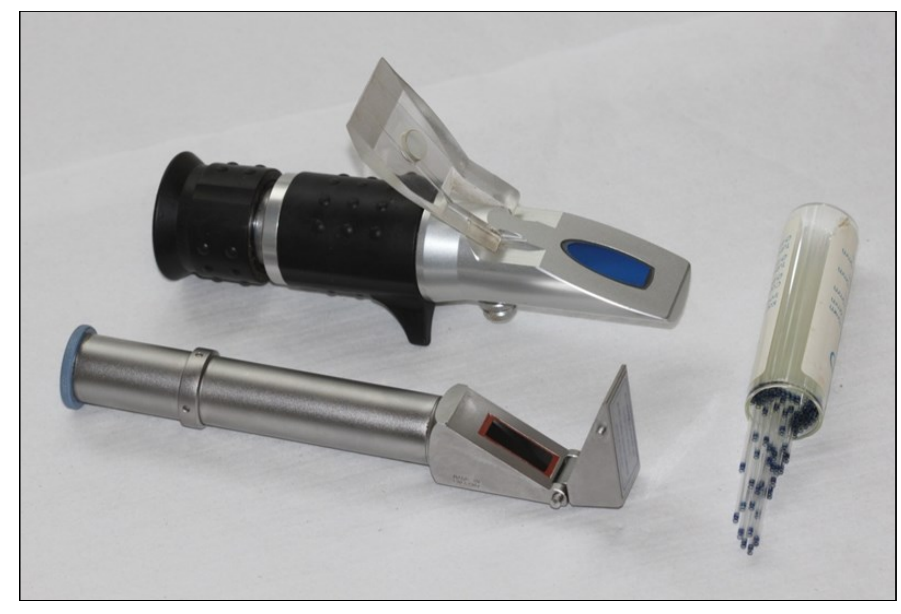

Fig. 35. Calibrated micropipettes/ micro-capillary tubes and refractometers used for measurements of nectar concentration

Photo: A Switala.

castanea (Aasphodelaceae) (Nicolson and Nepi, 2005, Fig 34) and an average of $66.5 \%$ in Carum carvi (Apiaceae) (Langenberger and Davis, 2002). It is generally known that the plants producing more concentrated nectar are the ones being visited and pollinated by insects, including bees (Pyke and Waser, 1981; Baker and Baker, 1982).

The method used for nectar collection will be determined by the intended use as well as by flower size, volume and concentration of nectar. Calibrated micropipettes/ micro-capillary tubes (1-20 $\mu$ l) (Fig. 35) are commonly used to extract nectar with volumes $>0.5 \mu$ and concentrations lower than 70\%. Calibrated syringes (Hamilton microsyringes) and filtered paper wicks are other methods for nectar collection (see Kearns and Inouye, 1993) for more detailed descriptions of the various techniques). We here described those most commonly used for collection from honey bees (section 4.7.3.1.) and from flowers (see section 4.7.3.2.). Refractometers (Fig. 35) are normally used for the measurement of sugar concentration (\% weight/ weight). In the case of very small amounts of nectar alternative methods are required (Kearns and Inoye, 1993; Dafni et al., 2005). There are various techniques for measurements of nectar volume and concentration is discussed by Dafni (1992) and Kearns and Inoye (1993) and the more common methods used in honey bee research will be discussed here. 


\subsubsection{Collecting nectar from honey bees}

Honey bee foragers collect nectar from flowers. This nectar is stored in their impermeable crops for transfer back to their hives. The crop can greatly expand for storage and it has been shown that workers can carry crop loads close to their own body mass (Nicolson, 2008). By inducing bees to regurgitate, full nectar loads can be collected (Roubik and Buchman, 1984; Roubik et al., 1995; Nicolson and Human, 2008; see the BEEBOOK paper on methods for behavioural studies (Scheiner et al., 2013) for the latter method).

1. Capture honey bees visiting flowers on the plant of interest or at the entrance of hives on their way back from nectar gathering.

2. Compress the thorax of individual bees gently dorsoventrally to obtain nectar to induce regurgitation of the content of the honey stomach (Roubik and Buchman, 1984). This should be done within $10 \mathrm{~min}$ of capture, to prevent the honey bee using her stomach load as fuel.

3. Collect the liquid nectar from the mouthparts in micro capillary tubes through capillary action.

4. Measure nectar volume.

Volumes $(\mu \mathrm{l})$ are determined from the column length in microcapillary tubes (length $75 \mathrm{~mm} / 75 \mathrm{ml}$ ).

5. Measure nectar concentration with a pocket refractometer (e.g. Bellingham and Stanley Ltd, Tunbridge Wells, UK) by placing a drop of nectar onto the prismatic surface of the refractometer (through capillary action). Concentration is measured as $\% \mathrm{w} / \mathrm{w}$ sucrose equivalents.

Pros:

- Bees are not killed.

- Non-invasive method as far as the hive is concerned.

Cons:

- Honey stomachs may contain nectar from the hive used as fuel for flight, which could dilute the nectar collected (Roubik and Buchmann, 1984; Nicolson and Human, 2008).

- It has been shown that nectar concentration can be changed during flight back to the hive (Nicolson and Human, 2008).

\subsubsection{Nectar collection from flowers}

It is necessary to prevent insect visitation to flowers before measuring their nectar production/ secretion since consumption by insects will reduce the volume available. Nectar is collected from flowers in disposable micro capillary/ hematocrit tubes (length $75 \mathrm{~mm}$, capacity $75 \mu l)$ through capillary action (e.g. Human and Nicolson, 2008; see references therein) (Fig. 36). It is standard procedure to measure both volume and concentration of nectar (the minimal information required) in any nectar/ foraging studies since this information is crucial.

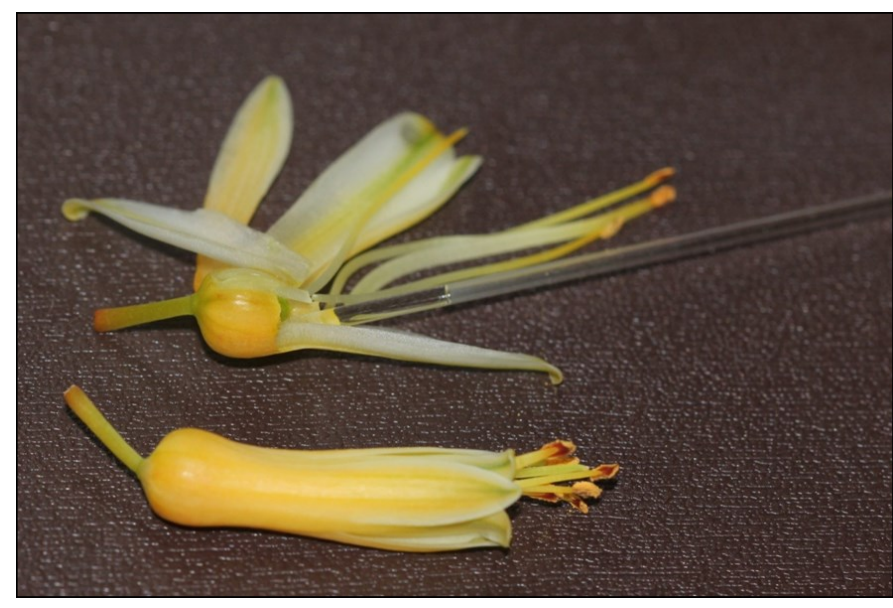

Fig. 36. Collection of nectar from (Aloe zebrina) through capillary action into micro-capillary tubes. The clear nectar is visible in the lower part of the tube.

Photo: A Switala.

1. Cover flowers to be examined with gauze ( $2 \mathrm{~mm}$ mesh size) to exclude visitation of any pollinators.

2. Remove flower petals gently to reveal nectar at the base of the flowers.

3. Withdraw/ collect the nectar from the flower in disposable micro-capillary tubes (length $75 \mathrm{~mm}$, capacity $75 \mu \mathrm{l}$ ) by capillary attraction.

4. Determine volumes of nectar from column length in the micro -capillary tubes ( $75 \mathrm{~mm}$ is equivalent to $75 \mu \mathrm{l}$ ).

5. Release the nectar onto the prismatic surface of a pocket refractometer.

6. Measure the nectar concentration as percent (w/w) sucrose equivalents.

7. Depending on the purpose of nectar collection, samples should either be used immediately in the field or transported to the lab on either dry ice or on filter paper (Whatman no 1) (Dafni et al., 2005) after which it should be stored in $15 \mathrm{ml}$ centrifuge tubes at $-20^{\circ} \mathrm{C}$ until ready for composition or residue analysis.

Pros: This is a cheap and easy way of nectar collection.

Cons: These methods are very tedious because of the small quantities of nectar that may be available per flower, and thus several hundred flowers may need to be extracted to collect the required quantities for analysis.

\subsubsection{Precautions when sampling pollen and nectar for residue analyses}

Pesticide residue levels in pollen and nectar are generally detected in the range of parts per billion (ppb). These extremely low traces of residues can easily occur due to cross-contamination. Therefore, it is essential that all steps in sample collection and processing, be optimised 
and quality assurance measures be deployed (e.g., use separate tools for each treatment sample, change disposable gloves between samples, etc.).

To quantify pesticide residues at the lowest level of detection, most analytical laboratories require samples of $3 \mathrm{~g}$ of pollen or $1.5 \mathrm{ml}$ of nectar, so different male flowers (usually $40-50$ for pumpkin) may need to be extracted over the flowering period to collect the required quantities for analysis. In this case, detected residues in nectar and pollen represent the cumulative average level during the entire collection period. For more information on toxicology, see the relevant BEEBOOK paper by Medrzycki et al. (2013).

\subsubsection{Collection of fresh pollen from flowers}

\subsection{Using paper bags to collect fresh pollen}

Pollen collection with wax coated paper bags can be used for crops such as maize and pumpkin (Fig. 37).

1. Place wax-coated paper bags over maize tassels just prior to anthesis (the time when a flower is fully open and functional, timing of anthesis require observations beforehand) to prevent pollinator visits. The same method can be followed for pumpkins (Stoner and Eitzer, 2012) (Fig. 38).

2. Twist the bag's opening around the stem of the flower, for securing it to the plant.

It is not necessary to seal tightly.

3. Remove bags from maize plants after one or two days. In the case of pumpkins, bags should be removed the next day when nectar production peaks, because nectar may contaminate the pollen.

4. Clean collected pollen by using sieves (pore sizes 0.119 and $0.0043 \mathrm{~cm}$ ) to remove anthers, insects, and other debris (Fig. 39).

5. Store collected pollen at $-20^{\circ} \mathrm{C}$ until ready for further testing.

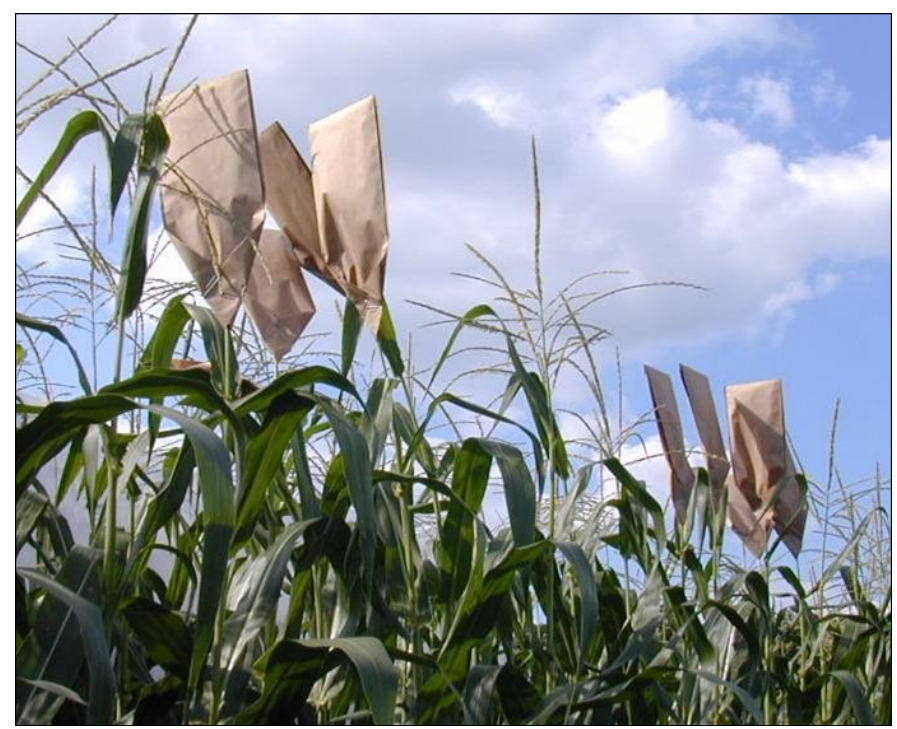

Fig. 37. Pollen collection with wax coated paper bags can be used for maize.

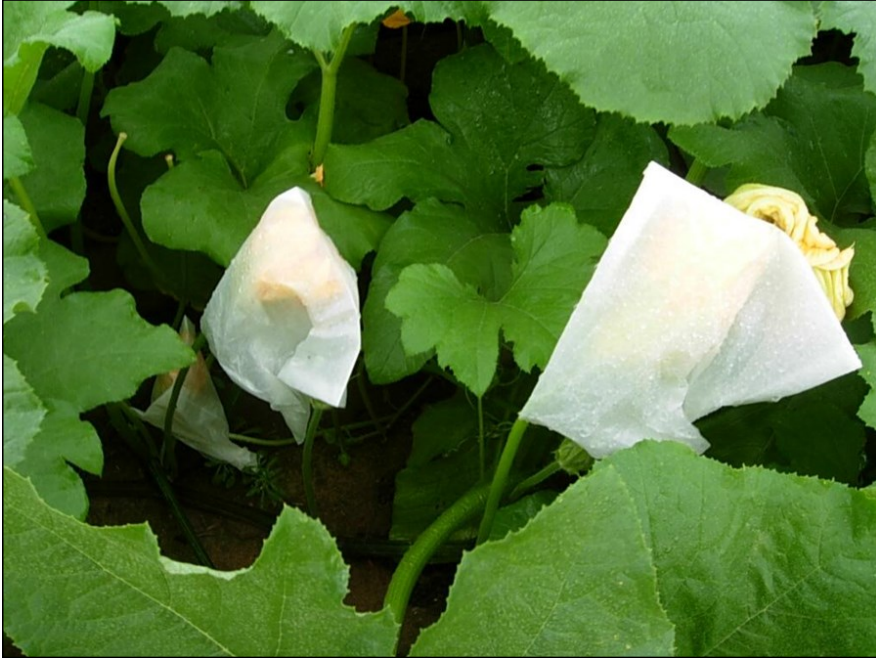

Fig. 38. Pumpkin flowers covered with bags.

Photo: G Dively.

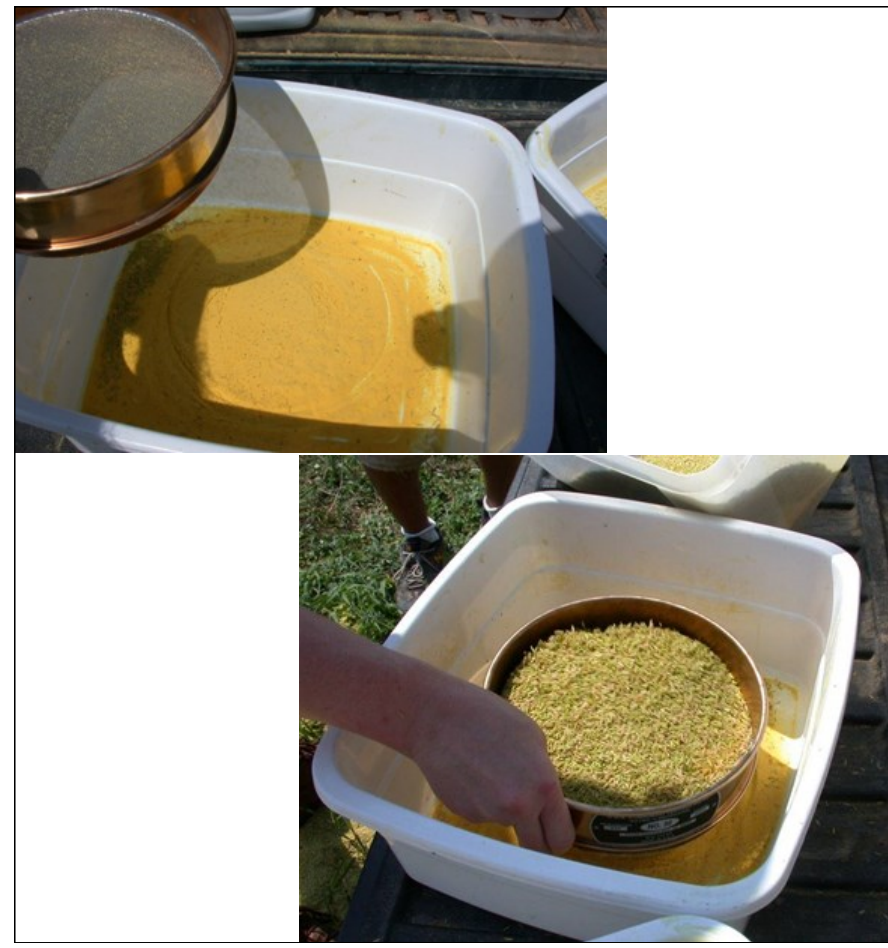

Fig. 39. Cleaning of pollen with sieves.

Photos: G Dively.

\subsection{Manual collection of fresh pollen}

Fresh pollen can also be collected from e.g. maize by literally shaking the tassels.

1. Shake maize tassels over large plastic trays at peak anthesis (when pollen shedding is at the highest, normally between $09.00 \mathrm{~h}$ and $10.00 \mathrm{~h}$ on field of sweet corn).

Collect early morning after the dew dries, but before pollen shedding is complete.

2. Transfer fallen pollen into containers.

3. Clean collected pollen by using sieves (pore sizes 0.119 and $0.0043 \mathrm{~cm}$ ) to remove anthers, insects, and other debris (Fig. 39).

4. Store collected pollen at $-20^{\circ} \mathrm{C}$ until ready for further testing. 


\subsection{Using a paint brush for collection of fresh pollen}

In the case of flowers where pollen is accessible from the outside of flowers e.g. sunflowers and aloes, one can also use a paint brush (Fig. 40; Human and Nicolson, 2006; Nicolson and Human, 2008).

1. Pick flowers.

2. Keep the flowers in containers in the laboratory at room temperature.

3. Use a paint brush to gently brush of pollen from the anthers into a container.

4. Continue collecting pollen this way on a daily basis until pollen shedding is complete.

5. Clean collected pollen using sieves (pore sizes 0.119 and $0.0043 \mathrm{~cm}$ ) to remove anthers, insects, and other debris.

6. Store collected pollen at $-20^{\circ} \mathrm{C}$ until ready for further testing.

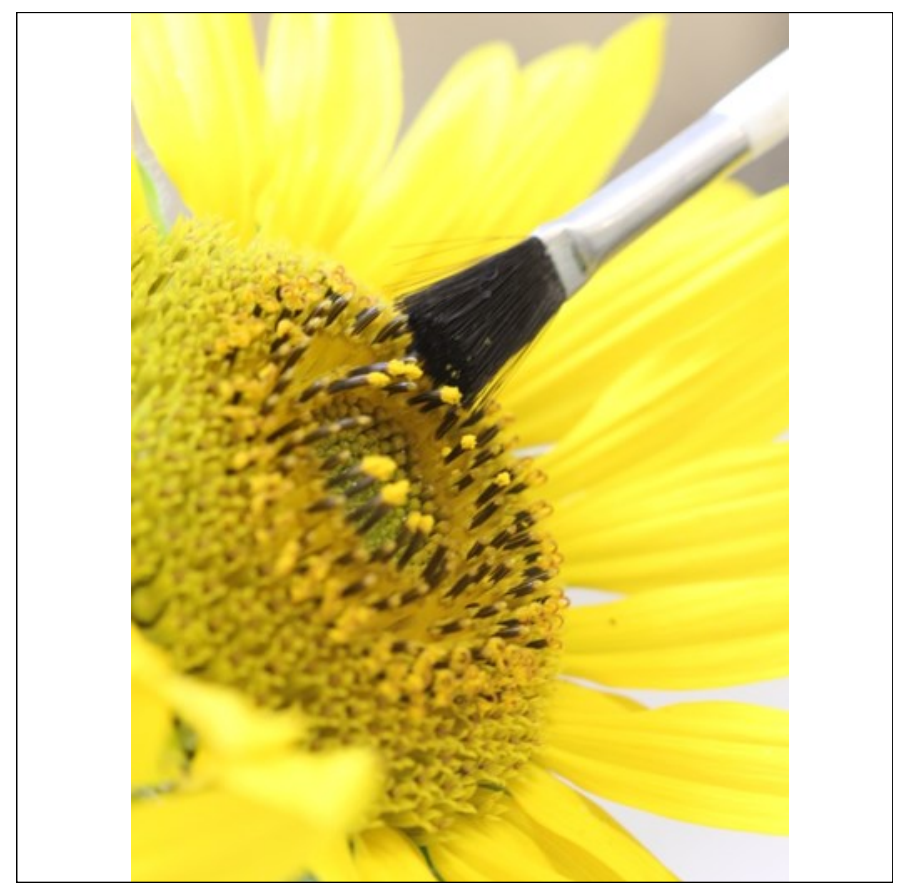

Fig. 40. Using a paint brush to collect pollen.

Photo: A Switala.

\subsection{Collection of fresh pollen from smaller flowers such as canola}

1. Collect flower clusters in the early morning when plants are 40 $-50 \%$ flowering.

2. Place the clusters into containers.

3. Allow the clusters to dry at a processing location.

4. Brush flowers over food strainers to separate pollen from anthers.

5. Clean samples of pollen by sifting through multiple sieves of different pore sizes (pore sizes 0.119 and $0.0043 \mathrm{~cm}$ ).

6. Store collected pollen at $-20^{\circ} \mathrm{C}$ until ready for further testing.
Pros:

- Above mentioned methods allow for the relatively easy collection of a large amount of pollen.

- Allow for the collection of pollen of single and known plant origin.

Cons:

- Methods such as the paint brush collection method is very time consuming and requires a large number of flowers (up to 30,000 in the case of aloes, see Human and Nicolson, 2006) to enable one to collect enough pollen.

- Sieving samples of pollen to clean all debris from collected pollen is time consuming.

- Working with large amounts of fresh pollen can be detrimental to health and increase allergies.

\subsubsection{Collection of bee collected pollen using pollen traps}

A common method of pollen collection is the use of a trapping device placed at the entrance of hives. A variety of specific types of "pollen traps" are commercially available, all designed to force returning foragers entering the hive to crawl through small openings/ a grid

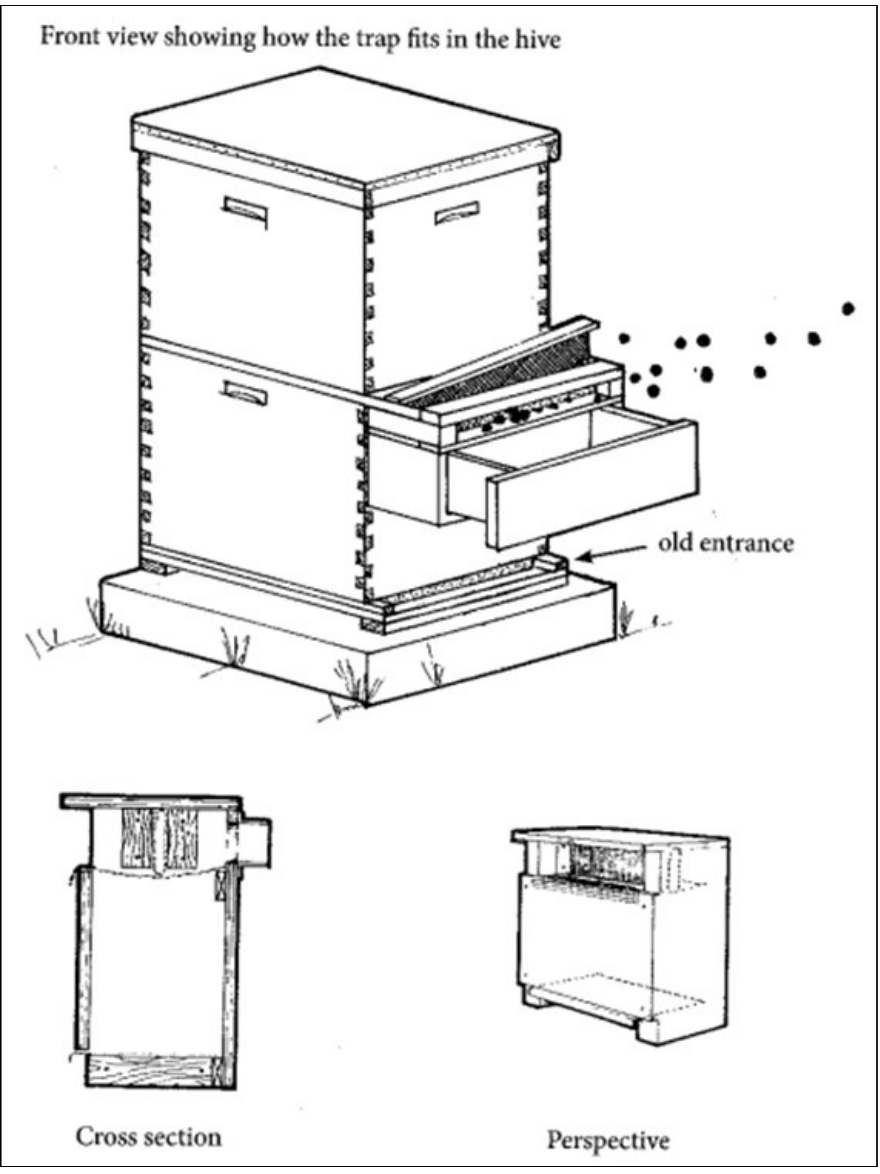

Fig. 41. Example of an Auger-Hole pollen trap with a front and cross sectional view. Source: E R Harp from Sammataro and Avitabile, 2011. 
(size of openings depends on the race of bees; African bees are known to be smaller than European races of bees (Johannsmeier, 2001)), which dislodge pollen pellets from their hind legs (see Fig. 41). The pellets then fall into a collection tray. Trap design varies in the size of the openings, installation location on the hive, and mechanism for accessing the collection tray to remove pollen. An effective pollen trap is easy to use, tightly fits the hive box, and can collect at least $60 \%$ of the foraged pollen pellets brought to the hive with minimum disturbance and climatic exposure to the colony and trapped pollen. Refer to the to the 'Pollen trapping' section of the BEEBOOK paper on pollination (Delaplane et al., 2013) for a method to measure trapping efficiency and how to use pollen traps.

\subsubsection{Ensuring quality of bee collected pollen}

Pollen traps are used in studies to measure foraging activity, identify pollen sources, analyse pollen for toxic residues, and to collect pollen for feeding studies. Dependent upon the intended use, steps should be taken to ensure the quality of trapped pollen. A heap of moist pollen is an ideal breeding place for small hive beetles (where they occur, see also the BEEBOOK paper on small hive beetle, Neumann et al., 2013) and wax moths (see the BEEBOOK paper on wax moths, Ellis et al., 2013) and is very attractive to ants (Johannsmeier, 2001). Pollen quickly degrades and will start to become mouldy if it gets wet. Pollen should therefore be collected every day, cleaned of larger debris either by hand or by sieving through different sized sieves (see section 4.7.2.1.3., step 5) and be stored immediately as a frozen or dried sample to maintain quality. This is essential for samples collected for pesticide residue analysis, which should be stored on ice in coolers in the field and then frozen immediately to $-20^{\circ} \mathrm{C}$ to prevent pesticide degradation until samples are processed.

Pros:

- Pollen traps are a less invasive technique of collecting bee collected pollen.

- Easy to collect a large quantity of pollen.

- Pollen from certain plants is more suitable for collection because of their abundance and high yield.

- Pollen pellets are usually of single plant origin, but may occasionally be a combination from different species.

Cons:

- Nutritional composition of pollen pellets may already be modified due to addition of nectar and glandular secretions added by bees.

- Pollen traps may reduce water and nectar collection because the congestion at the hive entrance slows the movement of foragers, which could stress the colony.

- Weaker colonies may be more stressed by pollen traps than strong colonies in an experiment, resulting in a confounding factor.
- If traps are left too long on hives there may be a reduction in brood rearing and honey production.

\section{Acknowledgements}

The COLOSS (Prevention of honey bee COlony LOSSes) network aims to explain and prevent massive honey bee colony losses. It was funded through the COST Action FA0803. COST (European Cooperation in Science and Technology) is a unique means for European researchers to jointly develop their own ideas and new initiatives across all scientific disciplines through trans-European networking of nationally funded research activities. Based on a panEuropean intergovernmental framework for cooperation in science and technology, COST has contributed since its creation more than 40 years ago to closing the gap between science, policy makers and society throughout Europe and beyond. COST is supported by the EU Seventh Framework Programme for research, technological development and demonstration activities (Official Journal L 412, 30 December 2006). The European Science Foundation as implementing agent of COST provides the COST Office through an EC Grant Agreement. The Council of the European Union provides the COST Secretariat. The COLOSS network is now supported by the Ricola Foundation - Nature \& Culture.

\section{References}

AASE, A L T O; AMDAM, G V; HAGEN, A; OMHOLT, S W (2005) A new method for rearing genetically manipulated honey bee workers. Apidologie 36: 293-299. http://dx.doi.org/10.1051/apido:2005003 ACCORTI, M; LUTU, F; TARDUCCI, F (1991) Methods for collecting data on natural mortality in bee. Ethology, Ecology and Evolution 1: 123-126.

ALAUX, C; DUCLOZ, F; CRAUSER, D; LE CONTE, Y (2010) Diet effects on honey bee immunocompetence. Biology Letters 6: 562-565. http://dx.doi.org/10.1098/rsbl.2009.0986

ALLEN, M D (1959) Respiration rates of worker honey bees of different ages and at different temperatures. Journal of Experimental Biology 36: 92-101.

ALLSOPP, M (2006) Analysis of Varroa destructor infestation of Southern African honey bee populations. Dissertation, University of Pretoria, South Africa. 285 pp.

AMDAM, G V; NORBERG, K; PAGE, R E; ERBER, J; SCHEINER, R (2006) Downregulation of vitellogenin gene activity increases the gustatory responsiveness of honey bee workers (Apis mellifera). Behavioural Brain Research 169: 201-205.

http://dx.doi.org/10.1016/j.bbr.2006.01.006 
ANTÚNEZ, K; MARTIN-HERNANDEZ, R; PRIETO, L; MEANA, A; ZUNINO, $\mathrm{P} ;$ HIGES, M (2009) Immune suppression in the honey bee (Apis mellifera) following infection by Nosema ceranae (Microsporidia). Environmental Microbiology 11(9): 2284-2290.

http://dx.doi.org/10.1111/j.1462-2920.2009.01953.x

ARUNDEL, J; OLDROYD, B P; WINTER, S (2012) Modelling honey bee queen mating as a measure of feral colony density. Ecological Modelling 247: 48-57.

http://dx.doi.org/10.1016/j.ecolmodel.2012.08.001

ATKINS, E L; TODD, F E; ANDERSON, L D (1970) Honey bee field research aided by Todd dead bee hive entrance trap. California Agriculture 24(10): 12-13.

AUSTIN, G H (1955) Effect of carbon dioxide anaesthesia on bee behaviour and expectation of life. Bee World 36(3): 45-47.

BAER, B; EUBEL, H; TAYLOR, N L; O'TOOLE, N; MILLAR, A H (2009) Insights into female sperm storage from the spermathecal fluid proteome of the honey bee Apis mellifera. Genome Biology 10(6): R67. http://dx.doi.org/10.1186/gb-2009-10-6-r67

BAKER, H G; BAKER, I (1982) Chemical constituents of nectar in relation to pollination mechanisms and phylogeny. In $M H$ Nitecki (Ed.). Biochemical aspects of evolutionary biology. University of Chicago Press, Chicago, USA. pp 131-171.

BARRON, A B; MALESZKA, J; MEER, R K V; ROBINSON, G E; MALESZKA, $R$ (2007) Comparing injection, feeding and topical application methods for treatment of honey bees with octopamine. Journal of Insect Physiology 53: 187-194.

BAUDRY, E; SOLIGNAC, M; GARNERY, L; GRIES, M; CORNEUT, J-M; KOENIGER, N (1998) Relatedness among honey bees (Apis mellifera) of a drone congregation. Proceedings of the Royal Society of London B265: 2009-2014.

BAUM, K A; RUBINK, W L; PINTO, M A; COULSON, R N (2005) Spatial and temporal distribution and nest site characteristics of feral honey bee (Hymenoptera: Apidae) colonies in a coastal prairie landscape. Environmental Entomology 34: 610-618.

http://dx.doi.org/10.1603/0046-225X-34.3.610

BENDAHOU, N; BOUNIAS, M; FLECHE, C (1999) Toxicity of cypermethrin and fenitrothion on the haemolymph carbohydrates, head acetylcholinesterase, and thoracic muscle $\mathrm{Na}^{+}, \mathrm{K}^{+}$-ATPase of emerging honey bees (Apis mellifera mellifera. L). Ecotoxicology and Environmental Safety 44: 139-146. http://dx.doi.org/10.1006/eesa.1999.1811

BERTHOLF, L M (1925) The moults of the honey bee. Journal of Economic Entomology 18: 380-384.

BEYE, M; HÄRTEL, S; HAGEN, A; HASSELMANN, M; OMHOLT, S W (2002) Specific developmental gene silencing in the honey bee using a homeobox motif. Insect Molecular Biology 11: 527-532. http://dx.doi.org/10.1046/j.1365-2583.2002.00361.x

BRODSCHNEIDER, R; RIESSBERGER-GALLÉ, U; CRAILSHEIM, K (2009)

Flight performance of artificially reared honey bees (Apis mellifera). Apidologie 40: 441-449. http://dx.doi.org/10.1051/apido/2009006
BÜCHLER, R; ANDONOV, S; BIENEFELD, K; COSTA, C; HATJINA, F; KEZIC, N; KRYGER, P; SPIVAK, M; UZUNOV, A; WILDE, J (2013) Standard methods for rearing and selection of Apis mellifera queens. In V Dietemann; J D Ellis; P Neumann (Eds) The COLOSS BEEBOOK, Volume I: standard methods for Apis mellifera research. Journal of Apicultural Research 52(1): http://dx.doi.org/10.3896/IBRA.1.52.1.07

BUCHMANN, S L; THOENES, S C (1990) The electronic scale: honey bee colony as a management and research tool. Bee Science 1: 40-47.

CANTWELL, G E (1970) Standard methods for counting nosema spores. American Bee Journal 110(6): 222-223.

CHÂLINE, N; RATNIEKS, F L W; RAINE, N E; BADCOCK, N S; BURKE, T (2004) Non-lethal sampling of honey bee, Apis mellifera, DNA using wing tips. Apidologie 35(3): 311-318. http://dx.doi.org/10.1051/apido:2004015

CHEN, Y P; EVANS, J; HAMILTON, M; FELDLAUFER, M (2007) The influence of RNA integrity on the detection of honey bee viruses: molecular assessment of different sample storage methods. Journal of Apicultural Research 46(2): 81-87. http://dx.doi.org/10.3896/IBRA.1.46.2.03

CHEN, Y P; PETTIS, J S; COLLINS, A; FELDLAUFER, M F (2006) Prevalence and transmission of honey bee viruses. Applied and Environmental Microbiology 72(1): 606-611. http://dx.doi.org/10.1128/AEM.72.1.606-611.2006

CHUDA-MICKIEWICZ, B; CZEKOÑSKA, K; SAMBORSKI, J; ROSTECKI, P (2012) Success rates for instrumental insemination of carbon dioxide and nitrogen anaesethetised honey bee (Apis mellifera) queens. Journal of Apicultural Research 51(1): 74-77. http://dx.doi.org/10.3896/IBRA.1.51.1.09

COBEY, S W; TARPY, D R; WOYKE, J (2013) Standard methods for instrumental insemination of Apis mellifera queens. In V Dietemann; J D Ellis; P Neumann (Eds) The COLOSS BEEBOOK, Volume I: standard methods for Apis mellifera research. Journal of Apicultural Research 52(4): http://dx.doi.org/10.3896/IBRA.1.52.4.09

COLES, J A; ORKHAND, R K (1983) Modification of potassium movement through the retina of the drone (Apis mellifera) by glial uptake. Journal of Physiology 340(1): 157-174.

CRAILSHEIM, K (1992) The flow of jelly within a honey bee colony. Journal of Comparative Physiology B162: 681-689. http://dx.doi.org/10.1007/BF00301617

CRANE, E (1999) The world history of beekeeping and honey hunting. Duckworth; London, USA. 720 pp.

CZEKONSKA, K (2007) Influence of carbon dioxide on Nosema apis infection of honey bees (Apis mellifera). Journal of Invertebrate Pathology 95(2): 84-86. http://dx.doi.org/10.1016/j.jip.2007.02.001 DADE, H A (2009) Anatomy and dissection of the honey bee. International Bee Research Association; Cardiff, UK. 196 pp. DAFNI, A (1992) Pollination ecology: a practical approach. Oxford University Press; Oxford, UK. 250 pp. 
DAFNI, A; KEVAN, P G; HUSBAND, B C (2005) Practical pollination biology. Enviroquest Ltd; Cambridge, Ontario, Canada. 583 pp. DAINAT, B; EVANS, J D; CHEN, Y P; NEUMANN, P (2011) Sampling RNA quality for diagnosis of honey bee viruses using quantitative PCR. Journal of Virological Methods 174(1-2): 150-152. http://dx.doi.org/10.1016/j.jviromet.2011.03.029

DE GRAAF, D C; ALIPPI, A M; ANTÚNEZ, K; ARONSTEIN, K A; BUDGE, G; DE KOKER, D; DE SMET, L; DINGMAN, D W; EVANS, J D; FOSTER, L J; FÜNFHAUS, A; GARCIA-GONZALEZ, E; GREGORC, A; HUMAN, H; MURRAY, K D; NGUYEN, B K; POPPINGA, L; SPIVAK, M; VANENGELSDORP, D; WILKINS, S; GENERSCH, E (2013) Standard methods for American foulbrood research. In $V$ Dietemann; $J D$ Ellis; P Neumann (Eds) The COLOSS BEEBOOK, Volume II: standard methods for Apis mellifera pest and pathogen research. Journal of Apicultural Research 52(1): http://dx.doi.org/10.3896/IBRA.1.52.1.11

DEGRANDI-HOFFMAN, G; CHEN, Y P; HUANG, E; HUANG, M H (2010) The effect of diet on protein concentration, hypopharyngeal gland development and virus load in worker honey bees (Apis mellifera L.). Journal of Insect Physiology 56: 1184-1191. http://dx.doi.org/10.1016/j.jinsphys.2010.03.017

DELAPLANE, K S; VAN DER STEEN, J; GUZMAN, E (2013) Standard methods for estimating strength parameters of Apis mellifera colonies. In V Dietemann; J D Ellis; P Neumann (Eds) The COLOSS BEEBOOK, Volume I: standard methods for Apis mellifera research. Journal of Apicultural Research 52(1): http://dx.doi.org/10.3896/IBRA.1.52.1.03

DE MIRANDA, J R; BAILEY, L; BALL, B V; BLANCHARD, P; BUDGE, G; CHEJANOVSKY, N; CHEN, Y-P; GAUTHIER, L; GENERSCH, E; DE GRAAF, D; RIBIÈRE, M; RYABOV, E; DE SMET, L VAN DER STEEN, J J M (2013) Standard methods for virus research in Apis mellifera. In V Dietemann; J D Ellis; P Neumann (Eds) The COLOSS BEEBOOK, Volume II: standard methods for Apis mellifera pest and pathogen research. Journal of Apicultural Research 52(4): http://dx.doi.org/10.3896/IBRA.1.52.4.22

DIETEMANN, V; ZHENG, H-Q; HEPBURN, C; HEPBURN, H R; JIN, S H; CREWE, R M; RADLOFF, S E; HU, F-L; PIRK, C W W (2008) Selfassessment in insects: honey bee queens know their own strength. PLOS ONE3(1): e1412. http://dx.doi.org/10.1371/journal.pone.0001412 DIVELY, G P; KAMEL, A (2012) Insecticide residues in pollen and nectar of a cucurbit crop and their potential exposure to pollinators. Journal of Agricultural and Food Chemistry 60: 4449-4456. http://dx.doi.org/10.1021/jf205393x

DUAY, P; DE JONG, D; ENGELS, W (2003) Weight loss in drone pupae (Apis mellifera) multiply infested by Varroa destructor mites. Apidologie 34: 61-65. http://dx.doi.org/10.1051/apido:2002052 EBADI, R; GARY, N E; LORENZEN, K (1980) Effects of carbon dioxide and low temperature narcosis on honey bees, Apis mellifera. Environmental Entomology 9(1): 144-147.
EDGELL, G H (1949) The bee hunter. Harvard University Press; Cambridge, MA, USA.

ELLIS, J D; GRAHAM, J R; MORTENSEN, A (2013) Standard methods for wax moth research. In $V$ Dietemann; $J$ D Ellis; $P$ Neumann (Eds) The COLOSS BEEBOOK, Volume II: standard methods for Apis mellifera pest and pathogen research. Journal of Apicultural Research 52(1): http://dx.doi.org/10.3896/IBRA.1.52.1.10

ERBER, J (1975) The dynamics of learning in the honey bee (Apis mellifica carnica). Journal of Comparative Physiology 99(3): 231242.

EVANS, J D; SCHWARZ, R S; CHEN, Y P; BUDGE, G; CORNMAN, R S; DE LA RUA, P; DE MIRANDA, J R; FORET, S; FOSTER, L; GAUTHIER, L; GENERSCH, E; GISDER, S; JAROSCH, A; KUCHARSKI, R; LOPEZ, D; LUN, C M; MORITZ, R F A; MALESZKA, R; MUÑOZ, I; PINTO, M A (2013) Standard methodologies for molecular research in Apis mellifera. In V Dietemann; J D Ellis; P Neumann (Eds) The COLOSS BEEBOOK, Volume I: standard methods for Apis mellifera research. Journal of Apicultural Research 52(4): http://dx.doi.org/10.3896/IBRA.1.52.4.11

FAROOQUI, T; ROBINSON, K; VAESSIN, H; SMITH, B H (2003) Modulation of early olfactory processing by an octopaminergic reinforcement pathway in the honey bee. The Journal of Neuroscience 23(12): 5370-5380.

FENOY, S; RUEDA, C; HIGES, M; MARTÍN-HERNÁNDEZ, R; DEL AGUILA, C (2009) High-level resistance of Nosema ceranae, a parasite of the honey bee, to temperature and desiccation. Applied and Environmental Microbiology 75(21): 6886-6889. http://dx.doi.org/10.1128/AEM.01025-09

FLETCHER, D J C (1978) The African bee, Apis mellifera adansonii, in Africa. Annual Review of Entomology 23: 151-171.

FORSGREN, E; FRIES, I (2010) Comparative virulence of Nosema ceranae and Nosema apis in individual European honey bees. Veterinary Parasitology 170(3-4): 212-217. http://dx.doi.org/10.1016/j.vetpar.2010.02.010

FORSGREN, E; BUDGE, G E; CHARRIÈRE, J-D; HORNITZKY, M A Z (2013) Standard methods for European foulbrood research. In V Dietemann; J D Ellis; P Neumann (Eds) The COLOSS BEEBOOK, Volume II: Standard methods for Apis mellifera pest and pathogen research. Journal of Apicultural Research 52(1): http://dx.doi.org/10.3896/IBRA.1.52.1.12

FRIES, I; CHAUZAT, M-P; CHEN, Y-P; DOUBLET, V; GENERSCH, E; GISDER, S; HIGES, M; MCMAHON, D P; MARTÍN-HERNÁNDEZ, R; NATSOPOULOU, M; PAXTON, R J; TANNER, G; WEBSTER, T C; WILLIAMS, G R (2013) Standard methods for nosema research. In $V$ Dietemann; J D Ellis; P Neumann (Eds) The COLOSS BEEBOOK, Volume II: Standard methods for Apis mellifera pest and pathogen research. Journal of Apicultural Research 52(1): http://dx.doi.org/10.3896/IBRA.1.52.1.14 
FROST, E H; SHUTLER, D; HILLIER, N K (2011) Effects of cold immobilization and recovery period on honey bee learning, memory, and responsiveness to sucrose. Journal of Insect Physiology 57(10): 1385-1390. http://dx.doi.org/10.1016/j.jinsphys.2011.07.001

GARY, N E (1960) A trap to quantitatively recover dead and abnormal honey bees from the hive. Journal of Economic Entomology 53(5): 782-785.

GLADSTONE, H C; GOWEN, I; GOWEN, J W (1964) Gamete-backcross matings in the honey bee. Genetics 50(6): 1443-1446.

HAGLER, J R; JACKSON, C G (2001) Methods for marking insects: current techniques and future prospects. Annual Review of Entomology 46: 511-543.

http://dx.doi.org/10.1146/annurev.ento.46.1.511

HEFNER, E; HSIUNG, F; MCCOLLUM, T; RUBIO, T (2010) Comparison of count reproducibility, accuracy and time to results between a haemocytometer and the $\mathrm{TC} 10^{\mathrm{TM}}$ automated cell counter. Cell counting. Tech note 6003, Bio-Rad Laboratories; USA.

HEINRICH, B (1979) Thermoregulation of African and European honey bees during foraging, attack, and hive exits and returns. Journal of Experimental Biology 80: 217-229.

HENDERSON, C E (1992) Variability in the size of emerging drones and of drone and worker eggs in honey bee (Apis mellifera L.) colonies. Journal of Apicultural Research 31: 119-123.

HENDRIKSMA, H P; HÄRTEL, S (2010) A simple trap to measure worker bee mortality in small test colonies. Journal of Apicultural Research 49(2): 215-217. http://dx.doi.org/10.3896/IBRA.1.49.2.13

HERBERT, E W; SHIMANUKI, H (1978) Chemical composition and nutritive value of bee-collected and bee-stored pollen. Apidologie 9: 33-40. http://dx.doi.org/10.1051/apido:19780103

HERBERT, E W; SHIMANUKI, H; ARGAUER, R J (1983) Effect of feeding pollen substitutes to colonies of honey bees (Hymenoptera: Apidae) exposed to carbaryl. Environmental Entomology 12: 758-762.

HRASSNIGG, N; CRAILSHEIM, K (1998) Adaptation of hypopharyngeal gland development to the brood status of honey bee (Apis mellifera L.) colonies. Journal of Insect Physiology 44: 929-939. http://dx.doi.org/10.1016/S0022-1910(98)00058-4

HRASSNIGG, N; CRAILSHEIM, K (2005) Differences in drone and worker physiology in honey bees (Apis mellifera L.). Apidologie 36: 255-277. http://dx.doi.org/10.1051/apido:2005015

HUMAN, H; NICOLSON, S W (2008) Flower structure and nectar availability in Aloe greatheadii var. davyana: an evaluation of a winter nectar source for honey bees. International Journal of Plant Sciences 169: 263-269. http://dx.doi.org/10.1086/524113

HUMAN, H; NICOLSON, S W (2006) Nutritional content of fresh, beecollected and stored pollen of Aloe greatheadii var. davyana (Asphodelaceae). Phytochemistry 67: 1486-1492. http://dx.doi.org/10.1016/j.phytochem.2006.05.023
HUMAN, H; NICOLSON, S W; STRAUSS, K; PIRK, C W W; DIETEMANN, $\mathrm{V}$ (2007) Influence of pollen quality on ovarian development in honey bee workers (Apis mellifera scutellata). Journal of Insect Physiology 53(7): 649-655.

http://dx.doi.org/10.1016/j.jinsphys.2007.04.002

ILLIES, I; MÜHLEN, W; DÜCKER, G; SACHSER, N (1999) A study of undertaking behaviour of honey bees (Apis mellifera L.) by use of different bee traps. In $L P$ Belzunces; $C$ Pélissier; $G B$ Lewis (Eds). Hazards of pesticides to bees. Avignon, France, 7-9 September. pp 237-244.

ILLIES, I; MÜHLEN, W; DÜCKER, G; SACHSER, N (2002) The influence of different bee traps on undertaking behaviour of the honey bee and development of a new trap. Apidologie 33: 315-326. http://dx.doi.org/10.1051/apido:2002014

JACKSON, D E; HART, A G (2009) Does sanitation facilitate sociality? Animal Behaviour 77: e1-e5.

http://dx.doi.org/10.1016/j.anbehav.2008.09.013

JAFFÉ, R; DIETEMANN, V; ALLSOPP, M H; COSTA, C; CREWE, R M; DALL'OLIO, R; DE LA RÚA, P; EL-NIWEIRI, M A A; FRIES, I; KEZIC, N; MEUSEL, M; PAXTON, R J; SHAIBI, T; STOLLE, E; MORITZ, R F A (2009a) Estimating the density of honey bee colonies across their natural range to fill the gap in pollinator decline censuses. Conservation Biology 24: 583-593.

http://dx.doi.org/10.1111/j.1523-1739.2009.01331.x

JAFFÉ, R; DIETEMANN, V; CREWE, R M; MORITZ, R F A (2009b) Temporal variation in the genetic structure of a drone congregation area: an insight into the population dynamics of wild and African honey bees (Apis mellifera scutellata). Molecular Ecology 18: 1511 -1522. http://dx.doi.org/10.1111/j.1365-294X.2009.04143.x

JAY, S C (1962) Colour changes in honey bee pupae. Bee World 43: 119-122.

JEAN-PROST, P; MÉDORI, P; KAULA, R K (1994) Apiculture: know the bee, manage the apiary. Intercept; Andover, UK.

JENSEN, A B; ARONSTEIN, K; FLORES, J M; VOJVODIC, S; PALACIO, $M$ A; SPIVAK, M (2013) Standard methods for fungal brood disease research. In V Dietemann; J D Ellis; P Neumann (Eds) The COLOSS BEEBOOK, Volume II: Standard methods for Apis mellifera pest and pathogen research. Journal of Apicultural Research 52(1): http://dx.doi.org/10.3896/IBRA.1.52.1.13

JOHANNSMEIER, M F (2001) Beekeeping in South Africa. Plant Protection Handbook No. 14, Agricultural Research Council; Pretoria, South Africa. $288 \mathrm{pp}$.

KEARNS, C A; INOUYE, D W (1993) Techniques for pollination biologists. University Press of Colorado; Niwot, Colorado, USA. 583 pp.

KLEINSCHMIDT, G J; KONDOS, A C (1978) The effect of dietary protein on colony performance. Australian Beekeeper 80: 251-257. 
KOCHER, S D; RICHARD, F J; TARPY, D R; GROZINGER, C M (2008) Genomic analysis of post-mating changes in the honey bee queen (Apis mellifera). BMC Genomics 9(232): 1-15.

http://dx.doi.org/10.1186/1471-2164-9-232

KÖHLER, A; PIRK, C W W; NICOLSON, S W (2012) Simultaneous stressors: additive effects of an immune challenge and dietary toxin are detrimental to honey bees. Journal of Insect Physiology 58: 918-923. http://dx.doi.org/10.1016/j.jinsphys.2012.04.007

KOYWIWATTRAKUL, P; THOMPSON, G J; SITTHIPRANEED, S; OLDROYD, B P; MALESZKA, R (2005) Effects of carbon dioxide narcosis on ovary activation and gene expression in worker honey bees, Apis mellifera. Journal of Insect Science 5: 36.

KUCHARSKI, R; MALESZKA, R (2003) Transcriptional profiling reveals multifunctional roles for transferrin in the honey bee, Apis mellifera. Journal of Insect Science 3: 1-8.

KUCHARSKI, R; MALESZKA, J; FORET, S; MALESZKA, R (2008)

Nutritional control of reproductive status in honey bees via DNA methylation. Science 319: 1827-1830.

http://dx.doi.org/10.1126/science.1153069

LANGENBERGER, M W; DAVIS, A R (2002) Temporal changes in floral nectar production, reabsorption, and composition associated with dichogamy in annual caraway (Carum carvi; Apiaceae). American Journal of Botany 89(10): 1588-1598.

http://dx.doi.org/10.3732/ajb.89.10.1588

LAUGHTON, A M; BOOTS, M; SIVA-JOTHY, M T (2011) The ontogeny of immunity in the honey bee, Apis mellifera L. following an immune challenge. Journal of Insect Physiology 57: 1023-1032. http://dx.doi.org/10.1016/j.jinsphys.2011.04.020

LE CONTE, Y; CORNUET, J M (1989) Variability of the post-capping stage duration of the worker brood in three different races of Apis mellifera. In $R$ Cavalloro (Ed.). Proceedings of the Meeting of the EC-Experts' Group, Udine 1988. CEC; Luxembourg. pp. 171-174. LOZANO, V C; ARMENGAUD, C; GAUTHIER, M (2001) Memory impairment induced by cholinergic antagonists injected into the mushroom bodies of the honey bee. Journal of Comparative Physiology A187: 249-254. http://dx.doi.org/10.1007/s003590100196

MACKENSEN, O (1947) Effect of carbon dioxide on initial oviposition of artificially inseminated and virgin queen bees. Journal of Economic Entomology 40(3): 344-349.

MAISTRELLO, L; LODESANI, M; COSTA, C; LEONARDI, F; MARANI, G; CALDON, M; MUTINELLI, F; GRANATO, A (2008) Screening of natural compounds for the control of nosema disease in honey bees. Apidologie 39: 436-445.

http://dx.doi.org/10.1051/apido:2008022

MARTIN, S J (1994) Ontogenesis of the mite Varroa jacobsoni Oud. in worker brood of the honey bee Apis mellifera L. under natural conditions. Experimental and Applied Acarology 18: 87-100. http://dx.doi.org/10.1007/BF000550033
MARTIN, S J (1995) Ontogenesis of the mite Varroa jacobsoni Oud. in the drone brood of the honey bee Apis mellifera L. under natural conditions. Experimental and Applied Acarology 19(4): 199-210. http://dx.doi.org/10.1007/BF00130823

MCLELLAN, A R (1977) Honey bee colony weight as an index of honey production and nectar flow: a critical evaluation. Journal of Applied Ecology 14: 401-408.

MEDRZYCKI, P; GIFFARD, H; AUPINEL, P; BELZUNCES, L P; CHAUZAT, M-P; CLAßEN, C; COLIN, M E; DUPONT, T; GIROLAMI, V; JOHNSON, R; LECONTE, Y; LÜCKMANN, J; MARZARO, M; PISTORIUS, J; PORRINI, C; SCHUR, A; SGOLASTRA, F; SIMON DELSO, N; VAN DER STEEN, J; WALLNER, K; ALAUX, C; BIRON, D G; BLOT, N; BOGO, G; BRUNET, J-L; DELBAC, F; DIOGON, M; EL ALAOUI, H; TOSI, S; VIDAU, C (2013) Standard methods for toxicology research in Apis mellifera. In V Dietemann; J D Ellis; P Neumann (Eds) The COLOSS BEEBOOK, Volume I: standard methods for Apis mellifera research. Journal of Apicultural Research 52(4): http://dx.doi.org/10.3896/IBRA.1.52.4.14

MEIKLE, W G; HOLST, H (2006) Using balances linked to data loggers to monitor honey bee colonies. Journal of Apicultural Research 45: 39-41. http://dx.doi.org/10.1051/apido:2008055

MEIKLE, W G; RECTOR, B G; MERCADIER, G; HOLST, N (2008) Within -day variation in continuous hive weight data as a measure of honey bee colony activity. Apidologie 39: 694-707. http://dx.doi.org/10.1051/apido:2008055

MICHELETTE, E R; SOARES, A E E (1993) Characterization of preimaginal developmental stages in Africanized honey bee workers (Apis mellifera L). Apidologie 24: 431-440. http://dx.doi.org/10.1051/apido:19930410

MILUM, V G (1930) Variations in time of development of the honey bee. Journal of Economic Entomology 23: 441-447.

MORITZ, R F A; DIETEMANN, V; CREWE, R M (2008) Determining colony densities in wild honey bee populations (Apis mellifera) with linked microsatellite DNA markers. Journal of Insect Conservation 12: 455-459. http://dx.doi.org/10.1007/s10841-007-9078-5

MULLIN, C A; FRAZIER, M; FRAZIER, J L; ASHCRAFT, S; SIMONDS, R; VANENGELSDORP, D; PETTIS, J S (2010) High levels of miticides and agrochemicals in North American apiaries: implications for honey bee health. PLOS ONE 5(3): e9754. http://dx.doi.org/10.1371/journal.pone.0009754

NAUG, D; GIBBS, A (2009) Behavioural changes mediated by hunger in honey bees infected with Nosema ceranae. Apidologie 40(6): 595-599. http://dx.doi.org/10.1051/apido/2009039

NEUMANN, P; PIRK, C W W; SCHÄFER, M O; EVANS, J D; PETTIS, J S; TANNER, G; WILLIAMS, G R; ELLIS, J D (2013) Standard methods for small hive beetle research. In V Dietemann; J D Ellis; $P$ Neumann (Eds) The COLOSS BEEBOOK, Volume II: Standard methods for Apis mellifera pest and pathogen research. Journal of Apicultural Research 52(4): http://dx.doi.org/10.3896/IBRA.1.52.4.19 
NGUYEN, B K; SAEGERMAN, C; PIRARD, C; MIGNON, J; WIDART, J; THIRIONET, B; VERHEGGEN, F J; BERKVENS, D; DE PAUW, E; HAUBRUGE, E (2009) Does imidacloprid seed-treated maize have an impact on honey bee mortality? Journal of Economic Entomology 102(2): 616-623. http://dx.doi.org/10.1603/029.102.0220

NICOLAS, G; SILLANS, D (1989) Immediate and latent effects of carbon dioxide on insects. Annual Review of Entomology 34: 97-116. http://dx.doi.org/10.1146/annurev.ento.34.1.97

NICOLSON, S W (2008) Water homeostasis in bees, with the emphasis on sociality. Journal of Experimental Biology 212: 429-434. http://dx.doi.org/10.1242/jeb.022343

NICOLSON, S W; HUMAN, H (2008) Bees get a head start on honey production. Biology Letters 4: 299-301.

http://dx.doi.org/10.1098/rsbl.2008.0034

NICOLSON, S W; NEPI, M (2005) Dilute nectar in dry atmospheres: nectar secretion patterns in Aloe castanea (Asphodelaceae). International Journal of Plant Sciences 166: 227-233. http://dx.doi.org/10.1086/427616

NICOLSON, S W; NEPI, M; PACINI, E (2007) Nectaries and Nectar. Springer; Dordrecht, The Netherlands. 396 pp.

ORGANISATION FOR ECONOMIC CO-OPERATION AND DEVELOPMENT (OECD) (2007) Guidance document on the honey bee (Apis mellifera I.) brood test under semi-field conditions Number 75 . ENV/JM/MONO22.

OKADA, R; AKAMATSU, T; IWATA, K; IKENO, H; KIMURA, T; OHASHI, M; AONUMA, H; ITO, E (2012) Waggle dance effect: dancing in autumn reduces the mass loss of a honey bee colony. The Journal of Experimental Biology 215: 1633-1641. http://dx.doi.org/10.1242/jeb.068650

OLDROYD, B P; THEXTON, E G; LAWLER, S H; CROZIER, R H (1997) Population demography of Australian feral bees (Apis mellifera). Oecologia 111: 381-387. http://dx.doi.org/10.1007/s004420050249 OOMEN, P; DE RUIJTER, A; VAN DER STEEN, J (1992) Method for honey bee brood feeding tests with insect growth-regulating insecticides. Bulletin OEPP/EPPO 22: 613-616.

PACINI, E; NEPI, M (2007) Nectar production and presentation. In $S W$ Nicolson; M Nepi; E Pacini (Eds). Nectaries and nectar. Springer; Dordrecht, The Netherlands. pp. 177-182.

PACINI, E; NEPI, M; VESPRINI, J L (2003) Nectar biodiversity: a short review. Plant Systematics and Evolution 238: 7-21. http://dx.doi.org/10.1007/s00606-002-0277-y

PANKIW, T; PAGE, R E (2003) Effect of pheromones, hormones, and handling on sucrose response thresholds of honey bees (Apis mellifera L.). Journal of Comparative Physiology A189(9): 675-684. http://dx.doi.org/10.1007/s00359-003-0442-y

PAUL, J (1975) Cell and tissue Culture. Churchill Livingstone; London, UK. 102 pp.

PEREZ, J L; HIGES, M; SUAREZ, M; LLORENTE, J; MEANA, A (2001)

Easy ways to determine honey bee mortality using dead-bee traps. Journal of Apicultural Research 40(1): 25-28.
PERNAL, S F; CURRIE, R W (2000) Pollen quality of fresh and 1-yearold single pollen diets for worker honey bees (Apis mellifera L.). Apidologie 31: 387-409. http://dx.doi.org/10.1051/apido:2000130 PICARD-NIZOU, A L; GRISON, R; OLSEN, L; PIOCHE, C; ARNOLD, G; PHAM-DELÈGUE, M H (1997) Impact of proteins used in plant genetic engineering: toxicity and behavioral study in the honey bee. Journal of Economic Entomology 90: 1710-1716.

PIRK, C W W; DE MIRANDA, J R; FRIES, I; KRAMER, M; PAXTON, R; MURRAY, T; NAZZI, F; SHUTLER, D; VAN DER STEEN, J J M; VAN DOOREMALEN, C (2013) Statistical guidelines for Apis mellifera research. In V Dietemann; J D Ellis; P Neumann (Eds) The COLOSS BEEBOOK, Volume I: standard methods for Apis mellifera research. Journal of Apicultural Research 52(4): http://dx.doi.org/10.3896/IBRA.1.52.4.13

PORRINI, C; GHINI, S; GIROTTI, S; SABATINI, A G; GATTAVECCHIA, E; CELLI, G (2002a) Use of honey bees as bioindicators of environmental pollution in Italy. In J Devillers; M-H Pham-Delegue (Eds). Honey bees: estimating the environmental impact of chemicals. Taylor and Francis; Florence, Italy. pp. 186-247.

PORRINI, C; MEDRZYCKI, P; BENTIVOGLI, L; CELLI, G (2002b) Studies to improve the performance of dead honey bee collection traps for monitoring bee mortality. In VIII Simposio Internazionale ICPBR on hazards of pesticides to bees, Bologna, Italy, 4-6 September 2002. pp 29.

PORRINI, C; SABATINI, A G; GIROTTI, S; GHINI, S; MEDRZYCKI, P; GRILLENZONI, F; BORTOLOTTI, L; GATTAVECCHIA, E; CELLI, G (2003) Honey bees and bee products as monitors of the environmental contamination. Apiacta 38: 63-70.

PYKE, G H; WASER, N M (1981) The production of dilute nectars by hummingbird and honeyeater flowers. Biotropica 13: 260-270. http://dx.doi.org/10.2307/2387804

REMBOLD, H; KREMER, J-P; ULRICH, G M (1980) Characterisation of postembryonic developmental stages of the females castes of the honey bee, Apis mellifera L. Apidologie 11: 29-38. http://dx.doi.org/10.1051/apido:19800104

RICHARD, F-J; AUBERT, A; GROZINGER, C M (2008) Modulation of social interactions by immune stimulation in honey bee, Apis mellifera, workers. BMC Biology 6: 50.

ROBINSON, G E; VISSCHER, P K (1984) Effect of low temperature narcosis on honey bee (Hymenoptera: Apidae) foraging behaviour. Florida Entomologist 67(4): 568-570. http://dx.doi.org/10.2307/3494466 ROGERS, S R; STAUB, B (2013) Standard use of Geographic Information System (GIS) techniques in honey bee research. In V Dietemann; $J$ D Ellis; P Neumann (Eds) The COLOSS BEEBOOK, Volume I: standard methods for Apis mellifera research. Journal of Apicultural Research 52(4): http://dx.doi.org/10.3896/IBRA.1.52.4.08 ROUBIK, D W; BUCHMANN, S L (1984) Nectar selection by Melipona and Apis mellifera (Hymenoptera: Apidae) and the ecology of nectar intake by bee colonies in a tropical forest. Oecologia 61: 1-10. http://dx.doi.org/10.1007/BF00379082 
ROUBIK, D W; YANEGA, D; ALUJA, M; BUCHMANN, S L; INOUYE, D W (1995) On optimal nectar foraging by some tropical bees (Hymenoptera, Apidae). Apidologie 26: 197-211. http://dx.doi.org/10.1051/apido:19950303

ROULSTON, T H; CANE, J H (2000) Pollen nutritional content and digestibility for animals. Plant Systematics and Evolution 222: 187-209. http://dx.doi.org/10.1007/BF00984102

RUEPPEL, O; HAYWORTH, M K; ROSS, N P (2010) Altruistic self-removal of health-compromised honey bee workers from their hive. Journal of Evolutionary Biology 23: 1538-1546. http://dx.doi.org/10.1111/j.1420-9101.2010.02022.x

SAMMATARO, D; AVITABILE, A (2011) The beekeeper's handbook. Cornell University Press; Ithaca, New York.

SASAKI, T; ISHIKAWA, H (2000) Transinfection of Wolbachia in the Mediterranean flour moth, Ephestia kuehniella, by embryonic microinjection. Heredity 85: 130-135.

SCHEINER, R; ABRAMSON, C I; BRODSCHNEIDER, R; CRAILSHEIM, K; FARINA, W; FUCHS, S; GRÜNEWALD, B; HAHSHOLD, S; KARRER, M; KOENIGER, G; KOENIGER, N; MENZEL, R; MUJAGIC, S; RADSPIELER, G; SCHMICKLI, T; SCHNEIDER, C; SIEGEL, A J; SZOPEK, M; THENIUS, R (2013) Standard methods for behavioural studies of Apis mellifera. In V Dietemann; J D Ellis; P Neumann (Eds) The COLOSS BEEBOOK, Volume I: standard methods for Apis mellifera research. Journal of Apicultural Research 52(4): http://dx.doi.org/10.3896/IBRA.1.52.4.04

SCHLÜNS, H; CROZIER, R H (2007) Relish regulates expression of antimicrobial peptide genes in the honey bee, Apis mellifera, shown by RNA interference. Insect Molecular Biology 16: 753-759.

SEELEY, T D (1983) Division of labour between scouts and recruits in honey bee foraging. Behavioural Ecology and Sociobiology 12: 253-259. http://dx.doi.org/10.1007/BF00290778

SEELEY, T D (1986) Honey bee ecology: a study of adaptation in social life. Princeton University Press; New Jersey, USA. 49 pp.

SEELEY T D; VISSCHER, P K (1985) Survival of honey bees in cold climates: the critical timing of colony growth and reproduction. Ecological Entomology 10: 81-88. http://dx.doi.org/10.1111/j.1365-2311.1985.tb00537.x

SHAIBI, T; LATTORF, H M G; MORITZ, R F A. (2008) A microsatellite DNA toolkit for studying population structure in Apis mellifera. Molecular Ecology Resources 8: 1034-1036. http://dx.doi.org/10.1111/j.1755-0998.2008.02146.x

STEYSKAL, G C; MURHPY, W L; HOOVER, E M (1986) Collecting and preserving insects and mites: techniques and tools. USDA Miscellaneous Publication no. 1443.

STONER, A; MOFFETT, J O; WARDECKER, A L (1979) The effect of the Todd dead bee trap, used alone and in combination with the Wardecker waterer, on colonies of honey bees (Hymenoptera: Apidae). Journal of the Kansas Entomological Society 2(3): 556-560.
STONER, K A; EITZER, B D (2012) Movement of soil-applied Imidacloprid and Thiamethoxam into nectar and pollen of squash (Cucurbita pepo). PLoS ONE 7(6): e39114.

http://dx.doi.org/10.1371/journal.pone.0039114

STROBER, W (1997) Monitoring cell growth. In J E Coligan; $A$ M Kruisbeek; D H Margulies; EM Shevach; W Strober (Eds). Current protocols in immunology. John Wiley \& Sons; Hoboken, New Jersey, USA.

TEIXEIRA, L; FERREIRA, A; ASHBURNER, M (2008) The bacterial symbiont Wolbachia induces resistance to RNA viral infections in Drosophila melanogaster. PLoS Biology 6: e1000002. http://dx.doi.org/10.1371/journal.pbio.1000002

THRASYVOULOU, A T; BENTON, A W (1965) Rates of growth of honey bee larvae. Journal of Apicultural Research 21: 189-192.

VAUDO, A D; ELLIS, J D; CAMBRAY, G A; HILL, M (2012a) Honey bee (Apis mellifera capensis/A.m. scutellata hybrid) nesting behaviour in the Eastern Cape, South Africa. Insectes Sociaux 59: 323-331. http://dx.doi.org/10.1007/s00040-012-0223-0

VAUDO, A D; ELLIS, J D; CAMBRAY, G A; HILL, M (2012b) The effects of land use on honey bee (Apis mellifera) population density and colony strength parameters in the Eastern Cape, South Africa. Journal of Insect Conservation 16: 601-611. http://dx.doi.org/10.1007/s10841-011-9445-0

VISSCHER, P K; SEELEY, T D (1989) Bee-lining as a research technique in ecological studies of honey bees. American Bee Journal 129: 536-539.

VISSCHER, P K; CRAILSHEIM, K; SHERMAN, G (1996) How do honey bees (Apis mellifera) fuel their water foraging flights? Journal of Insect Physiology 42(11-12): 1089-1094. http://dx.doi.org/10.1016/S0022-1910(96)00058-3

VON FRISCH, K (1967) The dance language and orientation of bees. Harvard University Press; Cambridge, MA, USA.

WALSH, P S; METZGAR, D A; HIGUCHI, R (1991) Chelex-100 as a medium for simple extraction of DNA for PCR-based typing from forensic material. BioTechniques 10: 506-513.

WANG, D I (1965) Growth rates of young queen and worker honey bee larvae. Journal of Apicultural Research 4: 3-5.

WANG, J (2004) Sibship reconstruction from genetic data with typing errors. Genetics 166: 1963-1979. http://dx.doi.org/10.1534/genetics.166.4.1963

WANNER, K W; NICHOLS, A S; WALDEN, K K O; BROCKMANN, A; LUETJE, C W; ROBERTSON, H M (2007) A honey bee odorant receptor for the queen substance 9-oxo-2-decenoic acid. Proceedings of the National Academy of Sciences 104(36): 1438314388. http://dx.doi.org/10.1073/pnas.0705459104

WELLS, P H; WENNER, A M (1971) The influence of food scent on behaviour of foraging honey bees. Physiological Zoology 44: 191-209. 
WENNER, A M; ALCOCK, J E; MEADE, D E (1992) Efficient hunting of feral colonies. Bee Science 2: 64-70.

WIESER, W (1973) Effects of temperature on ectothermic organisms. In $W$ Wieser (Ed.). Temperature relations of ectotherms. $A$ speculative review. Springer Verlag; Berlin, Germany. pp. 1-23. WILLIAMS, J L (1987) Wind-directed trap for drone honey bees. Journal of Economic Entomology 80: 532-536.

WILLIAMS, G R; ALAUX, C; COSTA, C; CSÁKI, T; DOUBLET, V; EISENHARDT, D; FRIES, I; KUHN, R; MCMAHON, D P; MEDRZYCKI, P; MURRAY, T E; NATSOPOULOU, M E; NEUMANN, P; OLIVER, R; PAXTON, R J; PERNAL, S F; SHUTLER, D; TANNER, G; VAN DER STEEN, J J M; BRODSCHNEIDER, R (2013) Standard methods for maintaining adult Apis mellifera in cages under in vitro laboratory conditions. In V Dietemann; J D Ellis; P Neumann (Eds) The COLOSS BEEBOOK, Volume I: standard methods for Apis mellifera research. Journal of Apicultural Research 52(1): http://dx.doi.org/10.3896/IBRA.1.52.1.04

WILLIAMS, G R; ROGERS, R E L; KALKSTEIN, A L; TAYLOR, B A; SHUTLER, D; OSTIGUY, N (2009) Deformed wing virus in western honey bees (Apis mellifera) from Atlantic Canada and the first description of an overtly-infected emerging queen. Journal of Invertebrate Pathology 101(1): 77-79.

http://dx.doi.org/10.1016/j.jip.2009.01.004

WILLIAMS, G R; SHAFER, A B A; ROGERS, R E L; SHUTLER, D; STEWART, D T (2008) First detection of Nosema ceranae, a microsporidian parasite of European honey bees (Apis mellifera), in Canada and central USA. Journal of Invertebrate Pathology 97 (2): 189-192. http://dx.doi.org/10.1016/j.jip.2007.08.005

WILLIAMS, G R; SHUTLER, D; LITTLE, C M; BURGHER-MACLELLAN, K L; ROGERS, R E L (2011) The microsporidian Nosema ceranae, the antibiotic Fumagilin- $\mathrm{B}^{\circledR}$, and western honey bee (Apis mellifera) colony strength. Apidologie 42(1): 15-22.

http://dx.doi.org/10.1051/apido/20100230.

WILSON, W T; ROTHENBUHLER, W C (1968) Resistance to American foulbrood in honey bees VIII. Effects of injecting Bacillus larvae spores into adults. Journal of Invertebrate Pathology 12: 418-424. http://dx.doi.org/10.1016/0022-2011(68)90349-2
WINNEBECK, E C; MILLAR, C D; WARMAN, G R (2010) Why does insect RNA look degraded? Journal of Insect Science 10(159): 1-7.

WINSTON, M L (1987) The biology of the honey bee. Harvard University Press; Cambridge, Massachusetts, USA, 281 pp.

WOYCIECHOWSKI, M; MORON, D (2009) Life expectancy and onset of foraging in the honey bee (Apis mellifera). Insectes Sociaux 56 (2): 193-201. http://dx.doi.org/10.1007/s00040-009-0012-6 WRIGHT, G A; MUSTARD, J A; SIMCOCK, N K; ROSS-TAYLOR, A A R; MCNICHOLAS, L D; POPESCU, A; MARION-POLL, F (2010) Parallel reinforcement pathways for conditioned food aversions in the honey bee. Current Biology 20: 2234-2240.

http://dx.doi.org/10.1016/j.cub.2010.11.040

YAMANE, T; MIYATAKE, T (2010) Reduced female mating receptivity and activation of oviposition in two Callosobruchus species due to injection of biogenic amines. Journal of Insect Physiology 56: 271276. http://dx.doi.org/10.1016/j.jinsphys.2009.10.011

YAÑEZ, O; ZHENG, H-Q; HU, F-L; NEUMANN, P; DIETEMANN, V (2012) A scientific note on Israeli acute paralysis virus infection of Eastern honey bee Apis cerana and vespine predator Vespa velutina. Apidologie 43(5): 587-589. http://dx.doi.org/10.1007/s13592-012-0128-y

ZAYED, A; PACKER, L; GRIXTI, J C; RUZ, L; OWEN, R E; TORO, H (2005) Increased genetic differentiation in a specialist versus a generalist bee: implications for conservation. Conservation Genetics 6: 1017-1026. http://dx.doi.org/10.1007/s10592-005-9094-5 ZHENG, H-Q; DIETEMANN, V; HU, F-L; CREWE, R M; PIRK, C W W (2012) A scientific note on the lack of effect of mandible ablation on the synthesis of royal scent by honey bee queens. Apidologie 43(4): 471-473. http://dx.doi.org/10.1007/s13592-011-0114-9 ZHENG, H-Q; JIN, S H; HU, F-L; PIRK, C W W (2009a) Sustainable multiple queen colonies of honey bees, Apis mellifera ligustica. Journal of Apicultural Research 48(4): 284-289. http://dx.doi.org/10.3896/IBRA.1.48.4.09

ZHENG, H-Q; JIN, S H; HU, F-L; PIRK, C W W; DIETEMANN, V (2009b) Maintenance and application of multiple queen colonies in commercial beekeeping. Journal of Apicultural Research 48(4): 290-295. http://dx.doi.org/10.3896/IBRA.1.48.4.10 
